\title{
A short story: senescence in an annual reptile, Labord's chameleon (Furcifer labordi)
}

\author{
Dissertation \\ for the award of the degree \\ "Doctor rerum naturalium" (Dr.rer.nat.) \\ of the Georg-August-Universität Göttingen
}

Within the doctoral program GAUSS Basic Program in Biology of the Georg-August University School of Science (GAUSS)

Submitted by

Falk Eckhardt

Born in

Duisburg, Germany

Göttingen, 2019 


\section{Thesis Committee}

Prof. Dr. Peter Kappeler, Department of Sociobiology/Anthropology, Georg-AugustUniversity of Göttingen

Prof. Dr. Stefan Scheu, J.F. Blumenbach Institute of Zoology and Anthropology, Department of Animal Ecology, University of Göttingen, Göttingen

PD. Dr. Matthias Waltert, Department of Conservation Biology/Workgroup on Endangered Species, Georg-August-University of Göttingen

\section{Members of the Examination Board}

\section{First Reviewer:}

Prof. Dr. Peter Kappeler, Department of Sociobiology/Anthropology, Georg-AugustUniversity of Göttingen

\section{Second Reviewer:}

Prof. Dr. Stefan Scheu, J.F. Blumenbach Institute of Zoology and Anthropology, Department of Animal Ecology, University of Göttingen

\section{Further members of the Examination Board}

Dr. Sven Bradler, J.F. Blumenbach Institute of Zoology and Anthropology, Department of Animal Ecology, University of Göttingen, Göttingen

Prof. Dr. Eckhard Heymann, Department of Sociobiology/Anthropology, Georg-AugustUniversity of Göttingen

Prof. Dr. Christina Strube, Institute for Parasitology, Centre for Infection Medicine, University of Veterinary Medicine Hannover, Hannover

PD. Dr. Matthias Waltert, Department of Conservation Biology/Workgroup on Endangered Species, Georg-August-University of Göttingen 


\section{CONTENTS}

$\begin{array}{ll}\text { Summary } & 1\end{array}$

$\begin{array}{ll}\text { Zusammenfassung } & 4\end{array}$

$\begin{array}{ll}\text { Chapter } 1 & 7\end{array}$

$\begin{array}{ll}\text { General Introduction } & 7\end{array}$

$\begin{array}{ll}\text { Why do we age? } & 8\end{array}$

$\begin{array}{ll}\text { How variable is senescence? } & 10\end{array}$

$\begin{array}{ll}\text { Aging under natural versus protected conditions } & 13\end{array}$

Semelparity 16

Study species: The Labord's chameleon Furcifer labordi (Grandidier, 1872) 18

$\begin{array}{ll}\text { Study aims and approaches } & 19\end{array}$

$\begin{array}{ll}\text { Chapter } 2 & 21\end{array}$

Highly variable lifespan in an annual reptile, Labord's chameleon (Furcifer labordi)

$\begin{array}{ll}\text { Chapter } 3 & 30\end{array}$

Life-histories, demographies and population dynamics of three sympatric chameleon species (Furcifer spp.) from western Madagascar

\section{Chapter 4}

Parasite burden in a short-lived chameleon, Furcifer labordi

\section{Chapter 5}

Stress-related changes in leukocyte profiles and telomere shortening in the shortest-lived tetrapod, Furcifer labordi.

Chapter 6

General Discussion

Intraspecific, interannual and intersexual differences in the lifespan of F. labordi 91

Lifespan of $F$. labordi in captivity $\quad 94$ 
Interspecific comparison and life-histories of chameleons

Intrinsic mechanisms of senescence in F. labordi

Potential of aging research in reptiles

Conclusion

References

106

Acknowledgement

List of figures

List of tables

Curriculum vitae

Publications

Declaration 


\section{Summary}

Among animals, the fast-slow continuum is the dominant axis that shapes life-history variation. As resources are limited a trade-off occurs between a short lifespan, young age at maturity, high reproductive rates and high aging rates or the other way round. At an ultimate level, rates of adult mortality with age are assumed to determine whether a species falls in the one or in the other continuum, at which high rates of extrinsic mortality select for fast life-histories. Within terrestrial vertebrates (tetrapods), the current record holder for short lifespan is the Labord's chameleon, Furcifer labordi. These chameleons, inhabiting the seasonal western and southwestern deciduous dry forests of Madagascar, were found to have a post-hatching lifespan of only several months. At the onset of the active respectively rainy season, in November, a cohort of hatchlings emerges. Their early life is determined by rapid growth, resulting in fast sexual maturity and subsequent reproduction in January-February. After the mating season, senescent declines become apparent, and at the beginning of the dry season, a fast die-off has been observed in both sexes. Hereafter, the population only exists as eggs, probably as an adaption to survive the harsh dry season. High adult mortality combined with relatively high juvenile (here egg) survival might have ultimately selected for this annual life-history. It is unique in tetrapods and makes this chameleon an intriguing model species for investigating the proximate and ultimate factors shaping rapid senescence, especially because perennial, sympatric congeners are available for comparative studies.

Semelparity, i.e. the strategy to allocate all energy in one reproduction event, is rarely found in tetrapods and has apart from a very few reptile species only been detected in a few small-sized marsupial species. However, in these marsupial species the die-off following the mating season is restricted to males, while several females survive until the next breeding season. Apart from these species, for which the male die-off is obligate, less extreme cases of semelparity have been documented. Here, facultative male die-off is restricted to some populations and/or only observed in some years and has been linked to variable resource availability. Strong prey seasonality that leads to a short breeding season has been suggested to explain male semelparity in marsupials, at which high levels of sperm competition combined with female reproductive synchrony select for obligate semelparity. Interestingly, males that were captured before engaging in reproductive season, can survive for more than two years. However, while captivity may shield males from early death due to extrinsic factors, they still experience loss in body mass and irreversible regression of sexual organs as observed in their wild conspecifics after the mating season, proposing an annual, intrinsic pacesetter. In contrast 
to these marsupials, the proximate causes leading to the short life in this chameleon species remain entirely unknown. Is it the consequence of extrinsic factors, such as intense intra-sexual competition, high predation rates, and low food availability, or are the physiological changes leading to rapid senescence internally "programmed" and thus impending? In the marsupials mentioned above, both factors seem to play a role. Furthermore, so far, only one population in the southernmost and thus driest distribution range of this species has been studied in detail. Thus, the ultimate aim of my thesis is to reflect on the interplay between the external and internal factors that favour the short life-history of this chameleon species.

In the first study, I investigated the variability of lifespan in a population of $F$. labordi in the Kirindy Forest, which has a much longer rainy season compared to the more southern habitat. I documented that the population wide die-off is prolonged in Kirindy several months forward. Moreover, I showed a bias in sex-specific mortality, in which females have a longevity advantage. To exclude most extrinsic factors of mortality, I kept several individuals in captivity and demonstrated that both sexes could survive until the next season of activity. Therefore, this study revealed considerable plasticity of this life-history that is associated to differences in ecological factors. Within the second study, I compared the life-history of $F$. labordi with those of the congeneric and sympatric species $F$. cf. nicosiai and $F$. oustaleti in the Kirindy forest and tested for potential niche segregation that might have driven evolutionary selection for this short lifespan. In all three species, I found high interspecific differences in time of hatching, growth rates, age at reproduction, adult body size and lifespan. While the cohort of $F$. labordi was already adult, hatchlings of the $F$. oustaleti and subsequently $F$. cf. nicosiai emerged. As hatchlings in these species are similar-sized, these differences indicate dietary niche segregation. However, I found that compared to other similar sized lizards, the lifespans of $F$. cf. nicosiai and F. oustaleti are considerably short and probably attributed to the ecology of chameleons. In the third study, I examined to which extend parasite infection as a proxy of overall health in F. labordi might be connected to the short lifespan. Therefore, I inspected gastrointestinal, - blood - and ectoparasite burden and compared my findings to those of the sympatric and longer living $F$. cf. nicosiai and the caged individuals. Within $F$. labordi, I found an intense increase of prevalence in gastrointestinal parasites over the reproductive period. Males showed a higher prevalence that could be caused by frequent male-male combats resulting in higher baseline stress levels and their earlier disappearance. Contrary to our expectations, gastrointestinal, - blood - and ectoparasite burden was higher in adult $F$. cf. nicosiai. In captivity, both sexes showed less parasite burden and were longer living than their wild conspecifics. The final study aimed at determining the effect of glucocorticoids (GCs) and 
telomere shortening as well as their interplay on the acceleration of the aging process in $F$. labordi. To indirectly measure baseline stress levels, I used the ratio between heterophils to lymphocytes $(\mathrm{H} / \mathrm{L}$ ratio) in blood smears as an indicator of physiological stress since a rise in GC level is closely correlate with a decrease in lymphocytes and increase of heterophils. I quantified telomere length using real-time quantitative PCR (qPCR) in relative telomere length (TL) in blood cells. I found that $\mathrm{H} / \mathrm{L}$ ratios were higher in wild $F$. labordi compared to $F$. cf. nicosiai. TL was longer in $F$. cf. nicosiai, but shortened rapidly towards the dry season. The captive specimens showed lower $\mathrm{H} / \mathrm{L}$ ratios compared to their wild conspecifics.

In summary, I evidenced that the short lifespan of $F$. labordi is not entirely "programmed" but highly variable and linked to ecological factors. Moreover, I found that males were the shorter living sex in the wild, but no significant intersexual differences in lifespan under protected caged conditions were observed. This implies that despite their earlier mortality, males do not obligatory experience faster senescence in components of health. Concerning gastrointestinal parasite infections, I found an increase towards the dry season in both sexes, whereas males showed continuously higher prevalences. Parasite infection was considerably low in the caged individuals, which might have affected their comparatively longer survival. In concordance to these findings, H/L ratios were higher in wild F. labordi compared to their captive conspecifics, probably resulting from the isolation of external stressors. The interspecific comparison with the longer living species $F$. cf. nicosiai suggests that the relatively slow growing juveniles invest comparatively more energy in selfmaintenance. Contrary to our predictions, adult stages seem to suffer from visible senescent declines towards the dry season. Therefore, the disappearance in the wild towards the dry season seems to be a "post-reproductive" phenomenon in both species. In conclusion, the results of this thesis support the fundamental predictions of life-history theory, at which species that experience high extrinsic mortality risk in the wild invest their cellular energy into growth and reproduction at the expense of cellular repair mechanisms. As observed in the semelparous marsupials, both intrinsic and extrinsic mechanisms seem to shape the life-history of $F$. labordi. 


\section{Zusammenfassung}

Bei Tieren ist das "schnell-langsame Kontinuum" die dominierende Achse, die die Variation der Life History prägt. Da Ressourcen begrenzt sind, kommt es offenbar zu einem Kompromiss zwischen einer kurzen Lebensdauer, einem frühen Erreichen der Geschlechtsreife, einer hohen Reproduktionsrate und einer schnellen Alterungsrate oder eben genau umgekehrt. Letztendlich wird angenommen, dass die Sterblichkeitsrate von adulten Tieren mit dem Alter bestimmt, ob eine Art in das eine oder andere Kontinuum fällt, wobei hohe extrinsische Sterblichkeitsraten für eine schnelle Life History ausschlaggebend sind. Innerhalb der terrestrischen Wirbeltieren (Tetrapoden) ist das Labord's Chamäleon, Furcifer labordi, der aktuelle Rekordhalter bezüglich Kurzlebigkeit. Es wurde festgestellt, dass diese Chamäleons, die aus den saisonalen Trockenwäldern im Westen und im Südwesten Madagaskars stammen, nur einige Monate nach dem Schlüpfen leben. Zu Beginn der Regenzeit im November schlüpft eine Kohorte von Jungtieren. Ihr frühes Leben ist durch schnelles Wachstum gekennzeichnet, das zu einer schnellen Geschlechtsreife und einer anschließenden Paarungszeit im Januar und Februar führt. Nach der Fortpflanzungsperiode zeigen sich Alterungsprozesse und zu Beginn der Trockenzeit ist bei beiden Geschlechtern ein schnelles Ableben zu beobachten. Hierauf existiert die Population nur noch in Form von Eiern, wahrscheinlich als Anpassung, um die raue Trockenzeit zu überstehen. Eine hohe Sterblichkeit bei aduten Tiere in Kombination mit einer relativ hohen Überlebensrate junger Stadien (hier Eiern) könnte letztendlich für diese annuelle Lebensgeschichte ausschlaggebend sein. Bei Tetrapoden ist diese Life History einzigartig und macht dieses Chamäleon zu einer faszinierenden Modellspezies für die Untersuchung der proximalen und ultimativen Faktoren für eine schnelle Seneszenz, insbesondere, weil längerlebige, sympatrische Furcifer-Arten für Vergleichsstudien zur Verfügung stehen.

Semelparität, d. h. die Strategie, die gesamte Energie in eine Reproduktionsperiode zu investieren, ist bei Tetrapoden selten anzutreffen und wurde, abgesehen von wenigen Reptilienarten, fast ausschließlich bei wenigen kleinen Beuteltierarten nachgewiesen. Bei diesen Arten ist das Sterben nach der Paarungszeit jedoch auf die Männchen beschränkt, während die Weibchen häufig bis zur nächsten Fortpflanzungssaison überleben. Abgesehen von diesen Arten, für die das Versterben der Männchen obligat ist, wurden auch weniger extreme Fälle von Semelparität dokumentiert. Hier ist das fakultative Sterben der Männchen auf einige Populationen beschränkt und/oder nur in einigen Jahren zu beobachten und wurde mit einer variablen Ressourcenverfügbarkeit erklärt. Eine starke Saisonalität der Nahrungsverfügbarkeit, die zu einer kurzen Paarungszeit führt, ist wahrscheinlich mitunter der Grund für die 
Semelparität bei den männlichen Beuteltieren. Ein hohes Maß an Spermienkonkurrenz kombiniert mit weiblicher Fortpflanzungssynchronität hat wahrscheinlich zu einer obligaten Semelparie geführt. Interessanterweise können Männchen, die vor der Paarungszeit gefangen wurden, ein Alter von über zwei Jahre erreichen. Zwar kann die Gefangenschaft vor äußeren Faktoren schützen, doch es kommt hier immer noch zu einem Verlust an Körpermasse und zu einer irreversiblen Rückbildung der Geschlechtsorgane, wie es bei ihren Artgenossen nach der Paarungszeit beobachtet wurden, was auf einen annuellen, intrinsischen Schrittmacher schließen lässt. Im Gegensatz zu diesen Beuteltieren sind die unmittelbaren Ursachen für das kurze Leben des Labord's Chamäleon völlig unbekannt. Ist es die Folge von extrinsischen Faktoren wie intensiver intra-sexueller Konkurrenz, hohem Prädationsdruck und schwindender Nahrungsverfügbarkeit, oder sind es physiologischen Veränderungen, die zu einer raschen Seneszenz führen, und der Tod somit vorprogrammiert? Bei den erwähnten Beuteltieren scheinen beide Faktoren eine Rolle zu spielen. Darüber hinaus wurde bisher nur eine Population im südlichsten und damit trockensten Verbreitungsgebiet von F. labordi detailliert untersucht. Das Hauptziel meiner Doktorarbeit ist es daher, das Zusammenspiel der äußeren und inneren Faktoren zu entschlüsseln, die die kurze Life History dieser Chamäleonart begünstigen. In der ersten Studie untersuchte ich die Variabilität der Lebensdauer einer Population von F. labordi im Kirindy-Wald, die im Vergleich zum südlicheren Verbreitungsgebiet eine längere Regenzeit aufweist. Ich konnte zeigen, dass sich das populationsweite Sterben in Kirindy um mehrere Monate verzögerte. Darüber hinaus zeigte sich, dass Weibchen langlebiger sind als Männchen. Um einen Großteil der extrinsischen Mortalitätsfaktoren auszuschließen, habe ich mehrere Individuen in Gefangenschaft gehalten und gezeigt, dass beide Geschlechter bis zur nächsten Aktivitätsperiode überleben können. Diese Studie ergab insgesamt eine erhebliche Plastizität dieser Life History, die mit Unterschieden von ökologischen Faktoren verbunden ist. In der zweiten Studie habe ich die Lebensgeschichte von $F$. labordi mit der von den sympatrischen und längerlebigen, zur selben Gattung gehörenden Arten $F$. cf. nicosiai und $F$. oustaleti im Wald von Kirindy verglichen. Hierbei habe ich die Arten auf potentielle Nischentrennung untersucht, die möglicherweise die Evolution einer so kurzen Lebensdauer begünstigt. Bei allen drei Arten fand ich hohe interspezifische Unterschiede vom Schlupfzeitpunkt, Wachstumsraten, Alter bei der Reproduktion, Körpergröße der adulten Tiere und der Lebensdauer. Während die Kohorte von $F$. labordi bereits adult ist, schlüpften die Jungtiere von $F$. oustaleti und anschließend $F$. cf. nicosiai. Da Jungtiere bei diesen Arten ähnlich groß sind, deuten diese Unterschiede auf eine zeitliche Nischentrennung in Bezug auf Nahrung hin. Ich stellte jedoch auch fest, dass im Vergleich zu anderen Echsen ähnlicher Größe die Lebenserwartung von $F$. 
cf nicosiai und F. oustaleti vergleichsweise kurz ist, was sich wahrscheinlich auf die Ökologie der Chamäleons zurückführen lässt. In der dritten Studie habe ich untersucht, inwieweit Parasiteninfektionen als Indikator für den allgemeinen Gesundheitszustand von F. labordi und deren kurzer Lebensdauer verbunden sein könnte. Aus diesem Grund habe ich die Gastrointestinal, - Blut - und Ektoparasitenbelastung untersucht und die Befunde mit denen des sympatrischen $F$. cf. nicosiai sowie den Tieren in Gefangenschaft verglichen. Bei $F$. labordi fand ich einen starken Anstieg der Prävalenz von gastrointestinalen Parasiten im Verlauf der Fortpflanzungsperiode. Männchen wiesen eine höhere Prävalenz auf, die wahrscheinlich durch häufige intrasexuelle Kämpfe und daraus resultierende hohe Stressniveaus begünstigt wurde und letzendlich zu ihrem früheren Verschwinden führte. Entgegen unseren Erwartungen war die Belastung durch gastrointestinale, - Blut - und Ektoparasiten bei adulten Individuen höher als bei $F$. labordi. In Gefangenschaft zeigten beide Geschlechter eine geringe Parasitenbelastung und lebten länger als ihre wildlebenden Artgenossen. Das Ziel der letzten Studie war es, die Wirkung von Glukokortikoiden (GC) und Telomerverkürzung sowie deren Zusammenspiel auf die Beschleunigung des Alterungsprozesses bei F. labordi zu untersuchen. Zur Messung des Ausgangsstressniveaus verwendete ich das Verhältnis von Heterophilen zu Lymphozyten (H/L-Verhältnis) in Blutausstrichen als indirektes Maß für den Stress, da dieser eng mit den GC-Niveaus aufgrund des GC-induzierten Leukozytenproduktion korreliert. Ich habe die Telomerlänge mithilfe der quantitativen real time-PCR (qPCR) in Bezug auf die relative Telomerlänge (TL) in Blutzellen quantifiziert. Ich fand heraus, dass das H/L Level in wilden $F$. labordi höher waren als bei F. cf. nicosiai. Die TL waren bei $F$. cf. nicosiai ursprünglich länger, aber zur trockenen Jahreszeit verkürzten sich die Telomere schnell. Die in Gefangenschaft gehaltenen Exemplare zeigten geringere H/L Level im Vergleich zu ihren Artgenossen in der Natur. Der interspezifische Vergleich mit der länger lebenden Art $F$. cf. nicosiai zufolge investieren die relativ langsam wachsenden juvenilen Tiere vergleichsweise mehr Energie in Selbsterhaltungsmechanismen. Entgegen unseren Vorhersagen scheinen die adulten Tiere zur Trockenzeit hin aber auch unter sichtbaren Altersprozessen zu leiden. Daher scheint das Verschwinden in der Wildnis zur Trockenzeit hin bei beiden Arten ein gängiges Phänomen nach der Fortpflanzungperiode zu sein. Zusammenfassend stützen die Ergebnisse dieser Arbeit die fundamentalen Vorhersagen der Life History Theory, bei denen Arten, die in freier Wildbahn einem hohen extrinsischen Mortalitätsrisiko ausgesetzt sind, ihre zelluläre Energie auf Kosten von inneren Reparaturmechanismen in Wachstum und Fortpflanzung investieren. Wie in auch bei den semelparen Beuteltieren beobachtet wurde, scheinen sowohl intrinsische als auch extrinsische Mechanismen die Life History von F. labordi zu prägen. 


\section{Chapter 1: General Introduction}

Lifespan covers the period from the fertilization of an egg cell towards the death of a multicellular organism. However, frequently, the beginning of life is understood as hatching from the egg or birth. This period differs due to the mortality risk of each individual of a species in a population. The statistical mean of a lifetime of individuals of a species is referred to as average lifespan, as opposed to the maximum lifespan is defined by the oldest known specimen. The course of the individual organism consists of several phases: development, maturation, reproduction, and senescence. The mean duration of each phase and the ratio of duration to each other are evolutionarily selected for each species (Rensing and Rippe 2014). In addition, there are phases such as hibernation and diapause, which reduce the mortality risk. Life-history studies the alterations that organisms experience from conception to death, but focuses mainly on the schedule of reproduction and survival (Stearns 1992, Charnov 1993). Life-history analysis is also a tool for examining hypotheses of evolutionary causes of adaptations in general (McNamara and Houston 1996, Nylin and Gotthard 1998). In fact, progressing age involves declines in physiological functioning. In humans, the average lifespan in industrialized countries has increased significantly in the last century, mainly due to medical advances in treating diseases, improved food quality and the avoidance of wars. In contrast, lifespan has declined in many African countries due to diseases such as AIDS, lack of food and armed conflict (Christensen et al. 2009).

Only quite recently, interest in aging as a phenomenon, beyond its effects on humans, has arisen. In fact, senescent decline was long considered a luxury of the sheltered anthropogenic environment reserved for humans and animals in their captivity. It was assumed that in nature, any deterioration would quickly lead to decease by natural selection (Hayflick 2000). An increase of research has followed the realization that actuarial (i.e. demographic senescence, the increasing risk of mortality with proceeding age) and functional senescence (within-individual deterioration of physical or physiological functioning with proceeding age) may be more widespread also in natural populations than assumed before (Nussey et al. 2013). Despite these recent advances, the study of senescence in wild populations, including the ultimate causes, variability among individuals and species, and the shaping of senescence by intrinsic and extrinsic factors is scarce. In my thesis, I will contribute to its progress by exploring the life-history of an annual chameleon by focusing on the extrinsic and intrinsic mechanisms leading to the short lifespan of this species. To the beginning, I will summarize some theories explaining "Why do we age". Further, I will point out "how variable is 
senescence" and will focus on differences between species and within species. Moreover, I will examine variances of aging under natural vs protected conditions as well as sex specific patterns of senescence and mortality under natural and protected conditions. Additionally, I will explain the phenomena "semelparity" and discuss its occurrence among different animal taxa. I will also introduce the study species used in this thesis, the Labord's chameleon (Furcifer labordi). Finally, I will outline the specific aims of my thesis and introduce the four distinct studies undertaken to achieve those aims.

\section{Why do we age?}

Many theories have emerged to explain which processes or mechanisms drive the process of senescence, but the distinction between causes and effects is often difficult. That is why, at present, no consensus exists over the specific causes of senescence. However, some theories have attained more empirical support than others have and will be discussed below.

Medawar (1952) and Williams (1957) assumed that senescent declines ultimately arise because natural selection is inefficient at eliminating maladaptive mutations that appear after an individual has already had the opportunity to pass on its genes. While evidence has been found to support their thesis (e.g. Hunt et al. 2006), the particular genetic mechanisms of the physiological changes associated with senescence still remain uncertain (Hughes et al. 2002, Kirkwood 2005, Moorad and Promislow 2009). However, a more general explanation offered for senescent deterioration, the "disposable soma theory" found concordant support (Kirkwood 1977, Kirkwood 2002, Kirkwood 2005). This theory predicts that a limited amount of resources is available for somatic self-maintenance, prevention and repair of cellular damage, as well as other functions, such as reproduction and growth. Here, inevitable trade-offs arise between selfmaintenance and the other functions concomitantly shaping the rate of aging (Kirkwood and Austad 2000, Lemaitre et al. 2014). Consequently, the effectiveness of self-maintenance is at the core of senescent declines, and several molecular mechanisms such as the accumulation of reactive oxygen species (e.g. Marnett 2002), and the shortening of telomeres (protective repetitive nucleotide sequences at the ends of chromosomes) (Monaghan 2014) have been identified as potential proximate causes of age-related functional decline. In the absence of appropriate prevention and repair mechanisms (e.g. DNA repair, anti-oxidant action, and telomerase activity), these molecular alterations lead to cellular damage (Kirkwood 2005) that in turn can bring on changes in physiological processes, tissue composition and functional 
performance at old age. The resulting effect is reflected in age-related diseases, disability and frailty and, in consequence, actuarial senescence in the vast majority of animal species (Gaillard 1994, Ricklefs 1998, Jones et al. 2014). Physiological stress is an essential mediator in the tradeoff between survival and reproduction (Boonstra et al. 2001, Ricklefs and Wikelski 2002). Glucocorticoids (GCs) affect the expression of up to $10 \%$ of the genome (Le et al. 2005) and some of their effects parallel those observed during aging, suggesting that chronic stress has a high potential to accelerate the aging process (Sapolsky et al. 1987, Veldhuis et al. 2013).

The immunosuppressive effects of chronic GC elevation and their consequences for morbidity and mortality have been studied intensively (e.g. Sapolsky et al. 2000, Dahabhar 2009). Alterations in key immunological parameters during chronic stress parallel those during normal immunosenescence to a large degree (Bauer 2008). One potential pathway shared by stress and aging is an oxidative stress-mediated shortening of telomeres (Haussmann and Marchetto 2010, Monaghan 2014). Elevated GC levels, particularly during long-term physiological or psychological stress, have been linked to increased oxidative stress, shortened telomeres, and reduced telomerase activity (Eple et al. 2004, Constantini et al. 2011).

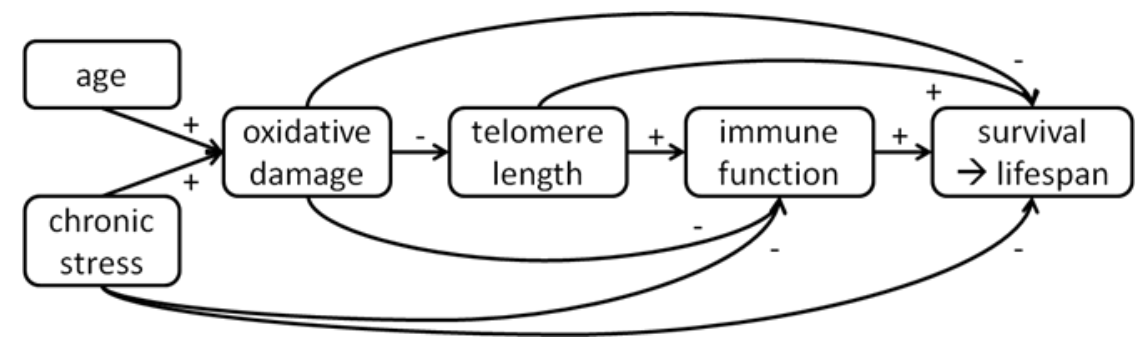

Fig 1. Hypothesized pathways by which age and chronic stress affect lifespan. Simplified and modified after (Vleck et al. 2007) and (Haussmann and Marchetto 2010).

Classical evolutionary models of aging predict that all species ultimately age (Hamilton 1966). However, studies from captivity and in the wild have shown that several species of fishes, amphibians, and reptiles, to name only vertebrates, fail to show signs of aging (Finch and Austad 2001). The authors specifically questioned whether exceptionally long-lived animals showed signs of negligible senescence on physiological and biochemical levels. The term negligible senescence was devised by the biogerontologist Caleb Finch (1990) to describe the very slow aging reported in bivalves, cold-water fish, and chelonians. Many of these 
organisms that were aged by growth zone analyses of the otolith, ear bone or shell, are assumed to live for more than 100 years. Finch proposed three specific criteria to test the incidence of negligible senescence, explicitly no observable: (1) age-related increase in mortality rate, (2) decrease in reproduction rate after sexual maturity, as well as (3) no age related decline in physiological functioning. Nevertheless, these animals have only been studied for a limited amount of time. Still, it is surprising that long-term studies revealed that females of Blanding's turtle and Painted turtle increased both survivorship and reproductive output with age (Congdon et al. 2001, Congdon et al. 2003). Moreover, Ruby et al. (2018) identified that the naked mole rats achieve negligible senescence that has never been documented in mammals before. Moreover, Buffenstein (2008) suggested that this rodent is a candidate species for negligible senescence. Interestingly, naked mole rats pose many challenges to molecular biogerontology theory. Their levels of oxidized lipids and proteins are remarkably high, without further age changes after maturation (Perez et al. 2008, Ungvari et al. 2008), which would not predict longevity in the usual model of critical oxidative load.

\section{How variable is senescence?}

Rates of senescence are highly variable both among and within species (Jones et al. 2014). The variance on species-level has been attributed to differences in e.g. body size, mating systems and reproductive schedules (Ricklefs 2010), as well as environment (Cayuela et al. 2019), and capabilities of escaping extrinsic hazard, e.g. flight (Austad and Fischer 1991, Healy et al. 2014), armored protection or weapons (Ricklefs 1998) sociality (Carey and Judge 2001, Buffenstein 2005, Keller and Jemielty 2006) and diet (e.g. Wasser and Sherman 2010). Tradeoffs between reproduction and individual survival via self-maintenance are arranged differently across animal taxa with varying life-histories (Jones et al. 2008). A key factor of the rate of aging is assumed to be the level of exposition to hazardous environments (Ricklefs 1998, Williams et al. 2006). Species, experiencing high extrinsic mortality due to predation, pathogens or natural accidents, are expected to invest their energy into early reproduction as the possibility of survival to the next reproductive event may be low (Jones et al. 2008). This leads to a "fast pace of life" or the so called "r-selected" life-history (Pianka 1970, Austad 1997), probably resulting in fast growth rates and reduced investment in somatic maintenance after reproductive maturity, leading to rapid senescent declines after reaching sexual maturity. It has also been suggested that fast juvenile growth rates are associated with a lower degree of developmental 'quality control', and therefore connected with a higher probability of 
developmental error (Sibly and Calow 1986). Since smaller animals tend to be more prone to predation they are subsequently expected to follow this life-history strategy. Contrary, in longer-lived animals with a slow life-history ("K-selected" species), a higher investment in somatic maintenance would be expected as reproductive success over lifetime tends to accumulate over several reproductive events a higher lifespans and the potential for continuous fitness increases (Jones et al. 2008).

Remarkably, even though larger species tend to have longer life expectancies, numerous cases are showing that smaller individuals within a species live longer in captivity (e.g. mice, rats, horses, and dogs [Miller et al. 2002, Rollo 2002]). Subsequently, larger species tend to be longer-lived, but on intraspecific level, smaller individuals tend to live longer, at least under protected conditions. Extreme examples for intraspecific variation in longevity in the wild are eusocial insects (e.g. Keller and Jemielity 2006). For example, queen honeybees have an average lifespan of approx. one year, whereas female workers typically live for only several weeks (Huges and Reynolds 2005). Similarly, within the eusocial mole rat Fukomys damarensis, queens live considerably longer than non-reproductive females (Schmidt et al. 2013). Intraspecific differences of lifespan on population level can also be caused by variability in nutrition availability in different environments (e.g. Wolfe et al. 2004) or ambient temperatures (e.g. Mangel and Abrahams 2001). Usually, in ectotherms, lower ambient temperatures result in delayed maturity and increased lifespan (Gosden 1996). Moreover, caloric restriction can significantly influence an individual's lifespan by attenuating oxidative mitochondrial damage. Caloric restriction is a diet that reduces calorie intake without incurring malnutrition or a reduction in essential nutrients. Several animal species that were maintained under caloric restriction showed extended lifespans compared to their conspecifics, which were fed ad libidum (reviewed in Masoro 2005).

Within some taxa, certain species groups conspicuously stand out as being exceptionally long-lived. Within vertebrates, longitudinal data tend to be available mainly for rather largebodied species exhibiting slow life-histories. Consequently, these taxa are best represented in studies of within-individual senescence (e.g. ungulates [Gaillard et al. 2008, Nussey et al. 2011], sea birds [Pardo et al. 2013], seals [Hindle et al. 2009], baboons [Altmann et al. 2010]). Still, a few studies have also been able to demonstrate senescence in natural populations of short-lived organisms, such as small fish (guppies [Reznick et al. 1990, Reznick et al. 2004]). Due to the predominant focus on species from the slow end of the pace-of-life continuum, considering their comparatively low risk of extrinsic mortality, it seems presumable that the 
observed patterns of senescence are biased towards seemingly preferred these habitats. Subsequently, due to their size and proximity to humans, mammals are the best-studied group. Besides a large diversity in average and maximum lifespan, we find many similarities in the aging process since it is postulated that the aging process of this taxon has, to some degree, a common origin (de Magalhaes and Toussaint 2002). Typically, mammals exhibited reproductive senescence (in females typically at mid-life), increased mortality with age, and evidence of functional decline with age (Cohen 2004). In general, eutherians are longer living than marsupials (e.g. Miller 1999). Comparing birds with mammals, several studies suggest that birds are the slower aging taxon (e.g. Holmes and Austad 1995, Holmes et al. 2001, Holmes and Ottinger 2003). Nonetheless, there are no verified reports of birds with negligible senescence. Since the longevities of some bird species approach those of humans, avian aging processes might actually be more similar to ours in some respects than those of the short-lived rodents typically used to model basic mammalian aging processes (Holmes and Ottinger 2003).

Reptiles tend to show a lower incidence and intensity of aging than most mammals (Finch 1990, de Magalhaes and Toussaint 2002). Some reptilian species exhibit signs of senescence comparable to that observed in mammals (Majhi et al. 2000, Jena et al. 2002, Olsson and Shine 2002). Several species, particularly chelonians, appear to feature negligible senescence and very long lifespans (Zug 1991). The record holder for longevity is Harriet, a Galapagos giant tortoise collected from the Galapagos islands a few years before Charles Darwin arrived, died in 2006 at the age of 175 years (Magelhaes and Costa 2009). In addition, crocodiles (e.g. Hutton 1986, Castanet 1994) and tuataras (Dawbin 1982) are known to be exceptionally long-living. By possessing shells (chelonians) and skin armor (crocodiles), both taxa show the so-called "protective phenotype" (reviewed in Schwartz and Bronikowski 2011), which predominantly shields them from environmentally-driven mortality. Besides, crocodiles show parental care (e.g. Tullberg et al. 2002) that highly increases juvenile survival probability (Garner 2016). Concerning tuataras, the low ambient temperatures and therefore reduced metabolic rates might favour their longevity. Although numerous species of squamate reptiles (lizards and snakes) exhibit long life-histories (Magelhaes and Costa 2009), we find several examples of short life-histories and even semelparity in this group (Dickmann 1999, Karsten et al. 2008, Rodrigos-Romero et al. 2011). Reptiles are an extremely diversified group, but regarding aging mechanisms, they are highly understudied. Recently, reptiles were found to have three times more variation in life-history traits compared to mammals (Babich Morrow et al. 2019). Moreover, they typically exhibit continued growth after their first reproduction, which distinguishes them from mammals and birds (Hariharan et al. 2016). Furthermore, a 
considerable increase in fecundity with age can occur in reptiles even in the oldest documented wild individuals (e.g. Sparkman et al. 2007, Warner et al. 2016). However, this does not exclude reproductive senescence at the end of the lifetime (Warner et al. 2016). Besides, several squamate species have tissue regenerative capacities that surpass those of mammals by far (e.g. Sun et al. 2018). Until now, there has been little consideration of how these regenerative capabilities impair the rate of aging in these species (Hoekstra et al. 2019). Therefore, it is highly possible that this group may feature various mechanisms to delay aging and age-related debilitation, making them an intriguing model to study aging. Lastly, comparisons among different taxa can yield insights into those mechanisms of aging that are fixed or constrained versus those that have evolved independently in different animal lineages.

\section{Aging under natural versus protected conditions}

Studies linking molecular alterations to senescence have mainly been focused in laboratory animals (e.g. Austad 1997). On the one hand, laboratory studies on the mechanisms of senescence profit from reduced heterogeneity among individuals and easier identification of senescent changes caused by the reduced mortality rates under protected conditions. However, previous selection for fertility may have also selected for short lifespans (e.g. laboratory mouse strains), generating biases in studies of senescence. In other words, it has been discussed that the life-extending gene variants found in these organisms may be simply restoring lifespan to what is usually found in the wild (Spencer and Promislow 2002). The fact that wild-derived mouse strains require a longer duration to reach sexual maturity and live significantly longer than common laboratory strains supports this view (Miller et al. 2002). An additional problem is that laboratory strains are regularly genetically homogeneous that offer more consistent results, but also implicate discrepancies between strains (Partridge and Gems 2007, de Magalhaes 2014). Thus, to evaluate the relative involvement of intrinsic and extrinsic factors shaping life-histories, comprising the onset and rate of senescence, it is essential to monitor senescence in natural populations. The main body of senescent studies are conducted under protective conditions Therefore, it is essential to evaluate how patterns observed in captivity are comparable to populations in nature to define how much of the decline observed in captivity depicts intrinsically biological versus behavioural variation, and the interactions of individual quality and the environment. Remarkable examples of a rapid increase in mortality rates following reproduction such as that documented in several salmon species and some small 
marsupial species (Lee et al. 1982, Oakwood et al. 2001) underpin the observation that senescence does occur in natural populations.

Besides its evolution-theoretic interest, knowledge about the basis of variance in senescence rates is required for human interventions of age-related disease and functional declines. Therefore, for entirely understanding the links between molecular self-maintenance, disease and mortality, and individual heterogeneity in these processes, it is vital to focus more senescence patterns in nature. In addition to intrinsic mortality by illness or physiological failures, morbid individuals may more likely succumb to mortality by extrinsic hazards, a process termed "selective disappearance" of lower quality individuals, (Bouwhuis et al. 2009, Hayward et al. 2013, Nussey et al. 2011, van de Pol and Verhulst 2006). Therefore, aging individuals may face an elevated mortality risk if their coping with extrinsic pressures is impaired by senescent declines in immunological, physical or cognitive functioning. If intrinsic qualities influence the lifespan of an individual, senescent declines would indeed be difficult to observe among populations in nature, as it may be difficult to conclude to what extent the observed deviation (particularly in cross-sectional data) in a given trait reflects the higher quality of the subset of animals alive. This issue is likely at the core of the earlier conclusions about an absence of a senescent decline in wild animals (Hayflick 2000, Williams 1957).

By the use of careful study designs, longitudinal data, and suitable methods of statistical inference, a number of studies have nevertheless been able to demonstrate senescence in the wild (Nussey et al. 2013). However, rates of senescence vary across traits (Nussey et al. 2009, Walker and Herndon 2010, Hayward et al. 2013) and senescent decline of physical function seems to be absent in some of the measured traits (e.g. Rueppell et al. 2007, Gonzalez et al. 2012). Due to the small number of studied taxa and the rarity of studies measuring senescence in multiple traits, it is still uncertain which aspects of the functioning of the organism are most affected and how environmental surroundings and life-history variation influence the traceability and rates of functional senescence. Nevertheless, the fact that different rates of senescence occur across the examined traits suggests that selective pressures to maintain functioning are stronger for some features than others. However, little attention has been paid to this possibility (Burger and Promislow 2006, Bouwhuis et al. 2012). The influence of extrinsic mortality on senescence has been studied using experimental manipulations and comparison of life-history characteristics in different natural environments (Reznick et al. 1990, Reznick et al. 2004). A comparison of wild and captive populations could be used to complement these approaches (Bronikowski et al. 2002, Magalhaes et al. 2007, Lemaitre et al. 
2013). However, this approach has thus far not been taken to assess how the environment shapes senescence.

Interestingly, and in contradiction to the results of Scharf et al. (2015) for squamates, captivity did not influence the recorded longevity within reptile species (Stark et al. 2018). Here, factors such as stress, poor keeping conditions, and disease are suggested to cause premature deaths in captivity, offsetting the positive effects of reducing predation and starvation (Robinson et al. 2015). Thus, average and maximum lifespan in several reptile species might be highly underestimated. In total, comparative life-history studies of reptiles in the wild and captivity are scares. This is probably because reptiles are often difficult to monitor in the wild and infrequently kept in laboratories in higher numbers, which is probably due to significant logistical, financial and ethical limitations (McDiarmid et al. 2012). Therefore, future work is needed to clarify differences in lifespan in captive and wild reptile populations.

\section{Sex-specific patterns of senescence and mortality}

Differences in life-history and rates of aging also arise on an intraspecific level (Stearns 1992). Among vertebrates, one of the main differences is the frequently documented sex-bias in longevity. Within mammals, females tend to be the longer living sex (Bonduriansky et al. 2008), whereas, in birds, the opposite is often, but not generally true. However, contrary to mammals, large-scale comparisons of the sex gap in aging patterns are still lacking in birds (Liker and Székely 2005). These differences among mammals and birds are partially attributed to the heterogamety in male mammals and female birds (e.g. Pipoly et al. 2015). Finally, intersexual differences in lifespan and senescence have been mainly addressed to the divergent strength of sexual selection on both sexes (Promislow et al. 1992, Liker and Székely 2005, Clutton-Brock and Isvaran 2007). Especially in species with polygamous mating systems, males achieve higher lifetime fitness by investing severely in reproduction during the peak reproductive age (Clutton-Brock and Isvaran 2007). For females, the fitness gains are more evenly distributed over successive reproductive events over their lifetime (Clutton-Brock and Isvaran 2007). Following Bateman's principle of sex-specific reproductive variance (Bateman 1948), mammalian females (or the sex that benefits from a prolonged reproductive lifespan) should live longer (Bonduriansky et al. 2008). In general, female vertebrates have greater immune responses than males (e.g. Terres et al. 1968), and it has been assumed that this is a consequence of the immunosuppressive effect of testosterone (Alexander and Stimson 1988, Schuurs and 
Verheul 1990). However, detailed studies of sex differences in immune functioning imply that humoral immune responses are higher in females rather than suppressed in males (Olsen and Kovacs 1996). Moreover, testosterone may also favour behaviours, such as aggression and dispersal, increasing the likelihood of external mortality risks (e.g. Zuk and McKean 1996, Roberts et al. 2001).

\section{Semelparity}

The term semelparity was shaped by the evolutionary biologist Lamont Cole (1954) and originates from the Latin words semel 'once, a single time' and pario 'to beget'. This differs from iteroparity seeing that iteroparous organisms spread their reproductive investments across multiple occasions during their lifetime (Bossert 1970, Benton and Grant 1999). Semelparity is also known as "big bang" reproduction, as the single reproductive event is usually large as well as deadly (Ricklefs and Miller 1999). It has been frequently demonstrated that semelparous species produce more offspring during their single reproductive event than closely related iteroparous species in any one of theirs (Charnov and Schaffer 1973). Within the animal kingdom, semelparity is frequently found in invertebrates. It is widespread among insects, including several taxa of lepidopterans, hemipterans, ephemeropterans etc. Ultimately, their fragile wings that become more tumbled over time might explain the relatively short life of most adult insect stages. This life-history strategy also occurs in several arachnids (e.g. Schneider and Lubin 1997), and numerous species of cephalopods (Rocha et al. 2001).

Among vertebrates, a classic example of semelparity are anadromous salmon species (Hendry et al. 2004, Morbey et al. 2005), which live for several years in the ocean before swimming to the freshwater rivers of its birth, spawning, and dying. The transition between oceanic water to freshwater and steep elevation changes in rivers could explain the evolution of semelparity because it would be extremely demanding to return to the ocean. Highly elevated glucocorticoid levels mediate the post-spawning death of the semelparous salmon species by causing tissue degeneration, suppressing of the immune system, and impairing various homeostatic mechanisms (Dickhoff et al. 1989). One of the main factors accelerating rapid senescence is that they do not feed during reproduction resulting in extremely reduced body weight (Morbey et al. 2005). Moreover, certain annual African fish species from the genus Nothobranchius, which are adapted to life in temporal water bodies, are semelparous and do not commonly live more than 12 weeks (Valdesalici and Cellerino 2003). Additional examples 
for this life-history strategy in bony fish are the smelt Thaleichthys pacificus (Clarke et al. 2007) and male capelin Mallotus villosus (Huse 1998).

However, this phenomenon is rarely found in vertebrates other than bony fish. Within amphibians, strict semelparity has never been documented, though a few species, such as the Northern cricket frog Acris crepitans exhibit an almost population-wide turnover within a year (Lehtinien and MacDonald 2011). In reptiles only a few lizards such as the Labord's chameleon of southwestern Madagascar (Karsten et al. 2008), bunchgrass lizards Sceloporus bicanthalis of the highlands of Mexico (Rodríguez-Romero et al. 2011) as well as some Australian agamid species of the genus Ctenophorus (e.g. Henle 1991, Dickman et al. 1999) exhibit an annual lifehistory. However, within these lizards, occasionally, a few individuals survive until the next breeding season. Among mammals, semelparity seems to be predominantly restricted to a few didelphid and dasyurid marsupials (e.g. Braithwaite et al. 1979, Ooakwood et al. 2001, Lopes and Leiner 2008). Apart from marsupials, semelparity has been detected in a rodent species, the desert woodrat Neotoma lepida from the Death Valley, California (Smith and Charnov 2001). Within birds, annual species have never been documented and lifespan of birds is typically 2 3 fold longer than that of mammals of comparable size (Austad 1997, Austad 2011). Lower aging rates in birds (e.g. Travin and Feniouk 2016), frequent biparental care (Cockburn 2006), and the ability to escape hazards by flight (Austad and Fischer 1991) might be the key factors behind this phenomenon.

The evolution for semelparity in both sexes has occurred several times in invertebrates and bony fish. Among tetrapods it occurs in in a few reptile species (e.g. Karsten et al. 2008). However, it is seldom found in mammals because maternal care is obligatory due to internal fertilization and incubation of offspring as well as subsequent nursing, requiring high maternal survival rates after fertilization and offspring weaning. Moreover, female mammals have relatively low reproductive rate compared to invertebrates or bony fish because they invest much energy in maternal care. However, male reproductive rate is much less constrained in mammals because only females bear young. Males that die after one mating season may still produce a high number of offspring by investing all their energy in intense mating with numerous females (Fischer et al. 2013). Natural selection might have allowed semelparity to evolve in the Dasyuridae and Didelphidae because of certain ecological preconditions. Females ancestral to these groups may have shortened their mating period to coincide with peak prey abundance. Because this window is so small, these females exhibit a reproduction pattern where the estrous of all females occurs simultaneously. Therefore, selection would favour aggressive 
male behaviour due to increased intersexual competition for accessing females. As mating period is so short, it is more advantageous for males to locate all their energy on mating, even more so if it is improbable to survive to the next reproductive season (Braithwaite et al. 1979). Within males, high levels of corticosteroids are sustained over long periods triggering immune and inflammatory system failure and gastrointestinal hemorrhage, which ultimately leads to death (Oakwood et al. 2001). However, in the relatively large marsupial Dasyurus hallucatus, a lack of elevated cortisol levels during mating periods indicates no current universal explanation for the mechanism behind increased male mortality in Dasyuridae. Postreproductive senescence has also been suggested as an explanation (Bradley 1997). In fact, most semelparous tetrapods live in habitats characterized by high environmental unpredictability (e.g. Henle 1991, Oakwood et al. 2001, Smith and Charnov 2001, Karsten et al. 2008).

\section{Study species: The Labord's chameleon Furcifer labordi (Grandidier, 1872)}

Of the approx. 210 described chameleon species, 90 species are endemic to Madagascar (Glaw 2015, Prötzel et al. 2017, 2018). Malagasy chameleons comprise the four genera Calumma, Furcifer, Brookesia and Palleon. The genus Furcifer is a monophyletic group (Tolley et al. 2013), actually presently containing 24 species (Sentis et al. 2018). All species of the genus show distinct sexual dimorphism and males are generally larger than females. Species of the genus are mainly located in western arid regions, whereas some species occur in rainforests. Typical features of Furcifer are a high and rounded casque (especially males), as well as the absence of occipital lobes (Glaw and Vences 2007). Within the genus, F. labordi is a comparatively small species. Males have a snout-vent length (SVL) of $80-120 \mathrm{~mm}$ and exhibit a large cranial casque, a well-defined rostral appendage, and a continuous dorsal crest containing more than 35 gular cones and up to $2 \mathrm{~mm}$ high. Ground colouration is a light green with a white lateral stripe. Females have an average SVL of $70-80 \mathrm{~mm}$ and sometimes offer a poorly developed dorsal crest situated in the nuchal region. Ground colouration is green with blue and violet blotches on the flanks and dorsally orientated bright orange markings and a red spot above the insertion of the arms (Glaw and Vences 2007). They inhabit the western and southwestern seasonal dry forests of Madagascar. They seem to be forest-associated and avoiding degraded forests and scrubland (Soazandry et al. 2010).

Furcifer labordi was suspected to occur on the peninsula Katsepy near Mahajanga and Soalala in northwestern Madagascar (Glaw and Vences 2007). However, within the recent study of Sentis et al. (2018), these northern populations were assigned to the recently resurrected 
species $F$. voeltzkowi (Boettger 1892), which was formerly treated as a synonym. Both species look very similar, but males of $F$. voeltzkowi have a smaller rostral appendage and heterogeneous scalation on the lateral continuous white band, whereas $F$. labordi has a constant homogeneous scalation and a discontinuous lateral band (Sentis et al. 2018).

Furcifer labordi, in particular is interesting to study senescence, as it is the shortest living tetrapod species and therefore provides an insight into aging mechanisms in short-lived vertebrates and especially reptiles, which are an understudied group according to senescence. Furthermore, their relatively small body size facilitates their husbandry in single cages for excluding extrinsic risks of mortality for comparative studies. Additionally, because this species has longer living sympatric congeners, this chameleon assemblage constitutes a promising model for comparative investigations of the ecological and physiological determinants of longevity and senescence in wild tetrapods.

\section{Study aims and approaches}

In the previous sections, I have illustrated the state of the art in studies of senescence in wild populations and identified several gaps. In particular, I have communicated a necessity for further examining patterns of senescence in multiple traits in nature. In light of these gaps, the main aim of this thesis was to disentangle exogenous and endogenous factors that shape the extremely short life-history in an annual chameleon.

The specific questions I defined to answer were:

1. How variable is the lifespan of F. labordi? In particular, I investigated environmentallydependent variability in lifespan: a) between populations (Kirindy vs. Ranobe); b) differences in lifespan within a population due to environmental variation between years in Kirindy; c) differences in sex-specific mortality, d) differences between wild and captive specimens, which were excluded from extrinsic factors of mortality.

2. To what extent does the life-history of F. labordi differ with the one of the two sympatric Furcifer species (F. cf. nicosiai and F. oustaleti) concerning population densities, survival, - growth - and reproduction rates?

3. Does parasite burden have an effect on the lifespan of F. labordi.?

4. To which extent do age-related changes in molecular mechanisms such as chronic 
physiological stress and telomere shortening contribute to the short lifetime of $F$. labordi?

To answer these questions, I examined the population dynamics of a wild population of $F$. labordi in the Kirindy forest via capture-mark-recapture study. I measured age trajectories three different components of health: 1) parasite burden, 2) H/L profiles that indirectly reflect baseline glucocorticoid hormone levels, and 5) telomere shortening. These indicators were selected because they reflect different aspects of general health and can significantly affect fitness and survival of wild individuals. All collected data of health parameters from the wild population were compared with the sympatric and longer living $F$. cf. nicosiai as well as captive specimens of $F$. labordi. I collected data within three field seasons (November 2013 -- mid July 2014, January - mid July 2015, October - December 2015). Blood samples that were used to measure $\mathrm{H} / \mathrm{L}$ profiles and telomere shortening were only collected in adult individuals. During my absence, the caged individuals were fed and watered, but no data except the date of death were collected. 


\section{Chapter 2: Highly variable lifespan in an annual reptile, Labord's chameleon (Furcifer labordi)}

Falk Eckhardt ${ }^{1 *}$, Peter M. Kappeler ${ }^{1,2,3}$ \& Cornelia Kraus ${ }^{1}$

${ }^{1}$ Dept. Sociobiology/Anthropology, Institute of Zoology and Anthropology, University of Göttingen, Kellnerweg 6, 37077 Göttingen, Germany

${ }^{2}$ Behavioral Ecology and Sociobiology Unit, German Primate Center, Kellnerweg 4, 37077 Göttingen, Germany

${ }^{3}$ Wissenschaftskolleg zu Berlin, Wallotstr. 19, 14193 Berlin, Germany

* Corresponding author: falkeckhardt@gmx.de

Keywords: semelparity, lifespan, aging, reptiles, Madagascar

Eckhardt, F., Kappeler, P.M., Kraus, C. (2017). Highly variable lifespan in an annual reptile, Labord's chameleon (Furcifer labordi). Scientific Reports, 7(1), 11397. https://doi.org/10.1038/s41598-017-11701-3 


\begin{abstract}
Among tetrapods, the current record holder for shortest lifespan is Labord's chameleon, Furcifer labordi. These reptiles from the arid southwest of Madagascar have a reported lifespan of $4-5$ months during the annual rainy season and spend the majority of their life ( $8-9$ months) as a developing embryo. This semelparous, annual life-history is unique among tetrapods, but only one population (Ranobe) in the southernmost distribution range has been studied. We therefore investigated the potential for environmentally-dependent variability in lifespan in a population in Kirindy Forest, which has a much longer warm rainy season. While no adults were found after March in Ranobe, the disappearance of adults was delayed by several months in Kirindy. Our data also revealed sex-biased mortality, suggesting that females have a longevity advantage. Furthermore, we found that, after an unusually long previous rainy season, one female was capable of surviving until a second breeding season. Keeping F. labordi in cages under ambient conditions demonstrated that also males can survive until the next season of activity under these conditions. Our study therefore revealed considerable variability in the extreme life-history of this tetrapod that is linked to variation in ecological factors.
\end{abstract}

\title{
Introduction
}

The fast-slow continuum is the dominant axis of life-history variation in tetrapods. Fast-living species are characterized by fast growth, high reproductive rates, high aging rates and short lifespans, compared to their slow-living counterparts (Dunham and Miles 1985, Saether 1998, Jones 2008). Among tetrapods, the most extreme example for short lifespan is provided by Labord's chameleon, Furcifer labordi. During their study in the arid southwest of Madagascar in Ranobe, Karsten et al. (2008) reported synchronous hatching of F. labordi with the onset of the annual rainy season in November. Here, early life of this chameleon is characterized by fast growth, resulting in sexual maturity at less than two months of age. After mating, senescent decline becomes apparent, and by the end of the rainy season in March, a population wide dieoff of both sexes occurs. Thus, with an incubation period of $8-9$ month, F. labordi spend the majority of their lifetime as a developing embryo in the egg, probably as an adaption to the highly seasonal climate. High adult mortality combined with relatively high juvenile survival might have ultimately selected for this semelparous, annual life-history (Charlesworth 1994, Charnov and Schaffer 1973). 
Semelparity, the strategy to invest in only one mating event, is rare among tetrapods, including a few small-sized marsupial species from the families Didelphidae and Dasyuridae. However, in these marsupials the die-off following the mating season is restricted to males, while some females survive to breed a second time (Lee et al. 1982). Strong prey seasonality leading to a short breeding season has been proposed to explain obligate male semelparity in these marsupials (Fisher et al. 2013). Interestingly, males that were captured before the mating season and prevented from competing for mates survived for more than two years (Bradley et al. 1980, Schmidt et al. 2006). Less extreme cases of semelparity among marsupials have also been described. Here, facultative male die-off in the wild is restricted to some populations and/or only observed in some years and linked to variable resource availability due to variable climatic conditions (Dickman and Braithwaite 1992, Wolfe et al. 2004).

Furcifer labordi has so far only been studied in the southernmost and driest part of its distribution range (Karsten et al. 2008). We therefore conducted a field study of a population in Kirindy Forest, which is situated near the northern distribution range and characterized by a longer annual rainy season, to investigate potential intraspecific variation in lifespan. Since Madagascar is known for its high unpredictability in inter-annual rainfall (Dewar and Richard 2007), we also focused on differences in lifespan due to environmental variation between years. Additionally, we examined differences in sex-specific mortality because mortality varies by sex in some semelparous marsupials (Fisher et al. 2013). To characterize intrinsic rates of aging, we excluded extrinsic factors of mortality due to predation, costs of reproduction, fighting as well as water and food shortage by keeping some individuals of both sexes in field cages.

\section{Materials and Methods}

Study site: Kirindy Forest is a dry deciduous forest, in Western Madagascar $\left(44^{\circ} 39^{\prime} \mathrm{E}, 20^{\circ} 03^{\prime} \mathrm{S}\right.$, 30 - $60 \mathrm{~m}$ above sea level). Climate is characterized by a hot rainy season (November - March, with on average $900 \mathrm{~mm}$ annual precipitation), followed by a cool dry season from (AprilOctober) (Kappeler and Fichtel 2012). Sampling took place over three field seasons: November 18, 2013 - July 9, 2014, January 11 - July 15, 2015, and October 12, 2015 - December 17, 2015.

Capture-mark-recapture: Furcifer labordi were located at night using flashlights. They often roost on distal branches at a height of $0.5-3 \mathrm{~m}$, and were therefore relatively easy to detect. Chameleons were either captured by hand or removed from higher branches using a stick to 
which they were encouraged to grip. We sampled alternating along two transects of $3 \mathrm{~km}$ length each. We had a recurring order of 10 sampling nights with a break of four nights within each field season. Each capture location was marked by a flag and a GPS recording was taken. Animals were taken to the research camp and handled the following morning. They were sexed and their age categorized (hatchling, juveniles and adults), and their snout-vent-length (SVL) was measured. Hatchlings were identified by the little opening of the abdominal wall due to the former connection with the yolk sack, which is visible during the first days after hatching. Growing individuals were assigned juvenile status until they were sexually mature. Female chameleons were identified as adult when the colourful mating patterns appear and males by the presence of a distinct hemipenis bulge and a hard, ossified rostral appendage. Chameleons were individually marked by visual implant elastomers (VIE; Northwest Marine Technology Inc., Shaw Island, WA). Hatchlings and small juveniles were individually marked by nail polish on the toes. Animals were released at their point of capture the next day. We measured juvenile growth rates and estimated adult sex ratios. To determine growth rate, we calculated daily growth rate from juveniles between their first capture and subsequent re-capture. We compared sex ratios monthly throughout the reproductive season using a $\chi^{2}$-test.

\section{Experimental housing}

We collected juveniles in early January at around two months of age in the forest outside the transect system to exclude any influence on the study population. In total, 20 males and 20 females were housed separately without visual contact in cylindrical outdoor enclosures made of nylon screen (90 cm height, $60 \mathrm{~cm}$ diameter). The enclosures were equipped with branches and artificial plants. They were placed in a large outdoor cage in the forest, close to the research camp. Thus, they experienced largely the same temperature and daylight conditions as their conspecifics in the wild. Chameleons received a standardized amount of insect food, depending on age and size to match growth and final size of free-ranging animals. Specifically, chameleons were fed five times per week with two crickets, grasshoppers or butterflies. Water was offered daily with a spray flask. We used the Kaplan - Meier estimator (Bland and Douglas 1998) to assess survival probability of both sexes in captivity. 


\section{Ethics statement}

All applicable international, national, and institutional guidelines for the capture and keeping of animals were followed. Research protocols, capture procedures, and keeping of chameleons were approved and permitted by the Ministry for the Environment, Water and Forests of Madagascar, MINEEF.

\section{Results}

\section{Capture-mark-recapture study}

Hatchlings were mainly found between mid-October and early December. Recaptures of marked individuals allowed us to estimate average daily juvenile growth rates for males $(1.37 \%$, $\mathrm{n}=13,0.76 \pm 0.48 \mathrm{~mm}$; mean $\pm \mathrm{SD})$ and females $(1.18 \%, \mathrm{n}=12,0.55 \pm 0.27 \mathrm{~mm}$; mean $\pm \mathrm{SD})$. We first found adult males in early January and adult females in late January. Average snoutventral length $(\mathrm{SVL})$ for adult males was $100.3 \pm 8.62 \mathrm{~mm}(\mathrm{n}=344)$ and for females $73.3 \pm 3.7$ mm $(n=500)$. Gravid females appeared from the end of January onwards. Later in the reproductive season, we found that some females could reproduce more than once $(n=3,4.6 \%$ of all re-captured adult females). We assumed a gestation period of maximally four weeks and recaptured these females at least five weeks after we noticed that they were gravid. Additionally, later in the reproductive season several gravid females $(n=48)$ showed abrasion on their wrist. These marks most likely resulted from excavation for the deposition of a previous clutch. While the sex ratio in juveniles was almost even, the adult sex ratio became highly female-biased across the reproductive season in 2014 (Feb to May-Jul $\chi^{2}=39.2$, df $=3, \mathrm{P}<$ 0.001 ) and 2015 (Feb to Jun-Jul: $\chi^{2}=48.2, \mathrm{df}=4, \mathrm{P}<0.001$ ). In the season 2013/14, no males were found after May 27, while single females were detected until July 1 (Fig. 2.1A). In contrast, in the reproductive season 2015, males were detected until June 9, and several females were active until the end of the field season in mid-July, when some were still in good physical condition and even gravid (Fig 2.1B). In total, recapture rates were rather low (98 out of 881 captures; $11.12 \%$ ) in the season 2013/14 and (33 out of 439 captures, $7.52 \%$ ) in the second season 2015 and ( 2 of 142 captures, 1.41\%) in the third field season. At the beginning of the third field season, we encountered an adult female originating from the previous active season on October 29. This animal was in good physical condition (Fig. 2.1B). For further observation, we kept her in captivity. In December, she was put together with an adult male, which had been 
kept alive in captive field conditions, resulting in immediate mating. This female survived until March 2016, a presumed lifespan of 16 months.
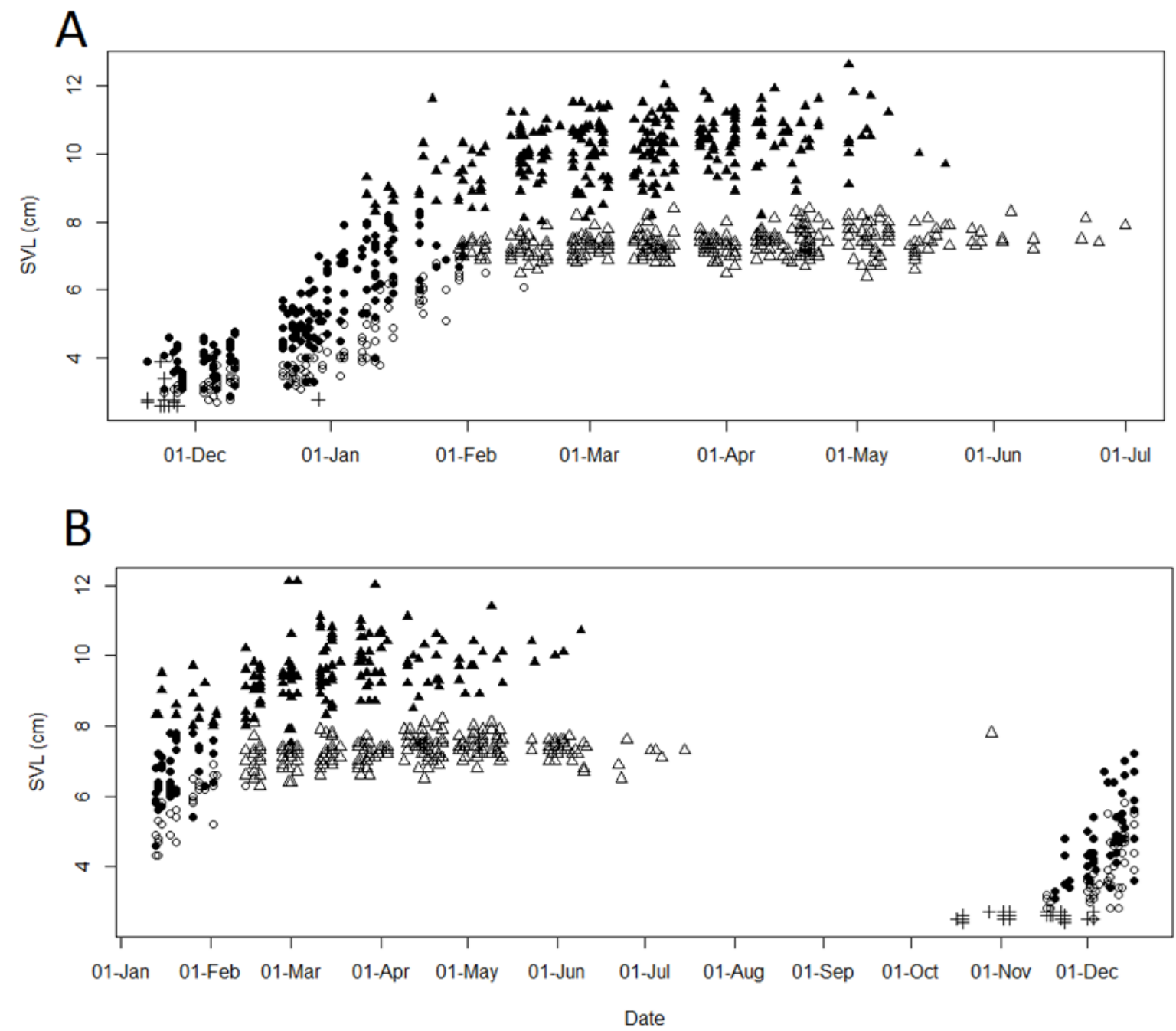

Fig. 2.1. Growth curves of F. labordi in Kirindy Forest. Depicted is SVL against date: unsexed hatchlings (+); males (filled symbols); females (open symbols); juveniles (circles); and adults (triangles). (A) Data of field season from November 19, 2013 - July 9, 2014 ( $\mathrm{n}=881$ ), (B) Data of field seasons from January 11 - July 2015 ( $\mathrm{n}=439)$, and October 12 - December 17, 2015 $(n=142)$.

\section{Experimental field enclosures - Keeping $F$. labordi in protected field conditions}

We found no significant differences in survival probability between captive males and females (logrank-test: $\chi^{2}=0.3, \mathrm{df}=1, \mathrm{P}=0.59$ ). Median survival time for females was 9.5 months and for males 8.2 months. Maximum lifespan for females was 11.5 months and for males 16 months. 
Two males and two females escaped from damaged cages during a cyclone. Moreover, three females died because of egg binding (Fig. 2.2).

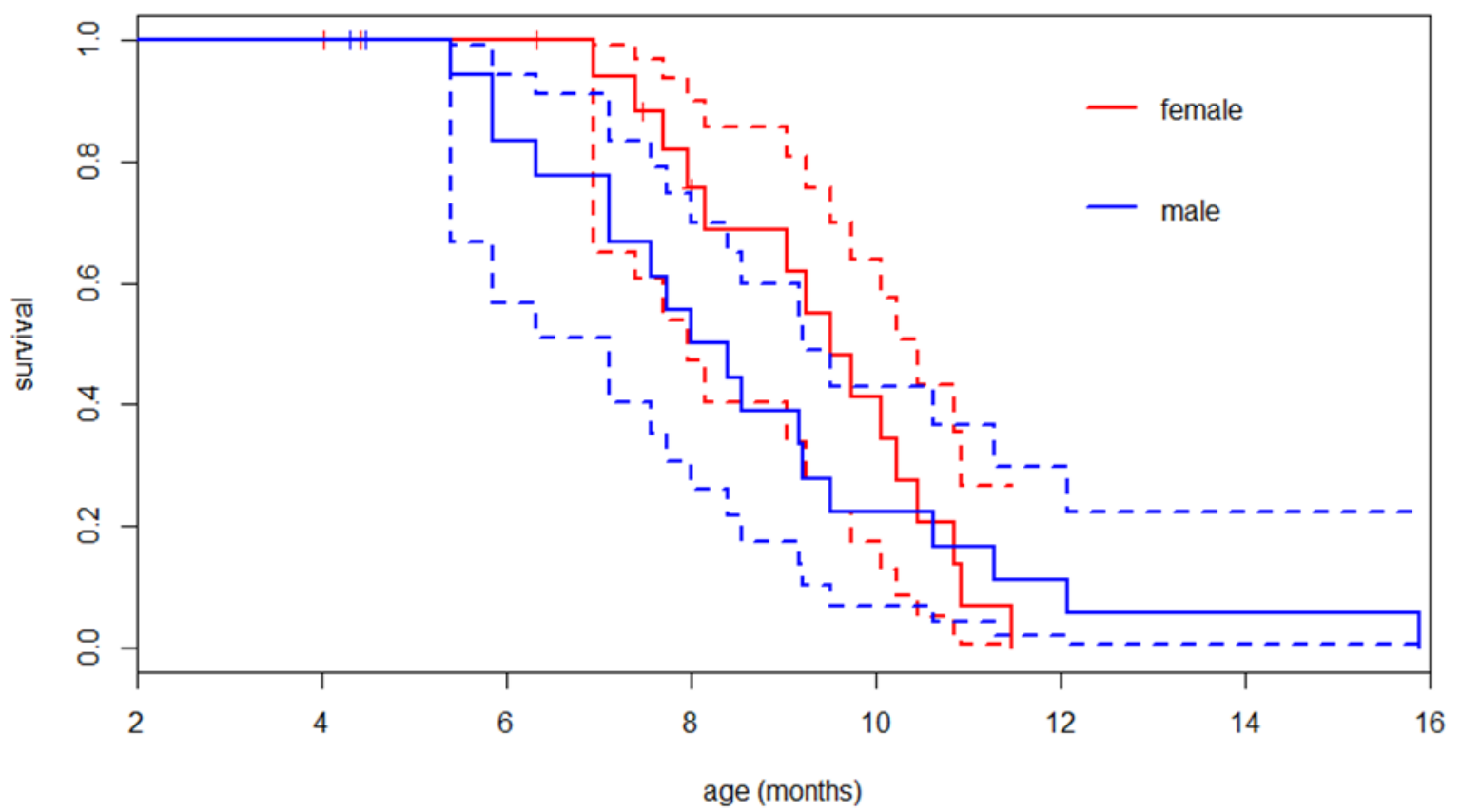

Fig. 2.2: Kaplan-Meier survival curves of $F$. labordi in captivity. Continuous lines indicate probability of survival of males (blue) and females (red). Dashed lines represent corresponding 95\% confidence interval. Small vertical bars show censored events due to escape or death by egg-binding.

\section{Discussion}

Our study revealed considerable variability in the life-history of $F$. labordi, suggesting that their survival in nature is to some degree responsive to ecological conditions. During an average rainy season in 2013/14, lifespan ranged from 6 - 9 months and was therefore longer compared to longevity reported for the southern population. Both populations also differed in several aspects of their life-history, with all stages of life being more extended at Kirindy. Karsten et al. (2008) reported synchronous hatching and rapid daily juvenile growth rates of $1.86 \%$ in SVL in both sexes reaching maturity at less than 60 days. Hatchlings emerged around four weeks earlier at Kirindy and we observed slower juvenile growth rates, resulting in first sightings of adult males after 79 and adult females after 105 days, counted from the detection of first hatchlings. Karsten et al. (2008) hypothesized that females produce only one clutch in their 
lifetime. We recaptured females that were gravid at least twice, suggesting that females in Kirindy may lay more than one clutch and, hence, are not strictly semelparous. Furthermore, both populations show a considerable difference in male adult body size (SVL, Kirindy: 100.3 $\pm 8.62 \mathrm{~mm}, \mathrm{n}=344$; Ranobe: $87.3 \pm 1.3 \mathrm{~mm}, \mathrm{n}=99$, (Karsten et al. 2009b). All these differences might be linked to higher annual precipitation levels and longer vegetation periods at Kirindy (900 mm) compared to Ranobe (420 mm) (Karsten et al. 2008).

We reviewed climate data for Kirindy (2005 - 2015) and found that rainfall during the second field season was, compared to the long-term average, exceptionally high, resulting in an extended vegetation period. Consequently, members of both sexes were detected about 2 weeks longer (minimum estimate for females), and one marked female was even found during the following active season. Thus, in rare cases, a very small proportion of adult females may survive the dry season under favourable environmental conditions and they may even enter the next reproductive season.

Our data revealed a remarkable difference in sex-specific mortality, indicating that females have a longevity advantage somewhat similar to semelparous marsupials (Lee et al. 1982). The obligate male die-off after reproduction in nature is likely related to intense intrasexual competition (Karsten et al. 2009a, 2009b), as many adult males showed wounds or scars, especially at the head. Karsten et al. (Karsten et al. 2009b) reported potentially receptive females being very selective in terms of mate choice, compared to a larger perennial species. Intense intra-sexual selection might have led to physically intense male encounters with increasingly females-biased adult sex ratios. Additionally, in several other chameleon species, mate guarding was observed, and some males did not feed for several days (Cuarando 2001). We detected numerous males roosting close to females, which is suggestive of mate guarding in this species as well.

Keeping $F$. labordi in captive field conditions revealed that both sexes could outlive their conspecifics in the wild, showing that senescence can be delayed. Moreover, no significant differences in sex-specific mortality were found under these sheltered conditions. However, two males showed extended survival (12 and 16 months) compared to free-living conspecifics. These observations resemble that of some male semelparous marsupials, where lifespan was dramatically expanded by capturing them before the mating season (Bradley et al. 1980). Moreover, one of the $F$. labordi males was able to mate at the age of 13 months. Hence, lifespan might strongly depend on external causes of mortality that were excluded in captivity. 
Despite the remarkable plasticity in lifespan of $F$. labordi, the accelerated life-history remains unique and several aspects favouring such a short lifespan remain unknown. Because F. labordi has perennial sympatric congeners, this chameleon assemblage constitutes a promising model for comparative investigations of the ecological and physiological determinants of longevity and senescence in wild tetrapods (Karsten et al. 2008).

\section{Acknowledgements}

We thank the Commission Tripartite de Direction des Eaux et Forêts, and CNFEREF Morondava for authorization and support for this study. We are thankful for support in the field to Camilla Chenni, Hauke Thiesler, Wanda von Bremen and the team of field assistants in Kirindy Forest.

\section{Author contributions statement}

F. E., P. K., and C. K. designed research and wrote the paper, F. E. conducted research, F. E. and C. K. analyzed data. All authors reviewed the manuscript.

\section{Additional information}

We have no competing financial interest. 


\section{Chapter 3. Life-histories, demographies and population dynamics of three sympatric chameleon species (Furcifer spp.) from western Madagascar}

Falk Eckhardt ${ }^{1}$, Cornelia Kraus ${ }^{1,2}$ \& Peter M. Kappeler ${ }^{1,2}$

${ }^{1}$ Abteilung Soziobiologie/Anthropologie, Institut für Zoologie und Anthropologie,

Universität Göttingen, Kellnerweg 6, 37077 Göttingen, Deutschland

${ }^{2}$ Abteilung Verhaltensökologie \& Soziobiologie, Deutsches Primatenzentrum - Leibniz-

Institut für Primatenforschung, Kellnerweg 4, 37077 Göttingen, Deutschland

Key words: Furcifer labordi, chameleon communities, lifespan, ageing, life-history

Eckhardt, F., Kraus, C., Kappeler, P.M. (2019). Life histories, demographies and population dynamicsof three sympatric chameleon species (Furcifer spp.) from western Madagascar. Amphibia-Reptilia, 40(1), 41-54. https://doi.org/10.1163/15685381-20181039 


\begin{abstract}
The life-histories and population dynamics of chameleons remain poorly known, most likely due to practical challenges related to their cryptic nature. However, several studies have indicated that some of these reptiles have unusually brief life-histories. Specifically, one Madagascan chameleon (Furcifer labordi) was found to have an annual life cycle characterized by population-wide survival of the austral winter in the egg stage; a unique life-history among tetrapods. In this study, we compare the life-history of $F$. labordi with two locally sympatric congeners ( $F$. cf. nicosiai and F. oustaleti) in Kirindy forest, western Madagascar, to determine how these species adjust their life-histories to a highly seasonal and unpredictable climate. We found differences in lifespan, timing of hatching, growth rates, survival, reproductive rates, adult body size, and roosting heights among all three species. Moreover, two species exhibited relatively short lifespans: $6-9$ months in F. labordi and 16-18 months in F. cf. nicosiai. In contrast, $F$. oustaleti is perennial and large-sized juveniles and adults aestivate during the dry season, but survival rates of adults seemed relatively low. Strikingly, the annual cohort of $F$. labordi was already adult when hatchlings of $F$. oustaleti and subsequently $F$. cf. nicosiai emerged. Our study suggests the co-existence of three different life-histories with seasonal adjustment that might be related to the partitioning of overall food availability and contributes valuable life-history data on enigmatic chameleon species.
\end{abstract}

\title{
Introduction
}

Life-history theory predicts that a high risk of extrinsic adult mortality selects for fast growth, early maturation, high investment in reproduction and short lifespans, whereas high adult survival probabilities favour slow growth rates, delayed maturation, low reproduction output and long lifespans (Stearns 1992). Reptiles contain both, the longest-lived tetrapod species (tortoises [Patnaik 1994, De Magalhaes and Costa 2009]), as well as the shortest-lived one: Labord's chameleon, Furcifer labordi. These chameleons from the deciduous dry forests in western Madagascar have a lifespan of only 4 - 9 months (Karsten et al. 2008, Eckhardt et al. 2017), probably as an adaptation to the biphasic and highly variable annual climate. At the beginning of the local rainy season in November, hatchlings emerge that grow rapidly, achieving sexual maturation after $2-3$ months. Hereafter, a mating season characterized by intense combat among males and egg deposition of females ensues. With the beginning of the dry season in April, both sexes begin to disappear rapidly. As temperature drops towards the 
dry season, eggs are presumably in torpor for several months, while embryonic development probably continues from August on until a new cohort of hatchlings appears with the onset of the next rainy season (Karsten et al. 2008).

Interestingly, there seems to be considerable intraspecific variability in lifespan of this species related to variation in ecological factors, such as precipitation and food availability, indicating that some life-history traits exhibit regional variability in response to ecological variation. While in the southernmost and driest part of their distribution range (Ranobe Forest, ca. $30 \mathrm{~km}$ north of Toliara), both sexes disappear synchronously at $4-5$ months of age (Karsten et al. 2008), lifespan near the northern distribution range (Kirindy Forest, ca. $60 \mathrm{~km}$ northeast of Morondava) is prolonged in both sexes to $6-9$ months (Eckhardt et al. 2017). Males from Kirindy were also significantly larger than their conspecifics from Ranobe (Eckhardt et al. 2017). Moreover, following an unusually long rainy season, one female at Kirindy survived until the next breeding season, and some caged individuals of both sexes survived the entire austral winter (Eckhardt et al. 2017).

While no other chameleon was yet reported to have such a short lifespan, little is known about the nature of life-histories of most other chameleon species. The few existing studies indicate that chameleons as a group are characterized by relatively fast life-histories. A study of Andreone et al. (2005) revealed that panther chameleons ( $F$. pardalis) show rapid growth rates and rarely live longer than one year. Furthermore, a study of Dwarf chameleons (Bradypodion pumilum) documented annual survival of about 5\% (Tolley et al. 2010). Moreover, a study of mortality rates of captive reptiles indicated that chameleons were the group in which probability of death within one year after purchasing was highest (Robinson et al. 2015). On the other hand, a recent study on one of the largest chameleon species Parson's chameleon (Calumma parsonii) revealed that some specimens survived up to 9 years in nature (Tessa et al. 2017). Therefore, additional studies are indicated to unravel the factors favouring the evolution of life-histories in this lizard family.

Labord's chameleon occurs sympatrically with other Furcifer species, making this lineage particularly well suited for comparative studies of interspecific life-history variation and its ecological determinants. In relation to other members of their genus, F. labordi is relatively small-sized exhibiting a mean snout-vent length (SVL) of $100.3 \pm 8.52 \mathrm{~mm}$ for males and $73.3 \pm 3.7 \mathrm{~mm}$ for females), $F$. cf. nicosiai a medium-sized (mean SVL $136.4 \pm 13.6 \mathrm{~mm}$ for males, $102 \pm 5.2 \mathrm{~mm}$ for females) and $F$. oustaleti a large-sized (mean SVL: $273.5 \pm 7.5$ $\mathrm{mm}$ for males, $170.2 \pm 9.6 \mathrm{~mm}$ for females) species. While $F$. labordi and $F$. cf. nicosiai are 
restricted to the remaining intact forests within their distribution range in western Madagascar, F. oustaleti is also relatively common in disturbed areas and has a vast distribution (Glaw and Vences 2007). Regarding the nomenclature of $F$. cf. nicosiai, the study population in Kirindy Forest is similar to F. nicosiai described from PN Tsingy de Bemaraha (Jesu et al. 1999). However, Randrianantoandro et al. (2010) mentioned some morphological differences between both populations and named the population occurring in the Menabe Central region $F$. cf. nicosiai, which we maintain here.

The specific aim of this study was to compare the life cycles of these three locally sympatric Furcifer species, focusing on population densities, survival, growth and reproductive rates. Moreover, we examined interspecific variation in roosting heights, which might be indicative of potential spatial niche segregation. Additionally, as the climate of Madagascar is characterized by highly unpredictable rainfall patterns from year-to-year (Dewar and Richard 2007), we also investigated inter-annual variation within species to compare intraspecific plasticity in life-histories. As chameleon populations might heavily depend on environmental factors such as rainfall, primary production and therefore insect occurrence, we correlated our findings to fluctuation of green vegetation cover. Here, we used the Normalized Difference Vegetation Index NDVI (Myneni et al. 1995) to determine the relationship between vegetation alteration and chameleon population dynamics.

\section{Materials and Methods}

\section{Study site}

Kirindy Forest is located in the region of Menabe Central, Western Madagascar, ca. $60 \mathrm{~km}$ northeast of Morondava $\left(44^{\circ} 39^{\prime} \mathrm{E}, 20^{\circ} 03^{\prime} \mathrm{S}, 30-60 \mathrm{~m}\right.$ asl). It is one of the largest remaining Malagasy dry deciduous forest fragments that has historically undergone selective logging, mainly for Dalbergia spp. (Zinner et al., 2014). The local climate is characterized by a hot rainy season between November and April, followed by a cool dry season from May to October (Kappeler and Fichtel 2012). 


\section{Study species}

Furcifer labordi is a medium-sized and sexually highly dimorphic chameleon from the western and southwestern regions of Madagascar. Males have a snout-vent length (SVL) of approx. 100 $\mathrm{mm}$ and exhibit a large cranial casque, a well-defined rostral appendage and a continuous dorsal crest. Ground colouration is a light green with a white lateral stripe. Females have an average SVL of $73 \mathrm{~mm}$ and offer a poorly developed dorsal crest situated in the nuchal region. Ground colouration is green with blue and violet blotches on the flanks and dorsally orientated bright orange markings (Glaw and Vences 2007).

Furcifer cf. nicosiai is a relatively large and seems to be associated with intact dry forests (Jesu, et al. 1999, Glaw and Vences 2007). Males have a SVL of approx. 136 (this study; see below) $\mathrm{mm}$ and a continuous dorsal crest extending on the tail. Females have a SVL of approx. 102 $\mathrm{mm}$ (see below) and a poorly developed short dorsal crest emerging from the nuchal region. Ground colouration of both sexes is a pale brown with diffused brown marbling and a white stripe, which is more dominant in males. During the mating season, males exhibit a bright yellow latero-ventrally orientated colouration. The body of the females appears in a reddish colouration accompanied by bluish cheeks. The population in the Kirindy Forest is similar to F. nicosiai that was described from the PN Tsingy de Bemaraha (Jesu et al. 1999), but morphology indicates some differences between both populations (Randrianantoandro et al. 2010). We therefore refer to the individuals from the population in Kirindy as $F$. cf. nicosiai to indicate that this taxon in need of further taxonomic investigation.

Furcifer oustaleti is one of the largest chameleon species growing to $273 \mathrm{~mm}$ in SVL in males and widespread throughout Madagascar (Glaw and Vences 2007). Males possess a high casque and a notable continuous dorsal crest. Ground colouration is a grayish brown with a reddish throat. Females have a SVL of approx. $170 \mathrm{~mm}$ and exhibit a smaller continuous dorsal crest and ground colouration is more variable.

\section{Vegetation cover: Normalized Difference Vegetation Index (NDVI)}

The NDVI has been reported to correlate strongly with above-ground net primary productivity (Myneni et al. 1995; see also http://daacmodis.ornl.gov). The index is obtained from the reflection rate of red light RED and near infrared light NIR [NDVI $=(\mathrm{NIR}-\mathrm{RED}) /(\mathrm{NIR}+$ RED)], in which NIR and RED are the amounts of near infrared light and red light that is reflected by the vegetation and recorded by the satellite's sensor. The formula results from the 
fact that chlorophyll strongly absorbs RED whereat NIR is re-emitted. To compare seasons with each other, we measured the proportion of vegetation cover from the beginning of the rainy season (Nov - Dec), from the peak until the end of the rainy season (Jan - Apr) and during the dry season (May - Oct) from November 2013 until December 2015. For analysis of the NDVI, we selected a square in the center of our study site.

\section{Capture-mark-recapture study}

Chameleons were located at night using LED flashlights. The capture location was marked and GPS data were taken. We sampled alternating along two transects of $3 \mathrm{~km}$ length each. We had a perseverative order of 10 sampling nights with a pause of four nights in each field season. Animals were transported to the nearby research station in cloth bags and handled the following morning. They were sexed, age categorized (hatchling, juvenile, adult), and their snout vent length (SVL) was measured. Hatchlings were identified due to a little opening of the abdominal wall caused by former connection with the yolk sack. In all three species, growing individuals were classified as juveniles until sexual maturity, which was inferred from the appearance of a colourful mating pattern in females and the presence of a distinct hemipenis bag in males. Animals were individually marked by visual implant elastomers (VIE; Northwest Marine Technology Inc., Shaw Island, WA) (MacNeil et al. 2011). Hatchlings and small juveniles were individually marked with nail polish on the toes. All chameleons were released at their point of capture within 12 h. Sampling took place over three field seasons: November 19, 2013 - July 8, 2014, and January 11, 2015 - July 15, 2015, and October 12, 2015 - December 17, 2015. Furcifer oustaleti were only sampled in the second and third field season.

\section{Growth rates}

We calculated the growth in snout-vent length (SVL) for each species per sex and month. We took the estimated point of hatching and calculated average SVL of hatchlings as a starting point for subsequent calculations. To assess intraspecific differences in growth and SVL between years, we used a $t$ - test to compare specimens captured in March, as sample size was highest in this month for adults of $F$. labordi and F. cf. nicosiai. Moreover, we showed the percentage of SVL difference from 2014 and 2015 in F. labordi from January until May and $F$. cf. nicosiai from January until April, when the amount of specimen was sufficient to compile an average SVL ( $\geq 5$ individuals/sex). 


\section{Survival probability (recapture rates)}

To estimate survival probabilities, we calculated the percentage and frequency of recaptured chameleons with regard to species, sex and age. Here, we treated F. labordi as one cohort and distinguished between juveniles and adults in the two other species. The cohort entering the rainy season was considered as adult. Individuals that hatched during the rainy season were considered as juveniles.

\section{Reproductive rates}

The abdomen of each collected adult female was palpated for the presence of eggs in the abdominal cavity. We calculated the percentage of gravid females per month during the entire reproductive period to estimate reproductive rates.

\section{Roosting heights}

For each detected specimen, we recorded roosting height to the nearest $0.1 \mathrm{~m}$ with a telescopic pole. We compared roosting heights among adults of all three species with ANOVA. When comparing roosting heights within species between different years, we used a $t$ - test. Here, we compared roosting heights between the years 2014 and 2015 that were measured from February until May to determine inter-annual variation within species that might be related to differences in rainfall patterns.

\section{Results}

\section{Normalized Difference Vegetation Index (NDVI)}

The average vegetation cover in the beginning of the rainy season in 2013/14 (Nov - Dec) showed a proportion of $0.586 \pm 0.045 \mathrm{SD}$, followed by $0.8265 \pm 0.06 \mathrm{SD}$ (Jan - Mar) and $0.6349 \pm 0.1063 \mathrm{SD}$ in the dry season (May - Oct). The average vegetation cover at the beginning of the rainy season 2014/15 (Nov - Dec) was $0.5147 \pm 0.038 \mathrm{SD}$, followed by 0.8507 $\pm 0.008 \mathrm{SD}(\mathrm{Jan}-\mathrm{Apr})$ and $0.7123 \pm 0.078 \mathrm{SD}$ in the dry season (Apr - Oct). Comparing seasons among each other revealed that the beginning of the rainy season in 2013/14 was characterized by more vegetation cover than in 2014/15. However, the following rainy and dry season in 2015 showed remarkably more vegetation than in 2014, following heavier rainfalls. Reviewing average vegetation cover from 2006 until 2015, we calculated an average value of 
$0.6415 \pm 0.1272 \mathrm{SD}$ for the beginning of the rainy season, $0.8382 \pm 0.048 \mathrm{SD}$ for the rainy season and $0.6395 \pm 0.095 \mathrm{SD}$ for the dry season. Comparing the field season with the average vegetation cover with the ten-year average, we found that the beginning of the rainy seasons showed relatively little vegetation cover in 2013/14 and especially in 2014/15. The rainy season in 2014 showed marginally lower, and in 2015 marginally higher proportion of vegetation cover. The dry season in 2014 was rather average, whereas the dry season in 2015 showed remarkably higher vegetation cover (Tab. 1). The high vegetation cover in this dry season was followed by an above average vegetation cover in the beginning of the subsequent rainy season.

Tabel 1. Averaged NDVI for the onset of the rainy season (Nov - Dec), rainy season (Jan Apr), and dry season (May - Oct).

\begin{tabular}{|l|l|l|l|}
\hline Year & onset rainy season & rainy season & dry season \\
\hline $2013 / 14($ Nov - Oct) & $0.586 \pm 0.045$ & $0.8265 \pm 0.06$ & $0.6349 \pm 0.1063$ \\
\hline $2014 / 15($ Nov - Oct) & $0.5147 \pm 0.038$ & $0.8507 \pm 0.008$ & $0.7123 \pm 0.078$ \\
\hline $2006-2015$ & $0.6415 \pm 0.1272$ & $0.8382 \pm 0.048$ & $0.6395 \pm 0.095$ \\
\hline
\end{tabular}

\section{Age, population structure and life-histories}

\section{Furcifer labordi}

We detected first hatchlings in mid-October, at the beginning of the rainy season. This cohort grew up and reached maturity by February. After the mating season, males disappeared in late May, whereas the last females were found at the beginning of July. However, after an unusually long rainy season (2015) both sexes survived considerably longer. For more detailed information, see Eckhardt et al. (2017) and Fig. 3.1. 


\section{Furcifer cf. nicosiai}

At the beginning of the rainy season in November 2013, we found a cohort of juveniles that had hatched during the previous active season. We encountered first adult males around midJanuary and the first adult females at the beginning of February. After this date, all collected individuals from this cohort were sexually mature. Hatchlings were found around midFebruary. In the season 2013/14, the last adult male was encountered on June 10, and the last adult female at the end of June. In the second season in 2015, however, adult males and females were encountered until the end of the field season in mid-July. At this point, some adults seemed to be in good physical conditions, whereas others showed visible signs of senescence. During the third field season in October 2015, we detected a cohort of juveniles as well as two adult females that had overwintered from the previous dry season. One of these females was marked in the previous season and subsequently recaptured several times in good physical condition (Fig. 3.1).

\section{Furcifer oustaleti}

In the second field season 2015, we encountered a cohort of large juveniles originating from the previous rainy season that were close to maturation. Additionally, we detected adult individuals that hatched at least in 2013. In mid-January, we observed hatchlings. Afterwards, we detected exclusively adults and young juveniles that grew up rapidly. During the final field season, we found both large juveniles that hatched in the previous rainy season and adults (Fig.3.1). 

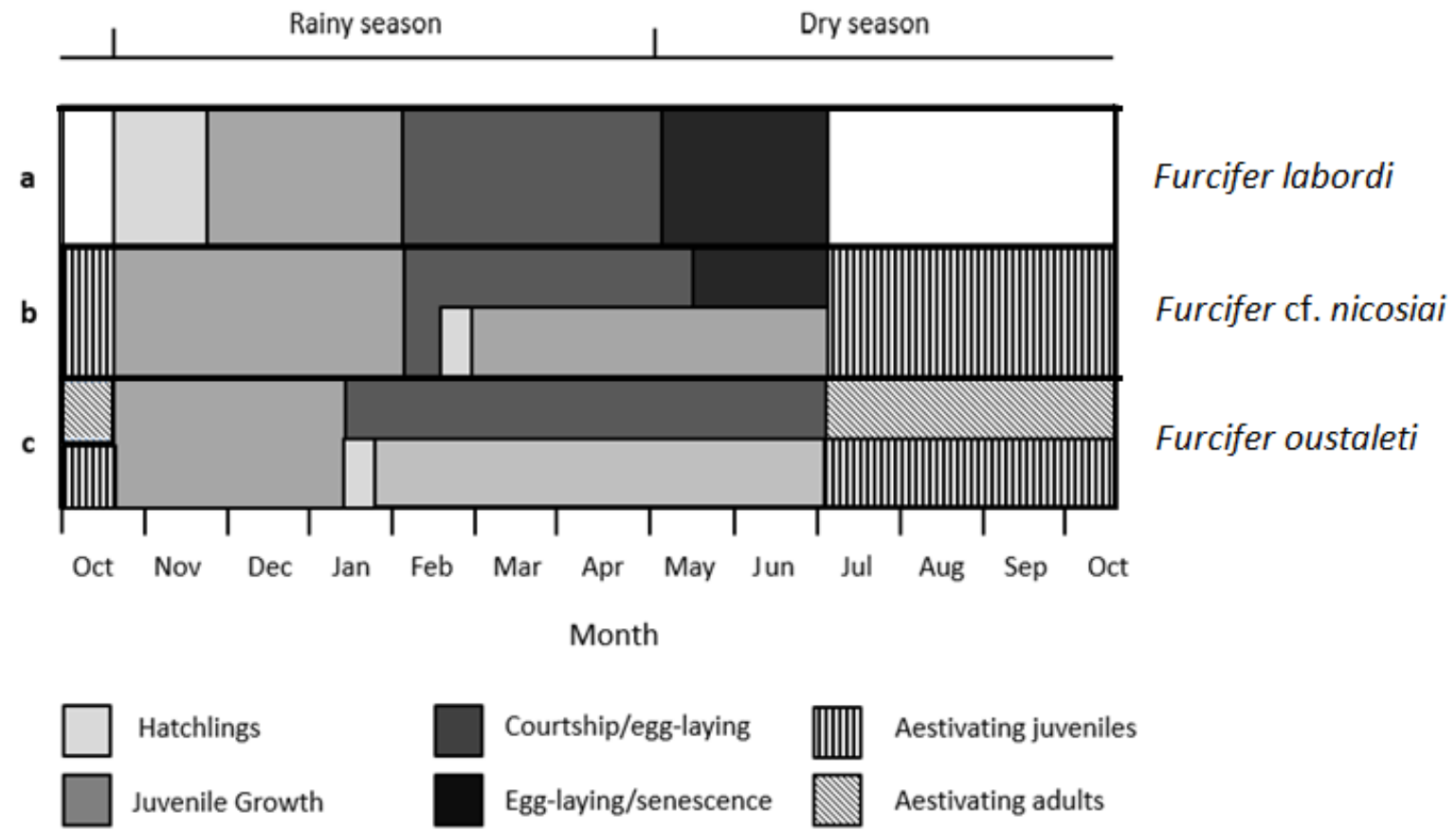

Fig. 3.1. Averaged life-histories of the three Furcifer species in Kirindy Forest. Upper row a shows the life-history of the annual $F$. labordi. Hatching takes place at the beginning of the rainy season, followed by rapid growth and maturation and subsequently population wide dieoff. Middle row $\mathbf{b}$ displays the life cycle of $F$. cf. nicosiai. With the beginning of the rainy season, a cohort of previously aestivating juveniles restarts growing until maturation in February. Adults disappear after the reproductive season. Juveniles hatch in mid-February and grow until the beginning of dry season with subsequent aestivation. Lower row $\mathbf{c}$ indicates the life cycle of $F$. oustaleti. Large juveniles grow fast to maturation and adults enter the rainy season. A new cohort of hatchlings emerges in mid-January that grows until the onset of the dry season.

\section{Species abundances}

In the second field season, F. labordi were the most frequently found chameleons until May, followed by a decline towards the dry season. Adult $F$. cf. nicosiai represented the second most abundant category of animals captured between January and March, with a subsequent decline in detection towards the onset of the dry season. From January (month of hatching) onwards, the number of detected juvenile $F$. oustaleti continuously increased. We found similar pattern 
for juvenile $F$. cf. nicosiai from February onwards (month of hatching). The number of recorded adult F. oustaleti was low throughout the season (Fig. 3.2).

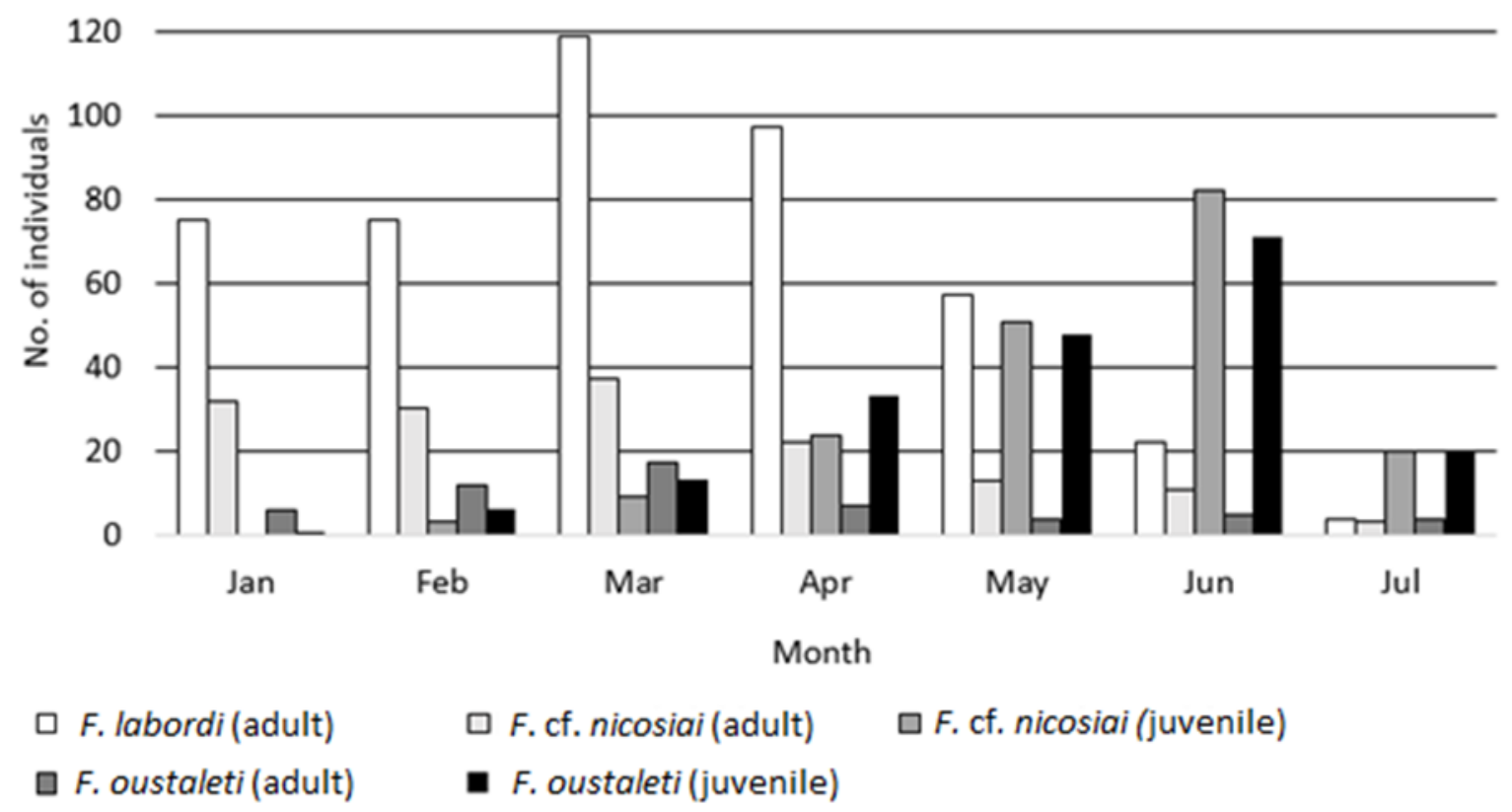

Fig. 3.2. Abundance of Furcifer labordi and adult and juvenile $F$. cf. nicosiai as well as adult and juvenile $F$. oustaleti from January to July 2015.

\section{Survival probability (rate of recaptures)}

The lowest rate of recaptures was found for $F$. labordi. Comparing adult $F$. cf. nicosiai with $F$. oustaleti, we found about twice as many individuals in the former species, whereas the probability to re-capture an adult $F$. oustaleti several times was much higher. Juvenile $F$. oustaleti had the highest percentage of repeated recaptures (see Fig. 3.3). 


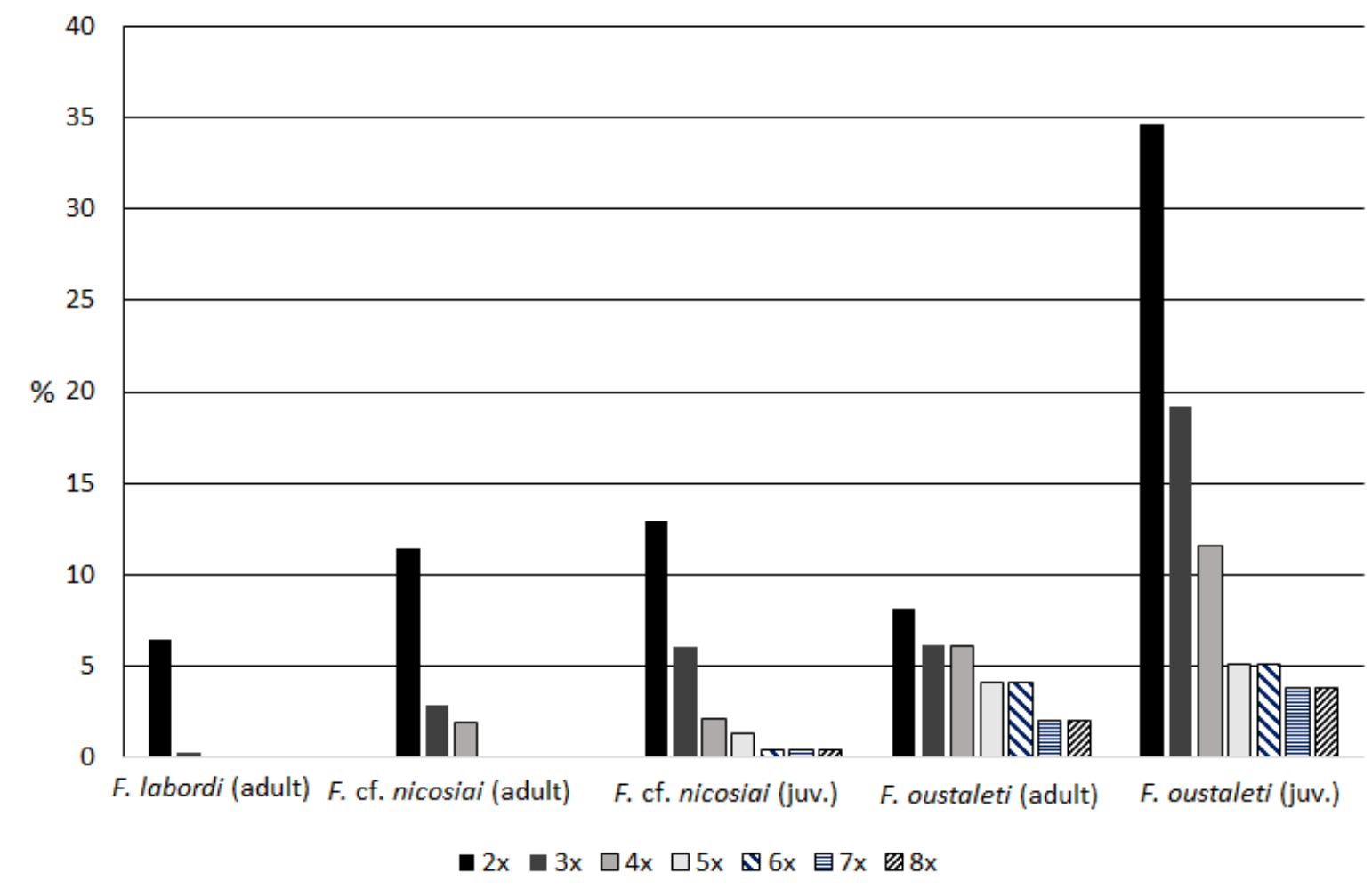

Fig. 3.3. Percentage of chameleons that were recaptured at least twice, or multiple times in the second field season between January and July 2015. Sample size was 439 for Furcifer labordi, 123 for adult $F$. cf. nicosiai, 205 for juvenile $F$. cf. nicosiai, 40 for adult $F$. oustaleti and 178 for juvenile $F$. oustaleti.

\section{Growth rates}

\section{Furcifer labordi}

We found first hatchlings at mid-October and considered this as the hatching date to calculate subsequent growth rates. We measured an average SVL for $F$. labordi hatchlings of $2.56 \pm 0.09$ $\mathrm{cm}(n=20)$. Even after maturation, growth seemed to continue in both sexes (Fig. 3.4). From the point of hatching (mid-October) until the beginning of the dry season (May) males gained $316 \%$ in average SVL and females gained $190.6 \%$ in average SVL. In 2014, average adult SVL was significantly larger in both males $(t=3.89, P<0.001)$ and females $(t=2.41, P<0.05)$ compared to 2015 (Fig. 3.5). 


\section{Furcifer cf. nicosiai}

In the first and second field season, we detected hatchlings in mid-February. Their average SVL was $3.08 \mathrm{~cm} \pm 0.09 \mathrm{~cm}(n=4)$. In 2014 , juvenile males gained $113 \%$ in average SVL and females gained $67.2 \%$ in average SVL until the onset of the dry season. In 2015, males average SVL increased by $107.8 \%$ and females average SVL increased by $60.4 \%$ of SVL until the onset of the dry season. As in F. labordi in 2014, average SVL was significantly larger in adult males $(t=3.51, P<0.001)$ and females $(t=3.74, P=<0.001)$ compared to 2015 (Fig. 3.5). In both seasons, we found remarkably more juvenile males $(n=319,71.8 \%)$ than females $(n=125$, $28.2 \%$ ). In average, males gained $342 \%$ and females $231 \%$ in SVL from the size of a hatchling until adult body size.

\section{Furcifer oustaleti}

In mid-January 2015, we found two hatchlings with an average SVL of $2.5 \mathrm{~cm} \pm 0.14 \mathrm{~cm}$. Both sexes grew rapidly, gaining $510 \%$ of average SVL in males and $424 \%$ of average SVL in females until the onset of the dry season. Within this cohort, we found more females ( $n=104$, $58.4 \%$ ) than males ( $n=74,41.6 \%$ ) (Fig. 3.4). In total, males gained in average $992 \%$ in SVL and females $580 \%$ from the size of a hatchling until adult body size. 

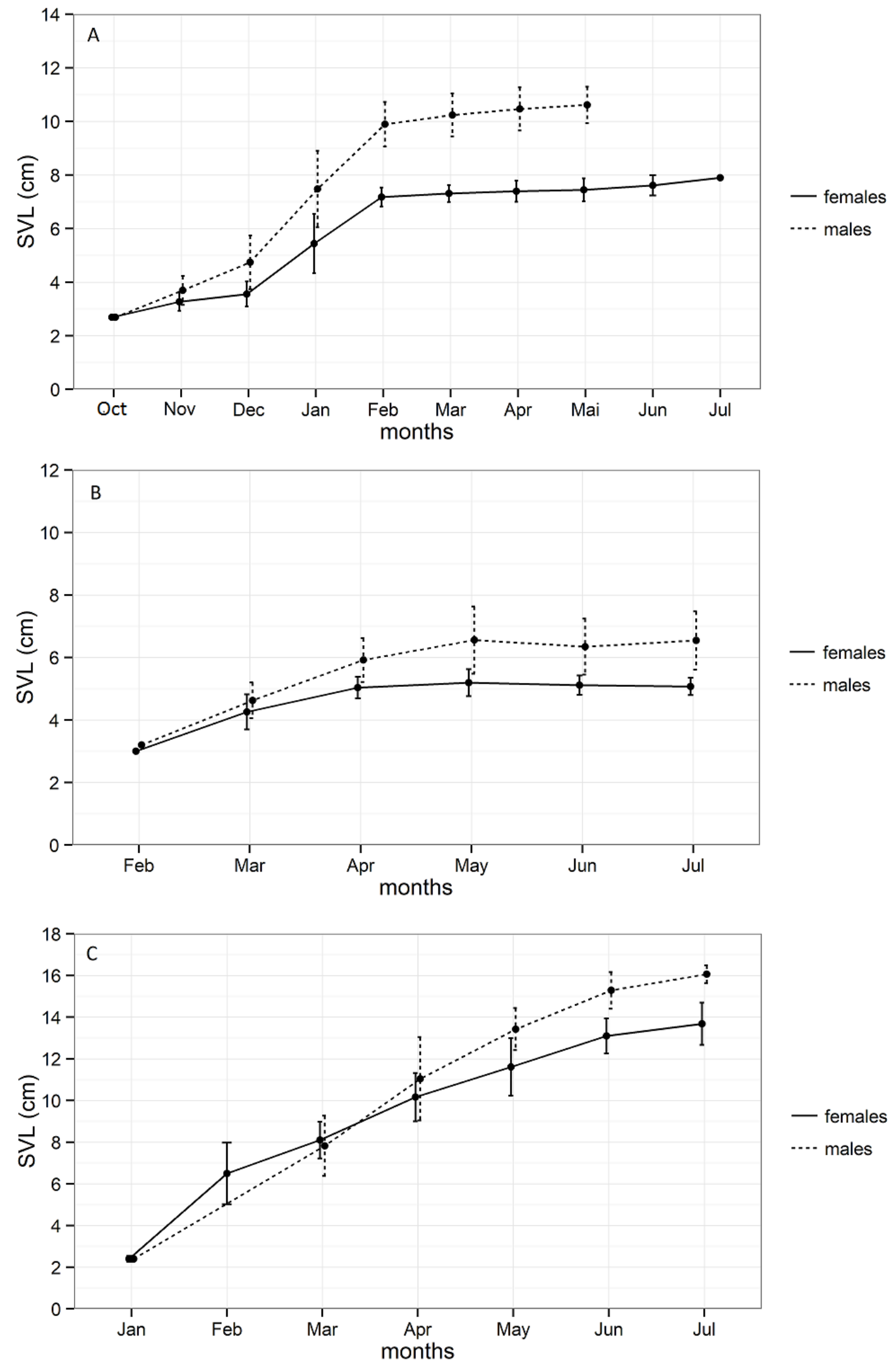

Fig. 3.4. Growth curves of (A) F. labordi in 2013/14, (B) F. cf. nicosiai in 2014 (C) F. oustaleti in 2015, Error bars indicate standard deviations. 

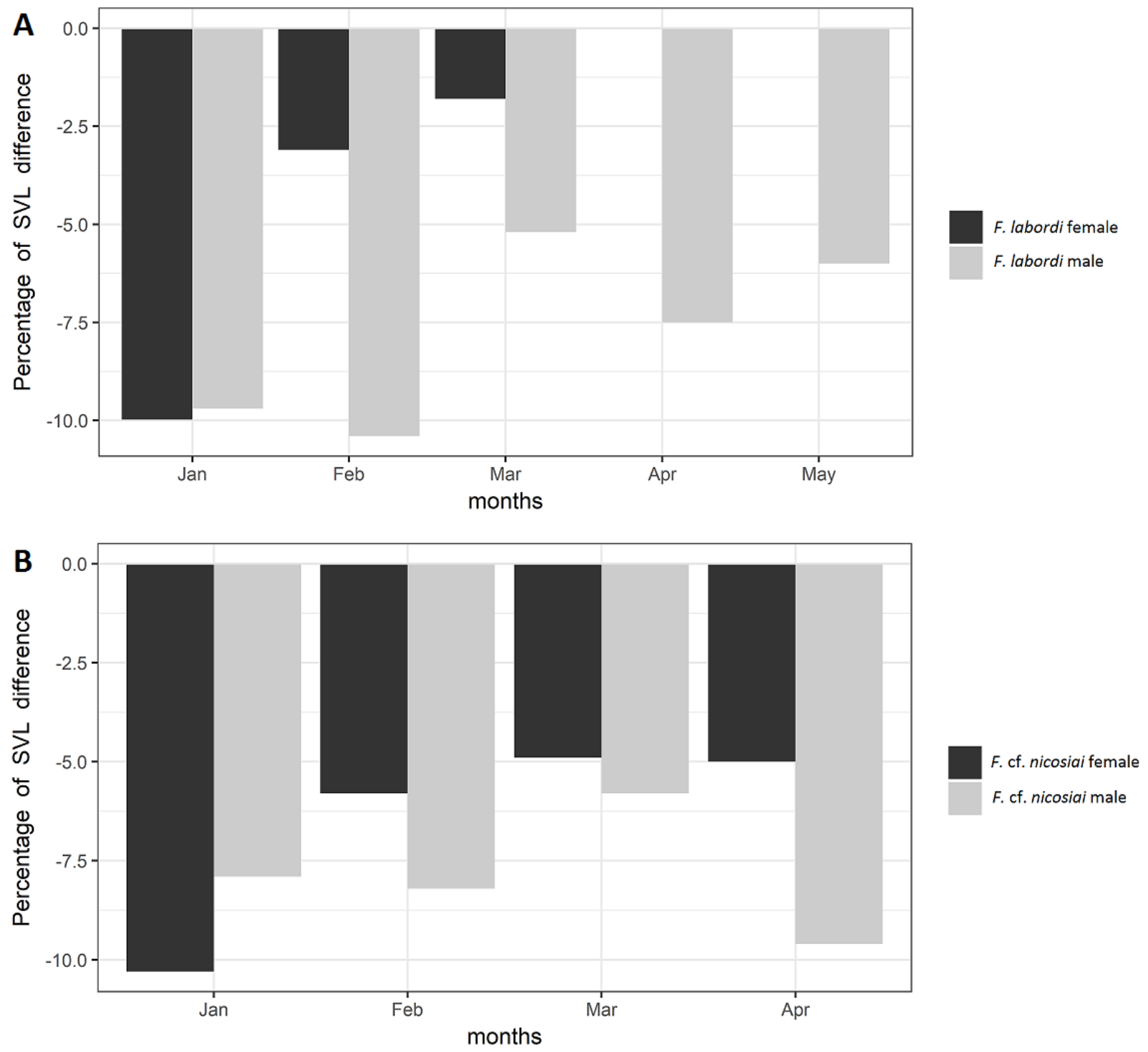

Fig. 3.5. Percentage of SVL difference of (A) F. labordi and (B) F. cf. nicosiai between 2014 and 2015. Zero line reflects the average SVL per month in 2014.

\section{Reproductive rates}

\section{Furcifer labordi}

In the reproductive season 2014, we first detected gravid females at the end of January. From this date on, we regularly found gravid females, and their percentage increased steadily (Tab. 2), whereas their total number decreased from the end of April onwards. During the reproductive season 2015, we found first gravid females at the beginning of February. Again, the percentage of gravid females increased towards the end of the reproductive season, and the total number of females decreased from the end of April onwards (Tab. 2). In total, we found 
four dead gravid females containing $6-8$ eggs in their bodies. Eggs of one female containing 7 eggs had a mean length of $1.24 \pm 0.03 \mathrm{~cm}$ and weight of $0.375 \pm 0.01 \mathrm{~g}$. Another clutch of 8 eggs showed a mean length of $1.16 \pm 0.01 \mathrm{~cm}$ and a weight of $0.313 \pm 0.01 \mathrm{~g}$.

\section{Furcifer cf. nicosiai}

In the reproductive season 2014, we found two gravid individuals (11.8\%) among 17 adult females. One gravid female was found in mid-February and the other one in mid-March. During the reproductive season 2015, we detected 41 females of which none seemed to be gravid. Subsequently, within the reproductive time of this species we found 58 adult females, of which two were definitely gravid (3.45\%).

\section{Furcifer oustaleti}

During the reproductive season in 2015, we encountered 12 adult females of which not a single one was detected as gravid.

Table 2. Total number of detected Furcifer labordi females per month and number of gravid females during reproduction time in 2014 and 2015.

\begin{tabular}{|l|l|l|l|}
\hline month/year & tot. no. of females & no. of gravid females & \% gravid females \\
\hline Jan 2014 & 55 & 1 & 1.81 \\
\hline Feb 2014 & 63 & 17 & 26.98 \\
\hline Mar 2014 & 88 & 27 & 30.68 \\
\hline Apr 2014 & 98 & 52 & 53.06 \\
\hline May 2014 & 54 & 34 & 62.96 \\
\hline Jun 2014 & 8 & 6 & 75 \\
\hline Jul 2014 & 1 & 1 & 100 \\
\hline Total 2014 & $\mathbf{3 6 7}$ & $\mathbf{1 3 8}$ & $\mathbf{3 7 . 6}$ \\
\hline Jan 2015 & 25 & 0 & 0 \\
\hline Feb 2015 & 37 & 6 & 16.21 \\
\hline Mar 2015 & 54 & 12 & 22.22 \\
\hline Apr 2015 & 50 & 22 & 44 \\
\hline May 2015 & 45 & 25 & 55,56 \\
\hline Jun 2015 & 20 & 15 & 75 \\
\hline Jul 2015 & 3 & 3 & $\mathbf{3 5 . 4 7}$ \\
\hline Total 2015 & $\mathbf{2 3 4}$ & $\mathbf{8 3}$ & \\
\hline
\end{tabular}




\section{Roosting heights}

When evaluating roosting heights of all three species (reproductive season 2015, Feb - May), we found a highly significant difference in roosting heights among the three species (ANOVA, $\left.F_{2,428}=80.15, P<0.001\right)$. Here, $F$. labordi showed an average roosting height of $1.28 \pm 1.13$ m. Furifer cf. nicosiai exhibited a roosting height of $1.93 \pm 1.1 \mathrm{~m}$. The roosting site of $F$. oustaleti averaged $3.68 \pm 1.51 \mathrm{~m}$. During the reproductive season 2014 (Feb - May) we found that the average roosting height of $F$. labordi was significantly lower compared to adult $F$. cf. nicosiai $(t=-5.98, P<0.01)$. Both, F. labordi showed heigher roosting heights $t=8.07, P<$ $0.001)$ in 2014 compared to 2015 as well as $F$. cf. nicosiai $(t=4.54, P<0.01)$ (Fig. 3.6).

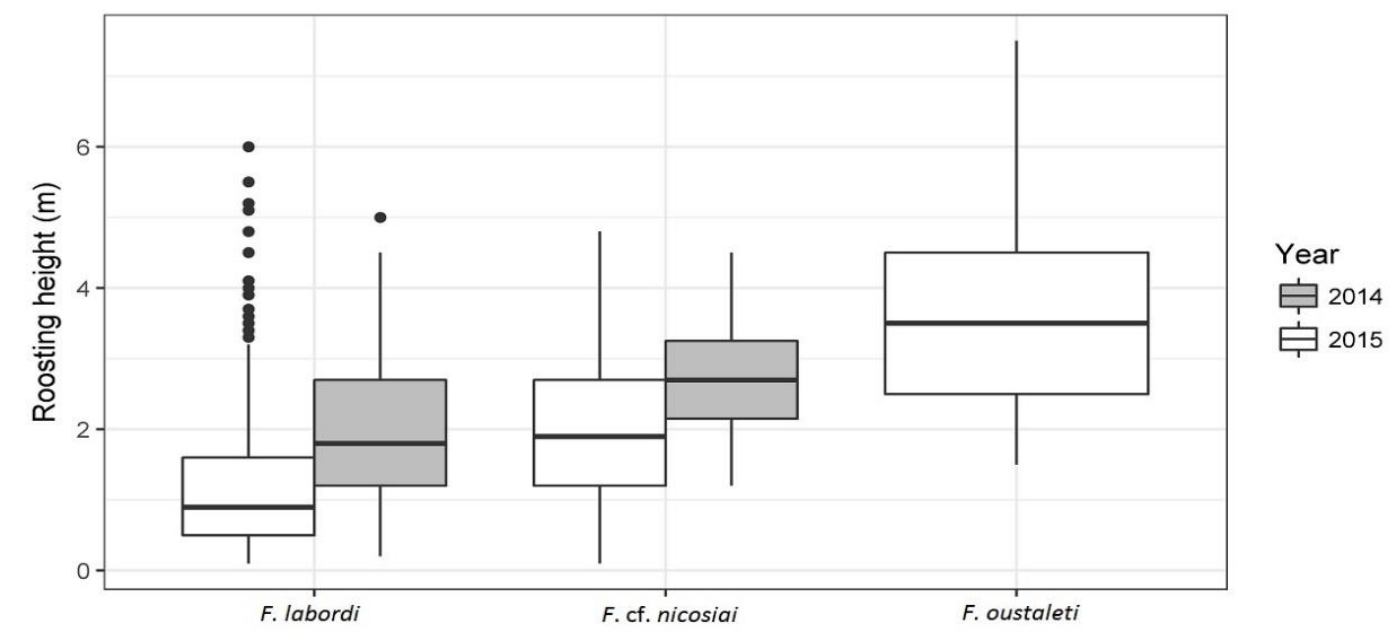

Fig. 3.6. Boxplots showing roosting heights of adult specimens of $F$. labordi, F. cf. nicosiai in the reproductive season in 2014 and F. labordi, F. cf. nicosiai and F. oustaleti in the reproductive season 2015 .

\section{Discussion}

\section{Age, population structure and life-histories}

Our study revealed considerable differences in life-history characteristics across three locally sympatric Furcifer species. We detected differences in the period of hatching, species abundance, survival probability, growth, reproduction and roosting heights. Hatchlings of $F$. labordi appear from mid-October onwards, and this cohort is already adult by the time 
hatchlings of $F$. oustaleti and $F$. cf. nicosiai appear. As juveniles of all three species are of similar size, the temporal shift in species-specific occurrence of hatching suggests resource portioning as an underlying factor. Since the increase in ambient temperature is considered to initiate development of diapausing embryos in chameleons (Andrews and Donoghue 2004; Andrews et al. 2008), the three species might have different temperatures terminating diapause. Moreover, we found different lifespans that correlated positively with body size [see also Speakman 2005] in combination with male-biased early mortality, which might be related to sex-specific costs of reproduction (Cuadrado 2001, Gehring et al. 2008). Finally, we documented some variability in the lifespan of $F$. labordi and F. cf. nicosiai, suggesting that their survival is related to the availability of suitable prey, water and habitat.

Compared to other lizards, chameleons seem to have remarkably shorter lifespans. Published reports of life-histories of chameleons in nature are rare, but available studies suggest that this family displays short lifespans in nature (Andreone et al. 2005, Karsten et al. 2008, Tolley et al. 2010). These findings also indicate that the reported high mortality rates of chameleons in captivity (Robinson et al. 2016) are due to their naturally fast life-histories.

An important variable of the life-history is age at maturity, which in lizards is generally positively correlated with body size (Meiri et al. 2012). However, several medium-sized Madagascan chameleons, such as $F$. campani, F. lateralis and F. antimena, are known to reach maturity within one season (Raselimanana and Rakotomalala 2003), suggesting a short lifespan in these species as well. Moreover, compared to many other similar-sized lizard taxa, chameleons have the largest clutches and are among the most productive ones (Meiri et al. 2012), indicative of fast life-histories. In addition, large clutch volumes and high relative clutch mass have predominantly been documented in reptiles with cryptic behaviour, where the probability of escaping predators does not depend on rapid movements (Vitt and Price 1982).

The short documented life cycles in chameleons might be due to their inability to store sufficient fat reserves to endure energy-demanding periods such as the mating season or aestivation. As most chameleons have a laterally compressed body and depend on their ability to hide behind branches, the storage of fat reserves might be disadvantageous in terms of predation avoidance. In contrast to many other lizards, chameleons do not store fat in their tail (Pond 1978). Additionally, chameleons rely on camouflage, but are the slowest of all lizards (Abu-Ghalyun, 1988), and when they are detected by a predator they have only a small probability of escaping. Ultimately, the reduced possibility of survival after detection of a predator and inability to store fat to endure strenuous periods might have selected for fast live 
cycles. The restricted time and probability of reproduction may also have driven the often mentioned high aggression in males (e.g. Nečas 1999, Karsten et al. 2009a) probably resulting in intense intra-sexual selection in this group. Especially males offer large casques that are a good indicator of bite force as males bearing higher heads probably have more jaw musculature, and in some species, casque height is positively correlated with fighting outcome (Stuart-Fox et al. 2006).

However, one of the largest chameleon species Parson's chameleon Calumma parsonii takes 3 to 5 years to reach maturity (Brady and Griffiths 1999). A recent study of this species based on skeletochronology of preserved specimens found that the highest minimum age was nine years for one male and eight years for a female, affirming a considerably longer lifespan (Tessa et al. 2017). This species occurs in rainforests where environmental conditions are more stable, which might explain the slower life-history compared to the ones reported here. Given the lack of long-term studies, further examinations are necessary to evaluate differences in lifehistories from chameleons originating from seasonal or more stable habitats.

\section{Species abundances}

We found that seasonality had an influence on species composition. In the second field season, we compared the abundances of F. labordi, F. cf. nicosiai and F. oustaleti directly. The cohort of adult $F$. labordi was the most abundant one until May, while the number of adult $F$. cf. nicosiai was relatively low, followed by adult $F$. oustaleti. Nevertheless, it is possible that the number of adult $F$. oustaleti was underestimated since they chose the highest roosting places and might therefore sometimes not have been detected. Regarding adult cohorts in the rainy season, our findings support those of Randrianantoandro et al. (2010), who examined chameleon populations in western dry forests of Madagascar. We add to this information by showing that there are pronounced seasonal fluctuations in species abundance and the timing of age cohorts.

From their point of hatching, the detection of juveniles $F$. oustaleti and $F$. cf. nicosiai increased substantially. From June onwards, juveniles of $F$. cf. nicosiai followed by $F$. oustaleti were the most abundant cohort. The fact that only a few hatchlings were found in both species is probably due to the fact that the forest is highly foliated during this period, hampering detection. Hatchlings of $F$. labordi were found in November, when the forest is not yet abundantly covered with vegetation. 


\section{Survial rates}

The probability and frequency of recaptures was lowest in the cohort of F. labordi. Here, besides intrinsic mortality risks with age, the declining detection over time may be due to external sources of mortality, such as predation and starvation. The probability to capture an adult $F$. cf. nicosiai for a second time was higher compared to $F$. oustaleti, but the probability for repeated recapture was higher in F. oustaleti, indicating some survival advantages in this cohort. Highest number of recaptures were for juvenile $F$. oustaleti, followed by juvenile $F$. cf. nicosiai, suggesting that the survival probability until the following reproductive season is relatively high. The patterns of survival as a function of body size and age at maturation coincide with those of lizards documented by Shine and Carnov (1992).

\section{Growth rates}

Furcifer labordi exhibited fast growth, $F$. oustaleti very fast growth and $F$. cf. nicosiai relatively slow growth. As an annual species, F. labordi invests all available energy into growth and reproduction in one season. Furcifer oustaleti hatches around the peak of the rainy season when insect food is abundant, enabling fast growth rates. At the onset of the dry season, juveniles are large-sized, which might provide an advantage with respect to predation. Since the cohort of $F$. cf. nicosiai hatches later in the rainy season, the period when insects are abundant is shortened, and probably results in slower growth. Conversely, their small size might protect these juveniles from detection of predators during the dry season. At least in F. labordi and F. cf. nicosiai we were able to show gradual growth after maturation. As fecundity in most female reptiles often increases with increasing SVL (Meiri et al. 2012), continuous growth might provide an advantage for further clutches.

Interestingly, adult $F$. labordi and $F$. cf. nicosiai had smaller average SVL in the reproductive season in 2015 compared to 2014. The smaller SVL might be explained by the lower vegetation cover at the onset of the rainy season in 2014/15. Additionally, heavy rainfalls and heavy cyclones in 2015 might have interfered with foraging. These observations indicate that growth rates and adult SVL in these species might depend strongly on environmental factors. Diaz-Paniagua et al. (2002) found similar pattern in females of the common chameleon (Chamaeleo chamaeleon), which exhibited smaller SVL in drier years. In contrast to our findings, Karsten et al. (2008) reported ceasing growth in adults with the onset of the reproductive season, and even negative growth was found in a small set of marked-recaptured males. Reptiles as a group are known for indeterminate growth after maturation (Halliday and 
Verrell 1988). The stagnating or even negative growth might be explained by the reduced availability of resources, inducing these specimens to invest more energy into fast reproduction.

\section{Reproduction rates}

As the smallest of our study species, $F$. labordi has the smallest clutch size $(6-8$ eggs). Although, we have no information about the clutch size of $F$. cf. nicosiai, we estimate that females of this species to lay 10 - 30 eggs, as known from similar-sized $F$. pardalis females (Müller et al. 2016, Gehring and Althaus 2017). Furcifer oustaleti was recorded to have an average clutch size of 42 eggs $(n=24)$ (Smith et al. 2016). These findings are in accordance with those reported by Meiri et al. (2012), who found that lizard species with larger mean adult female SVL tend to have larger clutch sizes. Interestingly, though adults of all three species differ significantly in SVL, hatchlings were similar-sized. In F. pardalis, Dierenfeld et al. (2002) mentioned that SVL from neonates range from $25-30 \mathrm{~mm}$. As documented in our study, larger chameleon species need longer to reach maturity, but survival probability over time is comparatively low, which might drive their investment in a larger numbers of eggs, rather than larger offspring.

\section{Roosting heights}

We found interspecific differences in roosting heights among all three species that might be related to habitat and food partitioning. Our findings resembled those of a previous study in western Madagascar (Randrianantoandro et al. 2010). Roosting site selection by chameleons remains poorly investigated but is probably related to the avoidance of nocturnal predators (e.g. snakes), as well as foraging opportunities the next day. Additional data on behaviour and feeding biology are necessary to develop a better understanding of whether differences in the roosting heights are related to diurnal resource partitioning.

Interestingly, the roosting heights of $F$. labordi and $F$. cf. nicosiai differed between 2014 and 2015. Both species seemed to prefer lower roosting heights in 2015, perhaps due to extremely heavy rainfall. Nevertheless, a denser foliage during the latter rainy season might have had a negative influence on the detection of individuals at higher roosting places. Some authors suggested that chameleons shift roost sites depending on weather conditions, such as rainfall, wind and cold temperatures, resulting in roosting sites on inner branches or under leaf cover (Raselimanana and Rakotomalala 2003). However, roosting site selection was found to be connected to perch diameter and thus likely related to hand and foot size (e.g. Razafimahatratra et al. 2008), so that the vertical distribution of the present study species might 
be size-dependent. Moreover, Akani et al. (2001) found that roosting and foraging sites differ strongly because chameleons moved from roosting to foraging sites during the day. Therefore, roosting sites might not always reflect foraging sites.

\section{Acknowledgements}

We thank the CAFF/CORE of the Direction Général des Eaux et Forêts, and CNFEREF Morondava for authorization and support for this study. We are thankful for support in the field to Camilla Cenni, Hauke Thiesler, Wanda von Bremen and the team of field assistants in Kirindy Forest. We thank Mark Scherz and three anonymous referees for helpful comments on this paper. 


\section{Chapter 4: Parasite burden in a short-lived chameleon, Furcifer labordi}

Falk Eckhardt ${ }^{1}$, Christina Strube ${ }^{2}$, Karina A. Mathes ${ }^{3}$, Frank Mutschmann ${ }^{4 *}$, Hauke Thiesler ${ }^{5}$, Cornelia Kraus ${ }^{1,6}$ Peter M. Kappeler ${ }^{1,6}$

${ }^{1}$ Dept. Sociobiology/Anthropology, Institute of Zoology and Anthropology, University of Göttingen, Kellnerweg 6, 37077 Göttingen, Germany

${ }^{2}$ Institute for Parasitology, Centre for Infection Medicine, University of Veterinary Medicine Hannover, Bünteweg 17, 30559 Hannover, Germany

${ }^{3}$ Clinic for Small mammals, Reptiles and Birds, University of Veterinary Medicine Hannover, Bünteweg 9, 30559 Hannover, Germany

${ }^{4}$ Exomed-Labor, Schönhauser Straße 62, 13127 Berlin, Germany

${ }^{5}$ Institute of Clinical Biochemistry, Hannover Medical School Carl-Neuberg-Strasse 1, 30625 Hannover, Germany

${ }^{6}$ Behavioral Ecology and Sociobiology Unit, German Primate Center, Kellnerweg 4, 37077 Göttingen, Germany

* deceased

Eckhardt, F., Strube, C., Mathes, K.A., Mutschmann, F., Thiesler, H., Kraus, C., Kappeler, P.M. (2019). Parasite burden in a short-lived chameleon, Furcifer labordi. International Journal for Parasitology: Parasites and Wildlife, 10, 231-240. https://doi.org/10.1016/j.ijppaw.2019.09.010 


\begin{abstract}
Life-history theory predicts that species with shorter lifespan should show higher investments into growth and reproduction at the expense of immune defenses. Labord's chameleon (Furcifer labordi) is the tetrapod with the shortest known lifespan. To investigate to which extent immunosenescence influences the die-off of these chameleons when they are only about 6 months old, we examined the gastrointestinal, - blood - and ectoparasite burden in F. labordi in Kirindy Forest (western Madagascar) and compared them with sympatric and longer living $F$. cf. nicosiai. Moreover, we included data from wild F. labordi that were singly housed under ambient conditions with daily food and water supply. Gastrointestinal parasite prevalence of wild $F$. labordi increased dramatically during the last 3 months of their lives, which include the reproductive period. Furcifer cf. nicosiai was found to have a belated increase in gastrointestinal parasites compared to F. labordi. In F. cf. nicosiai higher prevalence of blood parasites were found, which probably result from the longer exposure to the arthropod intermediate host. Both species showed infestations with ectoparasites, which peaked in the rainy season but disappeared towards the dry season. Male $F$. labordi showed a significantly higher prevalence of gastrointestinal - and ectoparasites and higher intensities of coccidians and ectoparasites than females. Males of $F$. cf. nicosiai exhibited higher prevalence of blood- and ectoparasites, as well as higher intensities in ectoparasites. Caged individuals of both sexes showed delayed senescence, reduced parasite burden and lived longer than their wild conspecifics. Overall, the increase in the prevalence in gastrointestinal - and blood parasites towards the disappearance of the wild population of F. labordi indicates that this species invests comparatively less energy in efficient immune system function, supporting the prediction of life-history theory.
\end{abstract}

Keywords: parasites, chameleons, immunosenescence, aging, Furcifer

\title{
Introduction
}

During aging, the accumulation of molecular and cellular damage is thought to lead to functional decline, resulting in compromised health and, finally, death (Kirkwood, 2005). According to "disposable soma theory", natural selection evaluates how much an organism invests into growth and reproduction versus self-maintenance and repair, and hence, determines the rate of aging and lifespan (Kirkwood 1977, Kirkwood 1979). Regarding immunity, "fast- 
living" species are supposed to rely more on low-cost nonspecific and inflammatory immune defenses, whereas "slow-living" species exhibit rather cost-intensive stronger specific and especially antibody-mediated immunity, which is required as defense against parasites, for instance (Lee 2006). Besides these trade- offs, within vertebrates the functioning of the immune system changes over time, from the development of adaptive immunity at birth to the deterioration of the system at old age (Albright and Albright 1994, Malaguanera et al. 2001, Humphreys and Grencis 2002, Hayward 2013). The latter process is known as immunosenescence, which is characterized by a down-regulation of type $\mathrm{Th} 2 \mathrm{immunity,}$ which is involved in parasite resistance (Malaguanera et al. 2001). For example, tissue destruction is often caused by parasites and $\mathrm{Th} 2$ cell mediated immunity evolved as an adaptive tissue repair mechanism that quickly heals the wounds they inflict (Allen and Wynn 2011).

Because non-invasive measurements of immunocompetence in free-ranging animals are challenging, parasite burden is often used as a surrogate index of general health (Zuk 2002, Hämäläinen et al. 2015). Especially gastrointestinal parasites can be monitored with marginally invasive means via fecal egg counts. While many parasites induce only moderate clinical symptoms, they may provoke considerable energetic costs due to immune defense investment required to countervail the effects of infection (Zuk 1996, Marcogliese and Pietrock 2011). These costs are intensified by reduced health due to poor nutrition Marcogliese and Pietrock, 2011) or other stressors (Zuk 1996), resulting in a trade-off between parasite resistance and reproductive performance (Helle et al. 2004, Mills et al. 2010) and an accelerated rate of immunosenescence (Hudson et al. 1992). Furthermore, parasite infections induce additional costs, including enhanced risks of predation (Temple 1987, Graham 2008) and further infections by additional parasites (Petney and Andrews 1998, Cox 2001, Bordes and Morand 2009, Johnson and Buler 2010), resulting in a more than linear increase of the associated costs (Ezeamama et al. 2008).

Host sex is one of the important determinants of the immune function profile (Alexander and Stimson 1988). Among mammals, a male bias in parasite infection rates is common (Moore and Wilson 2002). Ultimately, sex differences in immune responses are thought to originate from sex-specific life-history strategies, where males benefit from investing into reproductive effort during their prime reproductive age, whereas female fitness is generally improved by a longer reproductive lifespan due to their higher investment in each offspring. These conditions can favour greater female investment into health maintenance, which ought to prolong their lifespan, whereas males are more likely to invest in competitive success (Williams 1957, 
Trivers 1972, Clutten-Brock and Isvaran 2007), resulting in comparatively accelerated immunosenescence. For example, when male greater kudu Tragelaphus strepsiceros reach adulthood and begin to rut successfully, they compete so intensely in the annual rut that they commonly either die from exhaustion or are killed by predators (Owen-Smith 1993).

Labord's chameleon Furcifer labordi from the highly seasonal deciduous dry forests in western and southwestern Madagascar has a post-hatching lifespan of only 4-9 months (Karsten et al. 2008, Eckhardt et al. 2017). This extreme life-history makes this species an interesting model to study potential mechanisms of accelerated senescence, especially because longerlived sympatric congeners are available for comparative studies. During their short lives, this species undergoes hatching, juvenile growth, maturation and courtship followed by death of both sexes early during the annual dry season (Karsten et al. 2008, Eckhardt et al. 2017). Females tend to enjoy a slight longevity advantage, whereas no significant intersexual differences in lifespan were found in caged individuals that were kept under ambient conditions (Eckhardt et al. 2017). With such a fast life-history, chronic physiological stress might proximately contribute to immune suppression, which in turn facilitates parasite infections and ultimately leads to death. These mechanisms have been demonstrated in semelparous marsupials (Bradley et al. 1980, Lee et al. 1982, Dickman and Braithwaite 1992), where males in wild populations died considerably earlier compared to females, whereas captive males outlived their wild conspecifics.

To investigate to which extent changes in parasite burden across the lifespan contribute to the early die-off in F. labordi, we examined their gastrointestinal-, blood- and ectoparasite burden. To this end, we determined the prevalence of ectoparasites as well as gastrointestinal parasite reproductive stages (e.g. eggs, oocysts), and blood parasites (e.g. microfilariae) encountered in fecal and blood samples obtained from $F$. labordi throughout their life. Our study included two comparisons; one between wild $F$. labordi and their sympatric and longerlived congener $F$. cf. nicosiai, and one with $F$. labordi kept in single cages under ambient conditions, which buffered them substantially from physiological stress and to some degree from parasite infection. We predicted an increase in parasite loads towards the end of the reproductive season in wild $F$. labordi and a reduced increase in $F$. cf. nicosiai. Furthermore, as age-related changes in immunocompetence should be delayed in the longer-lived females, we predicted female $F$. labordi to exhibit a lower and comparatively slower increase in parasite load than males. Additionally, caged F. labordi, which were safeguarded against extrinsic 
mortality, the costs of reproduction and starvation, were expected to exhibit slower rates of aging, and hence reduced parasite infection, compared to their wild conspecifics.

\section{Materials and Methods}

\section{Study site, study species and capture-mark-recapture}

The study was conducted at Kirindy Forest $\left(44^{\circ} 39^{\prime} \mathrm{E}, 20^{\circ} 03^{\prime} \mathrm{S}, 30-60 \mathrm{~m}\right.$ asl), one of the largest remaining tracts of dry deciduous forests in central western Madagascar. The local climate is characterized by a hot rainy season from November until March and a cool dry season from April until October. The forest is relatively dense and has undergone selective logging (Kappeler and Fichtel 2012).

Furcifer labordi is a medium-sized and sexually highly dimorphic chameleon from the western and southwestern regions of Madagascar (Glaw and Vences 2007). Males have a body size of approx. $100 \mathrm{~mm}$, and females have a body size of $73 \mathrm{~mm}$. Furcifer cf. nicosiai is a relatively larger species, also sexually dimorphic, and appears to be associated with intact dry forests (Jesu et al. 1999, Glaw and Vences 2007). Males reach a body size of $136 \mathrm{~mm}$ and females $102 \mathrm{~mm}$ (Eckhardt et al. 2019a). Concerning ecological studies in the Kirindy forest, both species differ significantly in point of hatching, growth rates and roosting heights, which might suggest some interspecific niche segregation (Eckhardt et al. 2019a).

Chameleons were located at night using flashlights. The roost perch of each detected chameleon was marked with flagging tape. Collected animals were placed in a cloth bag and handled the following morning. Snout-vent length and body mass were recorded, as well as age and sex. Animals were released at their point of capture within $12 \mathrm{~h}$. Sampling took place over three field seasons: November 2013-July 2014, and January 2015-July 2015, and October 2015December 2015.

\section{Experimental housing}

We collected a total of 20 male and 20 female juveniles of $F$. labordi in early January, at approximately two months of age. On January 2014 as well as 2015, each 10 males and 10 females were collected. They were kept individually without visual contact in cylindrical outdoor enclosures ( $90 \mathrm{~cm}$ height, $60 \mathrm{~cm}$ diameter) made of nylon screen. The enclosures were equipped with branches and artificial plants. In order to experience the same temperature 
fluctuations and daylight conditions as their wild conspecifics, caged animals were positioned in a large outdoor cage in the forest. Chameleons received a standardized amount of food (crickets, grasshoppers or butterflies), adjusted to their age and size to match growth and final size of the wild population. Water was offered daily with a spray flask. We used the Kaplan Meier estimator to assess the survival probability of both sexes in captivity.

\section{Analyses of gastrointestinal parasites}

Fecal samples were collected opportunistically from cloth bags or during animal handling and stored in $70 \%$ ethanol. Parasite identification was based on size, shape and internal structure of eggs, oocysts and larval stages. We determined prevalence, intensity of egg and/or oocyst shedding and morphospecies richness of helminth and protozoan parasites. Egg shedding intensity was estimated using fecal egg counts (FEC/g feces) with a modified McMaster flotation egg counting technique (Sloss et al. 1994), a method commonly employed to estimate shedding intensity in wild populations of lizards (Hallas and Bull 2006, Fenner et al. 2011). Fecal samples that weighed less than $0.1 \mathrm{~g}$, were directly dispersed with a toothpick in a counting chamber, subsequently diluted with water and examined. Although FECs are a generally used method to study parasite infections, the method has been criticized for its potential inaccuracy, as parasite egg shedding rates fluctuates over time and a sample may not always contain the eggs of a parasite that is present in the host (Hallas and Bull 2006). However, as coccidians are considered as harmful protozoans (Modry et al. 2000, Schneller et al. 2008), the number of their spores (oocysts) reflects the degree of intestinal cells that are infected with macrogametes. Therefore, we evaluated the number of oocytes in the fecal samples.

\section{Analyses of blood parasites}

We quantified the prevalence of blood parasites such as microfilaria. Blood-sucking arthropods serve as intermediate hosts and infective microfilarial stages are transmitted to other reptiles (Mancianti et al. 2000). False-negative results are rare because both the adults and the microfilariae of the members of the family Onchocercidae are long-lived, and several species often produce significant microfilaremia (Szell et al. 2001). For detection of filariid infections, we used blood smears (Irizarry-Rovira et al. 2002). Here, a drop of blood was taken by lateral puncture of the caudal vein and placed on a microscope glass slide and distributed applying a second slid. After air-drying, blood smears were processed with a rapid differential haematology staining, using the Diff-Quik staining solution system (Medion Diagnostics AG, Düdingen, Switzerland). Samples were analyzed for prevalence of blood parasites applying a brightfield microscope (Zeiss Primo Star) and 100-fold or 400-fold magnification. No samples 
were taken from individuals that weighted less than $5 \mathrm{~g}$ or females that were very close to oviposition.

\section{Analysis of ectoparasites}

The body of each chameleon was inspected with a magnifying lens to identify and count the number of ectoparasites.

\section{Statistical analyses}

Generalized linear mixed effects (GLMM) models for longitudinal data were used to model the parasite data. As fixed factors, we added month (age), sex and species, while ID was included as a random factor for recaptured individuals. We conducted models including both species and models including $F$. labordi only. To test effects on prevalence, we used a binominal distribution and for intensity, we used a Poisson distribution (e.g. Peterson and Lello 2003, Verbeke and Molenberghs 2005). For all models, we compared the respective full model with the null model by using a likelihood ratio test. We also checked for model stability by determining Variance Inflation Factors (VIF) for a standard linear model excluding the random effects. In addition, we visually inspected normality and homoscedasticity with residual plots. For model analysis, we used the package lme4 (Bates et al. 2016). All data analysis was conducted in R (R-Code Team 2017). To test for interspecific differences according to multiple infections with different endoparasite taxa, we conducted a two-proportion $\mathrm{Z}$ - test.

\section{Results}

We observed first hatchlings of F. labordi in mid-October, at the onset of the rainy season. This cohort grew up and reached maturity not later than February. Towards the end of the mating season, males disappeared in late May, whereas females were found until the beginning of July. Thus, the lifespan of animals in this population ranged from six to nine months. However, after a remarkably long rainy season, males and females survived considerably longer; one adult female even survived until the next breeding season (Eckhardt et al. 2017). In November, we found a cohort of juvenile $F$. cf. nicosiai that had hatched during the previous active season. These juveniles grew up to adult size by February, i.e. more slowly than juvenile $F$. labordi (see also Eckhardt et al. 2019a). Hatchlings were detected around mid-February. Adult males were encountered until mid-June, and adult females until the end of June. After this date, we 
only detected small juveniles that ceased growing. However, after an unusually long rainy season adult males and females were found for longer and we found two adult females that overwintered the previous dry season. Concerning the 40 caged individuals of $F$. labordi, we found no significant differences in survival probability between males and females. Median lifespan for females was 9.5 months and for males 8.2 months. Maximum lifespan for females was 11.5 months and for males 16 months (see also Eckhardt et al. 2017).

In the coproscopic analyses, we identified one protozoan morphotype that was assigned to the Coccidians (Isospora sp.). We also detected two egg morphotypes that were assigned to the Cestoda (Cyclophyllidae, Oochoristica sp.) and Nematoda belonging to the family Heterakidae (Spinicauda sp.). Additionally, we found Oxyurids in five samples and Ascarids (Hexametra sp.) in two samples. Due to their rare occurrence and the possibility that the latter two nematode taxa were parasites of prey species, we exclude them from our analysis.

Between hatching in mid-October until December, we did not detect any infestation in the fecal samples of $F$. labordi. However, from January onwards, the prevalence of gastrointestinal parasites in this species increased significantly from $12.3 \%$ in January until $57.1 \%$ in June ( $\mathrm{z}=-8.539 ; \mathrm{P}<0.001$, Fig.4.1A and Tab. 4A). Moreover, adult males showed a significantly higher prevalence compared to females $(\mathrm{z}=4.432 ; \mathrm{P}<0.001$, see Fig. $4.1 \mathrm{~A}$ and Tab. 4). In $F$. cf. nicosiai, we found a low prevalence $(6.8 \%, \mathrm{n}=207)$ of gastrointestinal parasites in fecal samples of hatchlings and juveniles that were sampled between mid-February and mid-July. From January onwards, we also detected an increase of the prevalence of gastrointestinal parasites; in this species from 14.3 to $60 \%$ in May. When comparing gastrointestinal parasite prevalence among adult $F$. labordi and $F$. cf. nicosiai, we found that prevalence was higher in the latter species $(\mathrm{z}=-9.211$; $\mathrm{P}<0.001$, see Fig. 4.1B and Tab. 4B). In contrast to $F$. labordi, the prevalence of gastrointestinal parasite infection was lower in male F. cf. nicosiai. Regarding the shedding intensity of Isospora sp., we detected an average number of oocysts per g feces (OPG)/month in F. labordi ranging between 2600 and 73747. The highest number of oocysts was detected in May. Comparing both species, we did not find any significant differences. However, in male F. labordi, we detected a highly significant increase of oocyte number in May (Tab. 5) 

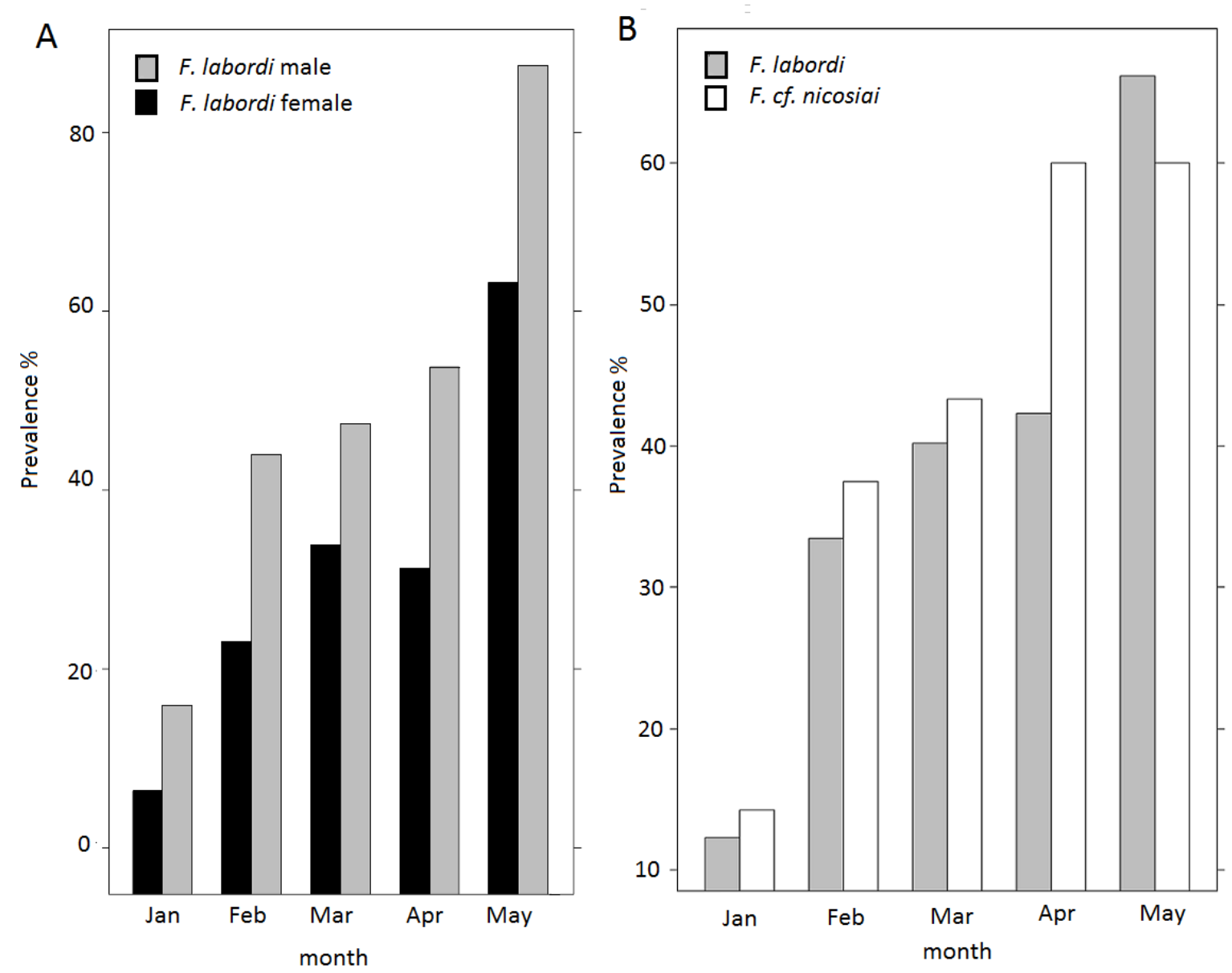

Fig.4.1: Prevalence in percentage of gastrointestinal parasitic infection A) in F. labordi males and females, B) F. labordi and F. cf. nicosiai (adult stages).

Tab. 3: Number of fecal samples collected per species (F. labordi and F. cf. nicosiai) and sex (F. labordi) per month.

\begin{tabular}{|l|c|c|c|c|c|c|}
\hline \multicolumn{1}{|c|}{ Species/sex } & Jan & Feb & Mar & Apr & May & Jun \\
\hline F. labordi & 204 & 183 & 224 & 164 & 64 & 8 \\
\hline F. cf. nicosiai & 27 & 24 & 30 & 17 & 10 & 9 \\
\hline F. labordi male & 126 & 92 & 114 & 41 & 8 & 0 \\
\hline F. labordi female & 78 & 99 & 128 & 133 & 56 & 8 \\
\hline
\end{tabular}


Concerning the taxonomic composition of gastrointestinal parasite taxa in the fecal samples of F. labordi, Isospora sp. (Eimeriidae, Coccidia) were most common and present in $31.7 \%$ of all fecal samples. Oocherisitica sp. (Cyclophyllidae, Cestoda) (12\%) and Spinicauda sp. (Heterakidae, Ascaridida) (8.5\%) had lower prevalences. In F. cf. nicosiai, we found a similar parasite composition, with $22 \%$ Isospora ssp., $18.3 \%$ Oocheristica sp. and $10.3 \%$ Spinicauda sp. prevalence (Fig. 4.2).
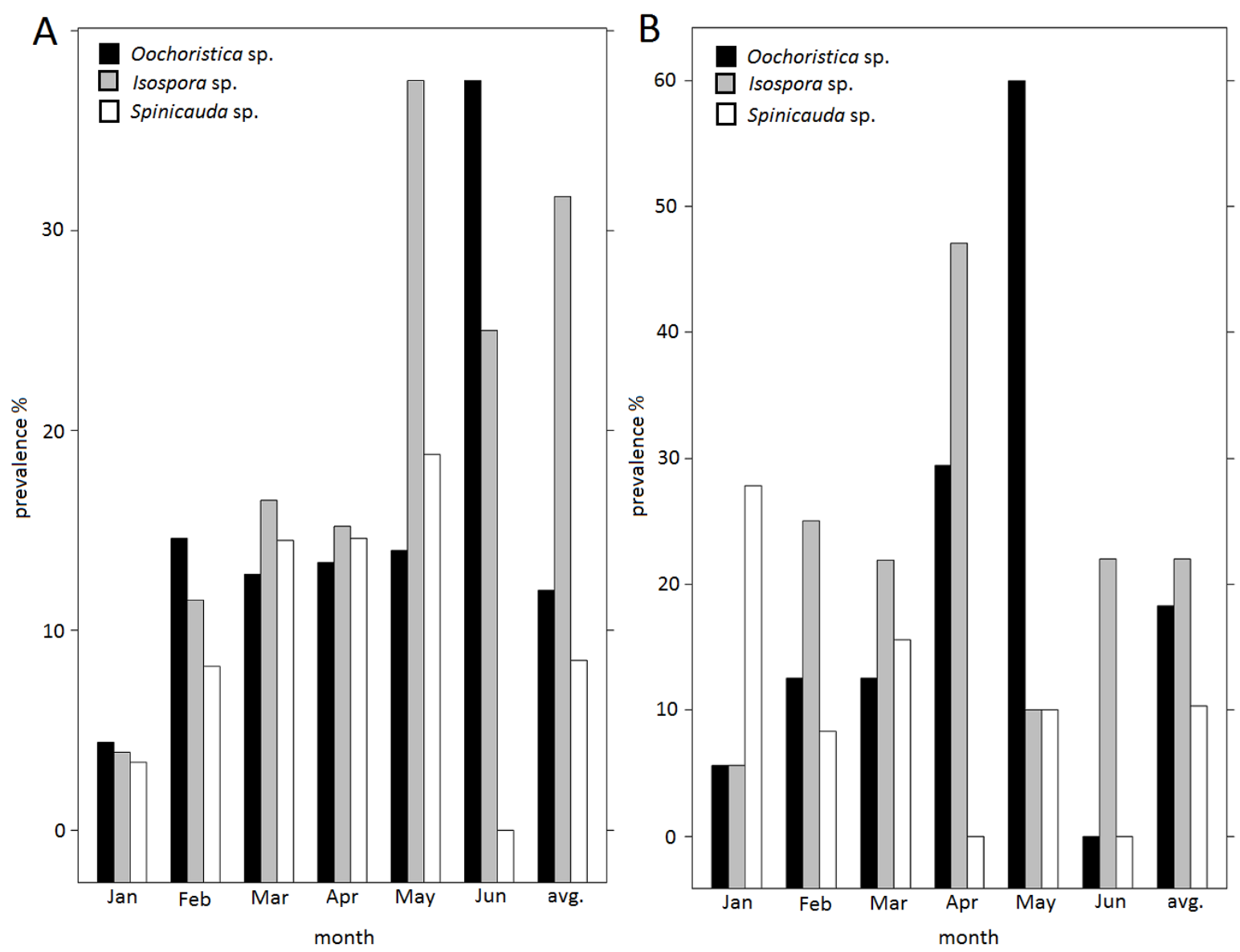

Fig. 4.2: Composition of gastrointestinal parasite taxa in the fecal samples of A) adult F. labordi and B) adult $F$. cf. nicosiai from January to June and in total.

Regarding multiple infections, the number of gastrointestinal parasite taxa ranged from 1 to 3 in infected samples. Of the 381 infected samples, $7.9 \%$ contained two gastrointestinal parasite taxa. Three morphotypes where only found in $0.5 \%$ of the infected samples. Double 
infection rates for males and females were $12.1 \%$ and $8.1 \%$, respectively. Triple infections where only found in $1.3 \%$ of female samples. As the rate of multiple infections was rather low, no clear dynamics with age could be observed. Of the 30 double infections, 53.3\% contained Spinicauda sp. and Oocheristica sp., 30\% contained Isospora sp. and Ooceristica sp., and $16.7 \%$ contained Isospora sp. and Spinicauda sp.. In 118 infected samples of $F$. cf. nicosiai, we found 7 double infections (5.9\%). The two-proportion Z-test revealed no significant differences of the rate of double infections between both species $\left(\chi^{2}=0.252, \mathrm{df}=1, \mathrm{P}=0.615\right)$

Among the caged chameleons, two males exhibited coccidiosis from February onwards and subsequently died at an age of approximately five months. The number of oocytes/g in their samples fluctuated between 2 and 86750, with an average increase towards the end of their lives. In parallel with the increase in oocytes, their body mass decreased dramatically. Additionally, we found that two males and two females were infected with Spinicauda sp..

The analysis of blood samples revealed that both species were infected by the nematode species Foleyella aff. furcata. Parasites of this genus have a limited geographic distribution and have been found only in the lizard family Agamidae and Chamaeleonidae (Barlett 1986). Foleyella spp. are long-lived and viviparous (Brygoo 1963). Adults are relatively large and predominantly inhabit muscle or skin whereas their progeny, the so-called microfilaria circulate in the blood of the host (Fenner et al. 2011). The prepatent period takes about six months (Szell et al. 2001). In F. labordi, the prevalence of filarial infection increased from the beginning of the reproductive season (Fig. 4.3). Within F. cf. nicosiai, incipiently the prevalence of blood parasites decreased from January until March, but hereafter increased remarkably from April towards June. The interspecific comparison revealed that $F$. cf. nicosiai was more frequently infected by Foleyella aff. furcata than F. labordi $(\mathrm{z}=2.187$; $\mathrm{P}<0.05)$. Concerning intersexual differences of prevalence in $F$. cf. nicosiai, we found that males showed higher significant prevalence of filarial infection. $(\mathrm{z}=2.34$; $\mathrm{P}<0.05$, see Fig. 4.3 and Tab. $4 \mathrm{C})$. Among the chameleons in the cages, we detected filarial infection in one male.

Tab. 4: Number of blood samples collected per species per month.

\begin{tabular}{|l|c|c|c|c|c|c|}
\hline \multicolumn{1}{|c|}{ Species } & Jan & Feb & Mar & Apr & May & Jun \\
\hline F. labordi & 6 & 109 & 94 & 59 & 44 & 13 \\
\hline F. cf. nicosiai & 3 & 15 & 32 & 30 & 13 & 11 \\
\hline
\end{tabular}




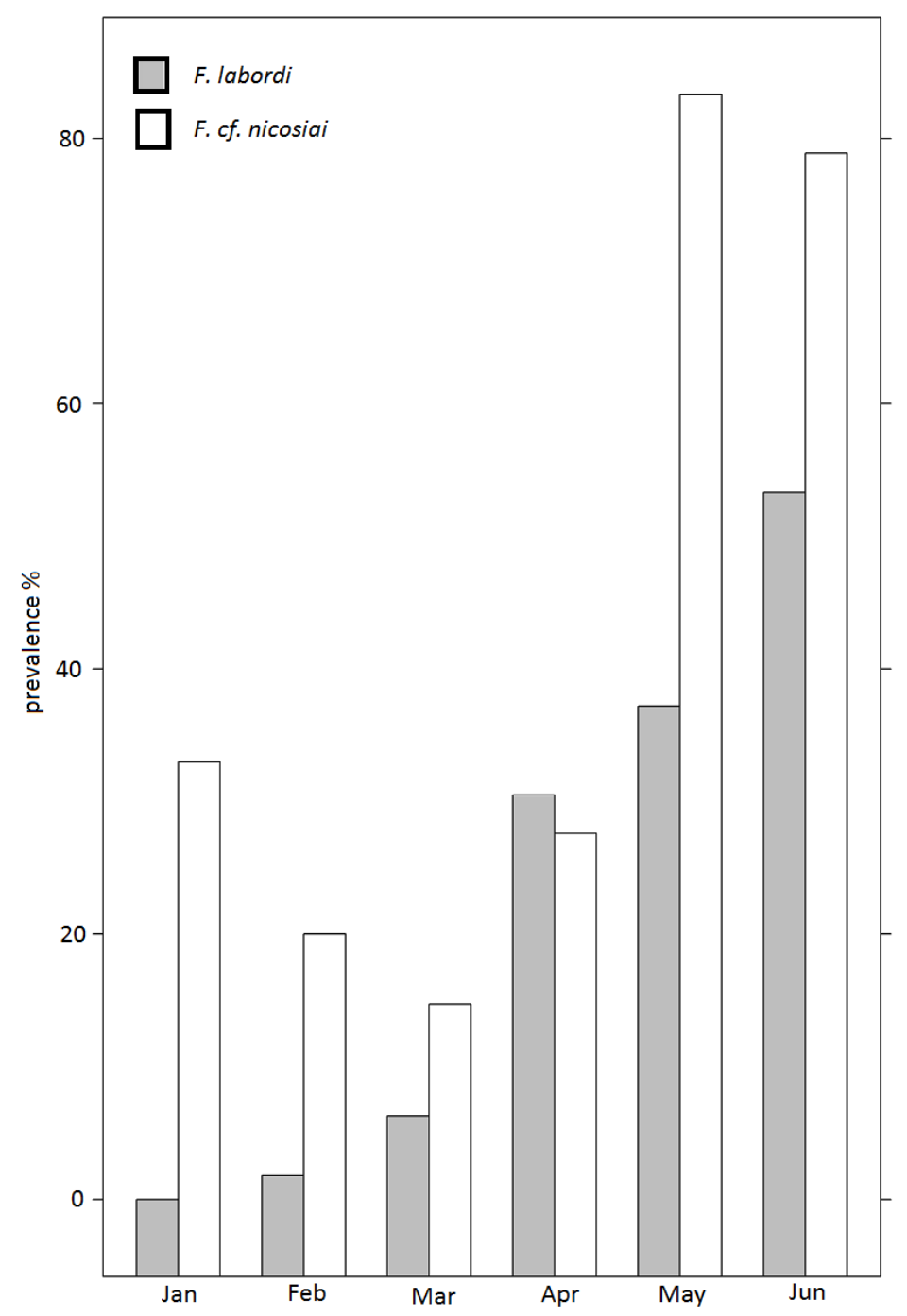

Fig. 4.3: Prevalence of filarial infection in F. labordi and F. cf. nicosiai.

We identified acarians of the family Trombiculidae (trombiculids) as ectoparasites in both Furcifer species, which were mostly located in the axillary pits. Acarian were detected from January onward. Their prevalence peaked in February and March and they were no longer detectable in June. Comparing both species, we found that a higher prevalence of acarians in $F$. cf. nicosiai (Fig. 4.4). Moreover, we found that the number of trombiculids was significantly higher in F. cf. nicosiai compared to F. labordi. Males of both species exhibited a higher prevalence and intensity of these ectoparasites than females $(\mathrm{z}=5.617 ; \mathrm{P}<0.001)$. In $F$. labordi, males showed a prevalence of $66.7 \%(\mathrm{n}=486)$ and carried $16.6 \pm 15.1$ mites, whereas $48.5 \%$ of the females were infested with an average of $8.0 \pm 8.1$ mites. In F. cf. nicosiai, $82.3 \%$ of all examined males $(n=96)$ were infested and showed $31 \pm 27$ mites, whereas $57.6 \%$ of 
females $(n=92)$ were infested and carried on average $12 \pm 12.7$ mites. Regarding intensity of ascarian infestation, we did not detect significant interspecific differences, though specimens of $F$. cf. nicosiai tended to have more mites compared to F. labordi (see Fig. 4.5, Tab. 6). Similar to the prevalence, the intensity increased at the peak of the rainy season and decreased towards the rainy season (see Fig. 4.5, Tab. 6). Among the caged animals, we rarely detected acarians and therefore excluded them from any statistical analysis.

A

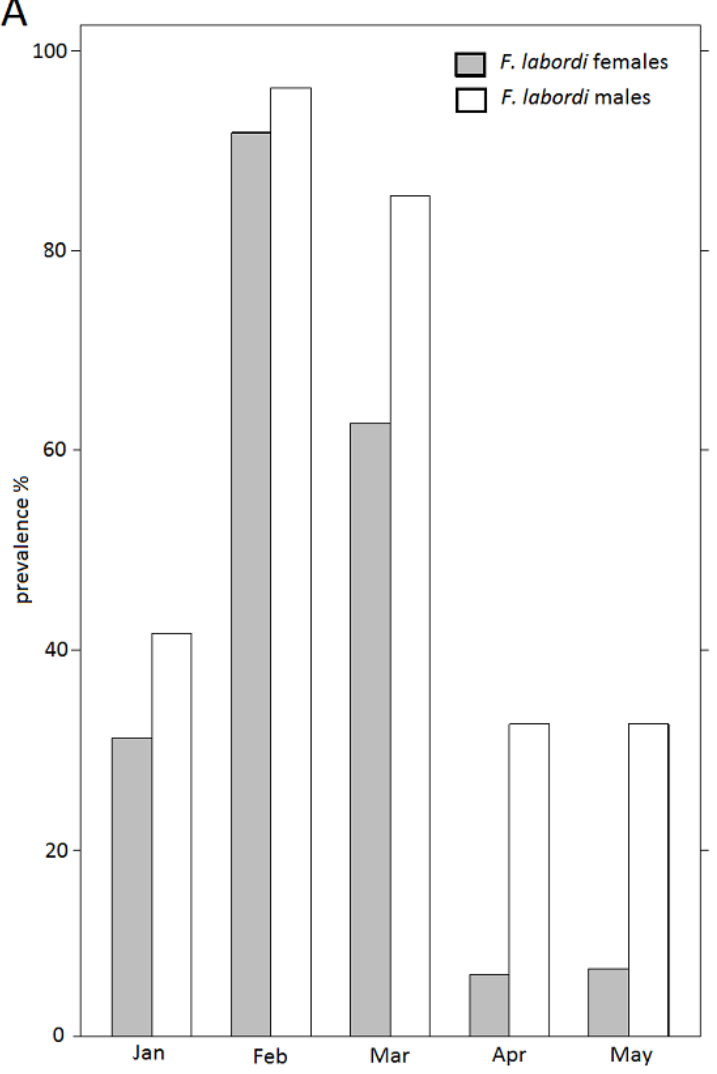

B

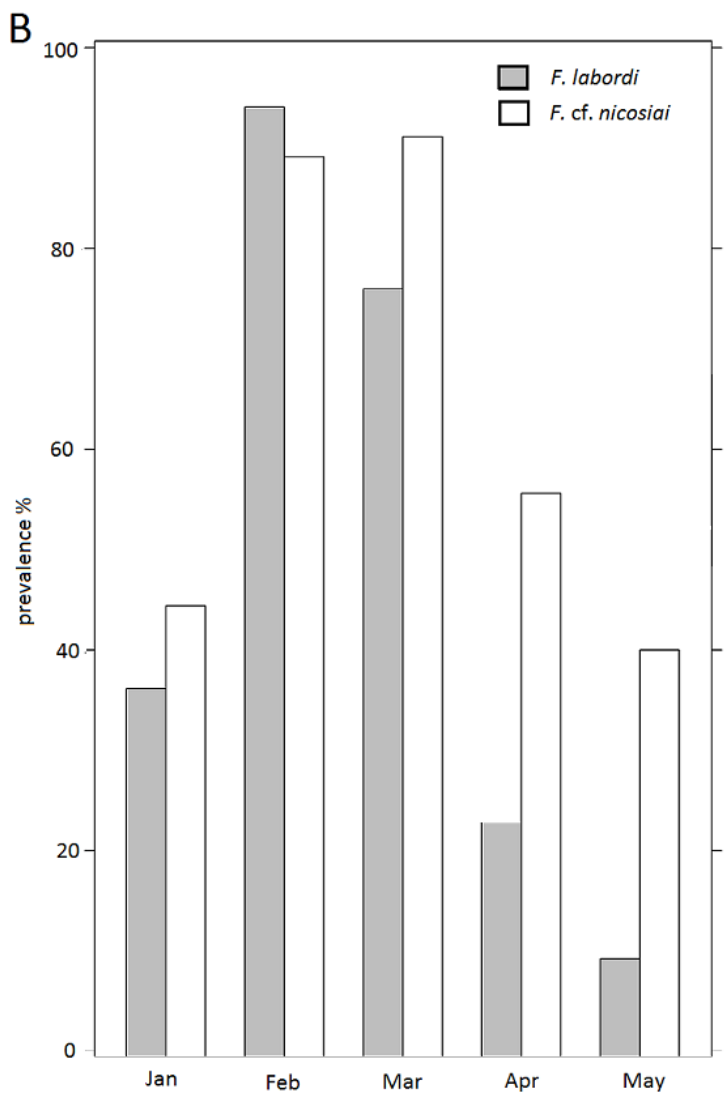

Fig. 4.4: Prevalence of mite infestation in A) F. labordi males and females, B) F. labordi and F. cf. nicosiai.

Tab. 5: Number of individuals per species/sex and month that were inspected for ectoparasites.

\begin{tabular}{|l|l|l|l|l|l|}
\hline Species/sex & Jan & Feb & Mar & Apr & May \\
\hline F. labordi & 207 & 205 & 308 & 246 & 119 \\
\hline F. cf. nicosiai & 52 & 37 & 55 & 36 & 17 \\
\hline F. labordi male & 127 & 108 & 166 & 86 & 20 \\
\hline F. labordi female & 80 & 97 & 142 & 160 & 99 \\
\hline
\end{tabular}




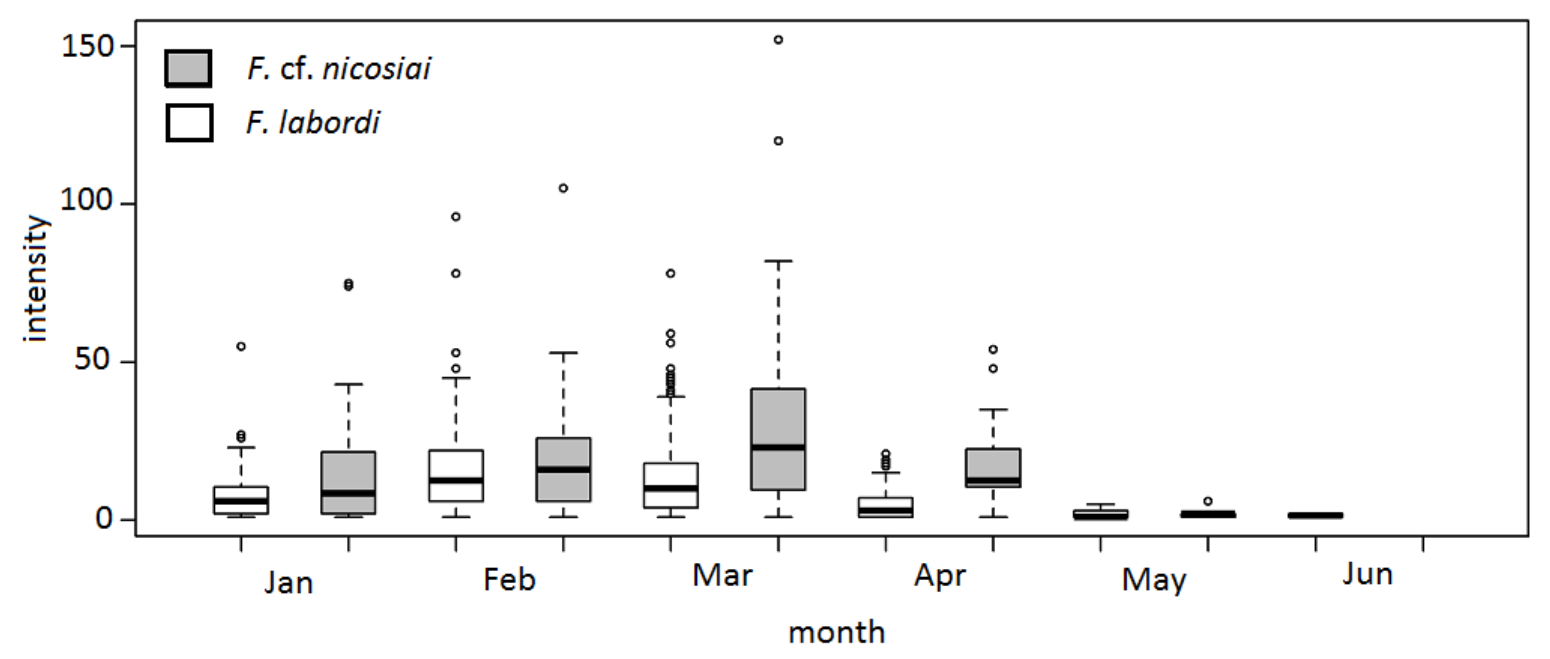

Fig. 4.5: Intensity of mite infestation in adult $F$. labordi and $F$. cf. nicosiai.

\section{Discussion}

\section{Furcifer labordi in nature}

As predicted, among wild living specimens of $F$. labordi, we detected a massive increase of gastrointestinal parasites related to prevalence and mixed infections over the reproductive period towards the dry season. A similar pattern of decline in immune function was reported for feral Soay sheep Ovis aries (Hayward et al. 2009). In contrast, Hämäläinen et al. (2015) found that parasite prevalence and morphotype richness decreased with increasing age in a small and relatively short-lived primate species (Microcebus murinus), indicating acquired immunity by older specimens. Besides, studies focusing on parasite infection with regard to aging in the wild are lacking. However, the detected increase of prevalence of gastrointestinal parasites according to time is probably linked to a decrease in immune functioning in F. labordi. We also found that males, but not females, of $F$. labordi showed a remarkable increase of oocyst shedding towards the end of the reproductive season. Concerning the prevalence of coccidian oocysts in the fecal samples, Modry et al. (2000) found that $32.5 \%$ of 83 examined chameleon specimens from east Africa were infected with coccidians, which is similar to our findings in both species. Additionally, in a coproscopic study on chameleons in captivity, Biallas (2013) found that Isospora was regularly detected (21.7\%). Accordingly, coccidians in general seem to be frequent gastrointestinal parasites in both, wild living and caged chameleons. Isospora sp. was the most commonly detected gastrointestinal parasite taxon in our study, but we may not have detected all kinds of gastrointestinal parasites, such as trematode eggs, that are too heavy 
to float during the flotation process in saturated $\mathrm{NaCl}$ solution. In their study, Morsey et al. (2012) found that $26.1 \%$ of 115 specimens of the common chameleon, Chamaeleo chamaeleon, were naturally infected with the digenetic trematode Postorchigenes sp. and $32.1 \%$ with Malagashitrema sp.. Thus, the number of gastrointestinal parasite taxa and their prevalence might be underestimated in our study. Moreover, as the samples were stored in ethanol, a detection of intestinal flagellates and ciliates was not possible. Although these groups are mostly considered as commensals, under physiological stress, they can have a severe effect on the host (Schneller et al. 2008).

Regarding blood parasites, we detected filarias belonging to the genus Foleyella. Here, we detected an increase of prevalence towards the dry season, which might have a severe influence on the individual's health. However, little is known about the clinical signs of foleyellosis in chameleons. Higher mortality rates were noted in Foleyella-infected chameleons than in uninfected animals, which were transported from a tropical to a temperate zone (Brygoo 1963). In their study, Maia et al. (2014) report a relatively high incidence of filarial infections in the Malagasy chameleon genus Furcifer, which we reported as well.

Concerning ectoparasites, we first detected acarian infestation in January, when humidity was relatively high. Their prevalence was highest in February and March, but decreased towards the dry season, eventually decreasing to zero. Thus, their detection seems to be highly associated with the rainy season, when chameleons are still in good physical conditions. In their study of the impact of tick load on the fitness of their lizard hosts, Bull and Burzokott (1993) did not find any influence on the longevity of the sleepy lizard Tiliqua rugosa. In addition, we found that trombiculids were obviously restricted to axillary situated so called "mite pockets".

At first sight, mite pockets are paradoxical structures as they seem to provide an optimal environment for the mites, giving protection from solar radiation, high temperatures, desiccation, and offering easily penetrated skin. Here, the most likely hypothesis for their function is that they reduce damaging effects of mite infestations (Arnold 1986). Mites are probably attracted to the pockets because they provide ideal conditions, whereas in return these invaginations appear to ameliorate much of their potential damage. These pockets have a large internal area of exposed skin compared with their volume, which enables large numbers of mites to be concentrated in places where they do not interfere with general cutaneous function. In particular, the epidermis is resilient and recovers rapidly after a mite has fed. The shape of the pocket enables large numbers of lymphoid cells to be concentrated around the feeding mites 
and it is probable that these cells reduce the effects of antigens and any pathogens introduced by the feeding mites, as well as contributing to their diet. Thus, due to the peak of the infestation in the rainy season and evolutionary adaptation to these parasites, we do not consider ascarian infestation as a decisive factor that is influenced by immunosenescence. However, these parasites cause blood loss and are potential vectors for pathogens that can have negative impacts on the health of the host (Schneller et al. 2008).

\section{Interspecific comparison of $\boldsymbol{F}$. labordi and $\boldsymbol{F}$. cf. nicosiai}

We found higher prevalence of gastrointestinal parasites in F. cf. nicosiai, but we found the first infections in F. labordi approx. 2 - 3 months after hatching. Among juvenile $F$. cf. nicosiai, which hatched around mid-February, we rarely detected any gastrointestinal parasites until the dry season in June. The delayed occurrence of gastrointestinal parasite infection in $F$. cf. nicosiai might be caused by a higher energy investment in the immune system and especially in parasite defense. In contrast to $F$. labordi, juveniles of this species exhibit rather slow growth rates, later sexual maturity and higher rates of recaptures and therefore potentially higher probability of survival (Eckhardt et al. 2019a) that might enable them to invest comparatively more energy into immune defense. Besides slow growth rates, juveniles probably digest less food insects and are therefore less prone to gastrointestinal parasites that are transferred by this route. Especially tapeworms that require reptiles as definite host use invertebrates as intermediate host. Furthermore, insects, such as flies can function as vectors to allocate parasite eggs to the next host (Schneller et al. 2008). However, the probability of infection might not be equal during the sampling period and might be an additional factor for the later detection of gastrointestinal parasites in $F$. cf. nicosiai. Regarding the comparison of the adults of both species per month, we found that $F$. cf. nicosiai exhibited a higher prevalence of gastrointestinal parasites apart from May. We suspect that the longer cumulative exposure might have an influence on this observation. The higher prevalence of gastrointestinal parasites in F. labordi in May might be attributed to the relatively small amount of fecal samples of $F$. cf. nicosiai (n =10) compared to F. labordi $(\mathrm{n}=64)$.

With respect to multiple infections, we observed no significant interspecific differences. Although, triple infections were only found in F. labordi. Furcifer cf. nicosiai, as the longer living species probably has a comparatively longer exposure to potential infections, might have developed some resistance against these pathogens. However, when entering the mating season, the prevalence of gastrointestinal and blood parasites increased in $F$. cf. nicosiai as well. 
Concerning the intensity of coccidian oocyst shedding, we did not detect interspecific differences. However, as $F$. cf. nicosiai is the larger species, similar intensities of coccidian infection probably have milder effects on the individual's body condition.

Within the samples of both species, we found a very low prevalence of oxyurids, which is in accordance to the findings of Lutzmann (2007), who examined fecal samples of several wild living chameleon species from Masoala, Madagascar. Contrary to our findings, these parasites were frequently detected in specimens that were kept in captivity (Biallas 2013). Probably, in a terrarium, where the home range is very restricted, oxyurid density can increase rapidly due to their direct life cycle and resistant eggs.

In $F$. cf. nicosiai, we found a higher prevalence of filariid infection, which could be in turn explained by the comparatively longer exposition to blood-sucking arthropods such as Culex and Aedes due to their comparatively longer lifespan. Moreover, adult specimen of $F$. cf. nicosiai are considerably larger than adults of F. labordi and might therefore be easier to detect for mosquitos. As the prepatent period takes approx. 6 months (Szell et al. 2001), due to its shorter lifespan F. labordi is less prone to be adversely affected by foleyellosis. Subsequently, this species rather irregularly functions as primary host for Foleyella aff. furcata. Contrary to F. labordi, we found that the comparatively high prevalence in January decreased towards March in F. cf. nicosiai, but hereafter rises towards June. Initially, this observation might be explained by the small amount of blood samples $(\mathrm{n}=3)$ from $F$. cf. nicosiai in January. However, as sample size is respectively higher in the following months, this might indicate some immune defense mechanisms against the parasite, which changes to immunosenescence towards thebeginning of the dry season. Additionally, the life cycle of Foleyella might also have an influence of the observed pattern. As adult stages are known to predominantly inhabit skin or muscle tissue, an infection with this parasite might not have always been detected.

We found that the prevalence and intensity of mites was higher in $F$. cf. nicosiai, which could be caused by their larger average body size and subsequently easier detection for mites. Moreover, regarding the differences in intensity, mite pockets are larger in $F$. cf. nicosiai and might therefore offer more space for these ectoparasites.

Concerning interspecific comparison, niche differentiation may in turn result in differences in the exposure to parasites. In our previous study (Eckhardt et al. 2019a), we observed that adults of $F$. cf. nicosiai showed significant higher roosting sites, which might reflect differences in habitat use of both species. Here, the composition of food insects (vectors 
for gastrointestinal parasites), mosquitos (vectors for blood parasites) and mites might be unequal.

In total, detailed studies investigating parasite burden and in connection with their lifehistory and seasonality in reptiles are lacking (Zimmerman et al. 2010). However, a comparative study in mammals revealed weak relationships between parasite species richness and longevity (Cooper et al. 2012). These authors found a significant negative relationship between longevity and parasite species richness for ungulates, but not for carnivores or primates, indicating no general pattern of parasite richness according to life-history in vertebrates. In contrast to our expectations, we found higher prevalences of gastrointestinal-, blood - and ectoparasites in adult $F$. cf. nicosiai compared to adult $F$. labordi. As $F$. cf. nicosiai is the longer living and larger species, these observations could be caused by differences of cumulative exposure, as well as body size. Here, it is difficult to disentangle, which factors or interplay of factors influence these pattern. However, the fact that juveniles of $F$. cf. nicosiai show comparatively low infection rates until their maturation that takes approx. 11 months, suggests some immune defense mechanisms in juveniles compared to F. labordi. Although, following maturation this species seems to be affected by serious parasite infections, indicating that this age cohort reallocates their energy investment from self-maintenance to reproduction. Moreover, the accelerated growth rates that we observed after the aestivation (Eckhardt et al. 2019), which involves higher food requirements might additionally influence the raise in gastrointestinal parasites.

\section{Intersexual comparison}

In F. labordi, males showed a significantly higher prevalence of gastrointestinal parasites and additionally higher intensity in coccidian infestation than females. Similarly, a study of the small marsupial Antechinus stuartii found that males, which are the significantly shorter living sex, had remarkably higher prevalence of gastrointestinal parasites at the end of the mating season compared to females (Beveridge and Barker 1976). Additional studies in lizards (Uller and Olsson 2003) found that males are more susceptible to parasite infection, which was attributed to the immune-suppressive effects of testosterone, at least during the reproductive period. Among wild vertebrates, the prevalence and intensity of parasitic infections is also generally higher in males than females (Klein 2000). Here, sex differences in exposure as well as susceptibility to parasites probably contribute to sex-based differences in the intensity and prevalence of parasites. For example, males are more likely to engage in behaviours, such as aggression and dispersal, increasing the likelihood of contact with parasites (Zuk and McKean 
1996, Roberts et al. 2001). Males also often are larger than conspecific females, which may make them more obvious targets for parasites (Zuk and McKean 1996). Despite differences in the likelihood of exposure, several studies illustrate that harsh intrasexual combats and chronic physiological stress leads to increased susceptibility to infections, which is in accordance with the earlier die-off of in males (Eckhardt et al. 2017). In their review examining the immunocompetence handicap hypothesis, Roberts et al. (2004) suggest that there is at best weak evidence that testosterone directly influences immune function of males.

In contrast to our predictions, we did not find any sex difference in F. labordi with respect to filarial infections. As observed in both species, the microfilaria prevalence increased with season, and males of $F$. cf. nicosiai showed a higher prevalence than females, perhaps because of their larger body size and/or higher susceptibility.

Moreover, in both species, we detected sex differences in the intensity of acarian infestation, with males housing considerably more mites. This pattern could be caused by the differences in body size and therefore higher amount of blood, which enables larger males to host more mites without higher losses of blood compared to their female conspecifics. Higher intensities of mites in male lizards were also found in a study of Cox and Alder (2007), where males on average carried twice as many mites compared to females. Interestingly, castration reduced mite parasitism to levels comparable to that of females and treatment of castrated males with exogenous testosterone elevated mite counts to levels characteristic of intact males.

\section{Furcifer labordi in captivity}

When comparing caged individuals with their wild conspecifics, we found that the prevalence of gastrointestinal parasite infection was significantly higher in the latter one. Although we tried to shield captive specimens from infection, they probably took up parasites from the crickets, lepidopterans and orthopterans that were fed to them. These insects might have transferred parasitic eggs or oocysts. Since the caged chameleons were collected from the forest at the age of approximately two months, they might have also taken up parasite stages before. The two males that were infected with coccidians showed obvious senescent declines. Compared to the median survival time of caged males, (8.2 months, Eckhardt et al. 2017), these specimens showed a remarkably shorter lifespan. In contrast to their wild living conspecifics, we did not find significant intersexual differences in survival within the caged animals. Similar results were obtained in mouse lemurs $M$. murinus, where survival in the wild was strongly femalebiased (Kraus et al. 2008, Languille et al. 2012), whereas longevity in captivity was slightly male-biased (Perret 1997). These findings support the previously mentioned suggestion of 
Roberts et al. (2004) that testosterone alone is unlikely to be responsible for accelerated senescence and die off in males in the wild. In total, as the caged chameleons were shielded from predation, starvation, desiccation, and at least partly from infections, it is not possible to pinpoint the factors facilitating their longer survival in captivity. To identify to which extant the presence or absence of parasites influence the lifespan of caged animals, an experimental manipulation of parasite burden could give insight into the direct effect of parasite infection.

\section{Conclusions}

Our study provides rare information about the age-related patterns of health in the shortest living tetrapod species in the wild and suggest that $F$. labordi rather relies on nonspecific and inflammatory immune defenses than on acquired immunity. Moreover, as vertebrates obligatorily develop an adaptive immune system, we assume a downregulation of the acquired immunity with age. As the prevalence in parasites increased comparatively later in $F$. cf. nicosiai, we suspect that this species invests more energy in the development of an adaptive immune system until maturation. However, adults of both species seem to suffer from parasite infections. The parasite burden observed in fecal and blood samples revealed the combined outcome of several factors: the parasites encountered by the host, when the parasite matured and reproduced within the host, and how effective the host's immune system was in preventing or eliminating the infection. While it is difficult to disentangle these factors, we found males having higher parasite infection rates than females, and the older animals to suffer from the higher parasite burden, suggesting a downregulation of the acquired immunity in both species. Finally, the conduction of cage experiments including both species and sexes with a controlled manipulation of parasite burden could clarify the direct influence of the effect of parasites on the lifespan of both species.

\section{Acknowledgements}

We thank the CAFF/CORE of the Direction Général des Eaux et Forêts, and CNFEREF Morondava for authorization and support for this study. We are thankful for support in the field to Camilla Cenni, Wanda von Bremen and the team of field assistants in Kirindy Forest. 
Tab. 6. Parameter estimates from the generalized linear mixed model for the prevalences of A) gastrointestinal parasites in F. labordi B) gastrointestinal parasites of both species, C) blood parasites in both species, D) ectoparasites in both species

\begin{tabular}{|c|c|c|c|c|c|c|c|}
\hline \multicolumn{8}{|c|}{ A) Prevalence: gastrointestinal parasites $F$. labordi } \\
\hline \multicolumn{5}{|c|}{ Parameter estimates } & \multicolumn{3}{|c|}{ Likelihood ratio test } \\
\hline Fixed effects & Est. & SE & $\mathbf{z}$ & $\mathbf{P}$ & $x^{2}$ & df & $\mathbf{P}$ \\
\hline Intercept & -2.7265 & 0.3193 & -8.539 & $<0.001$ & \multirow{7}{*}{$\frac{\varkappa}{110.75}$} & \multirow[t]{7}{*}{6} & \multirow[t]{7}{*}{$<0.001$} \\
\hline Sex (male) & 0.8484 & 0.1914 & 4.432 & $<0.001$ & & & \\
\hline Feb & 1.5103 & 0.3007 & 5.023 & $<0.001$ & & & \\
\hline Mar & 1.8755 & 0.2986 & 6.280 & $<0.001$ & & & \\
\hline Apr & 2.1040 & 0.3263 & 6.448 & $<0.001$ & & & \\
\hline May & 3.3748 & 0.4497 & 7.505 & $<0.001$ & & & \\
\hline Jun & 2.7370 & 0.8500 & 3.220 & $<0.01$ & & & \\
\hline \multicolumn{8}{|c|}{ B) Prevalence: gastrointestinal parasites $F$. labordi and $F$. cf. nicosiai } \\
\hline \multicolumn{5}{|c|}{ Parameter estimates } & \multicolumn{3}{|c|}{ Likelihood ratio test } \\
\hline Fixed effects & Est. & SE & $\mathbf{z}$ & $\mathbf{P}$ & $\chi^{2}$ & df & $\mathbf{P}$ \\
\hline Intercept & -2.6471 & 0.2874 & -9.211 & $<0.001$ & \multirow[t]{9}{*}{129.93} & \multirow[t]{9}{*}{8} & \multirow[t]{9}{*}{$<0.001$} \\
\hline F. cf. nicosiai & 1.0532 & 0.3197 & 3.295 & $<0.001$ & & & \\
\hline Sex (male) & 0.8159 & 0.1832 & 4.453 & $<0.001$ & & & \\
\hline Feb & 1.4755 & 0.2726 & 5.413 & $<0.001$ & & & \\
\hline Mar & 1.8089 & 0.2689 & 6.727 & $<0.001$ & & & \\
\hline Apr & 2.0870 & 0.2974 & 7.018 & $<0.001$ & & & \\
\hline May & 3.2360 & 0.4002 & 8.085 & $<0.001$ & & & \\
\hline Jun & 2.0317 & 0.6291 & 3.230 & $<0.01$ & & & \\
\hline $\begin{array}{c}\text { F. cf. nicosiai } \\
\text { (male) }\end{array}$ & -2.0865 & 0.5175 & -4.032 & $<0.001$ & & & \\
\hline \multicolumn{8}{|c|}{ C) Prevalence: blood parasites $F$. labordi and $F$. cf. nicosiai } \\
\hline \multicolumn{5}{|c|}{ Parameter estimates } & \multicolumn{3}{|c|}{ Likelihood ratio test } \\
\hline Fixed effects & Est. & SE & $\mathbf{z}$ & $\mathbf{P}$ & $\chi^{2}$ & df & $\mathbf{P}$ \\
\hline Intercept & -2.7623 & 0.7641 & -3.615 & $<0.001$ & \multirow[t]{7}{*}{90.78} & \multirow[t]{7}{*}{6} & \multirow[t]{7}{*}{$<0.001$} \\
\hline F. cf. nicosiai & 0.7187 & 0.3287 & 2.187 & $<0.05$ & & & \\
\hline Sex (male) & 0.7567 & 0.3233 & 2.340 & $<0.05$ & & & \\
\hline Feb & -1.7501 & 1.0150 & -1.724 & 0.08468 & & & \\
\hline Mar & -0.3750 & 0.7466 & -0.502 & 0.61550 & & & \\
\hline Apr & 1.1826 & 0.7179 & 1.647 & 0.09950 & & & \\
\hline May & 2.3222 & 0.7508 & 3.093 & $<<0.01$ & & & \\
\hline \multicolumn{8}{|c|}{ D) Prevalence: ectoparasites $F$. labordi and $F$. cf. nicosiai } \\
\hline \multicolumn{5}{|c|}{ Parameter estimates } & \multicolumn{3}{|c|}{ Likelihood ratio test } \\
\hline Fixed effects & Est. & SE & $\mathbf{z}$ & $\mathbf{p}$ & $\chi^{2}$ & df & $\mathbf{P}$ \\
\hline Intercept & -1.3332 & 0.2198 & -6.066 & $<0.001$ & \multirow{8}{*}{$\frac{\alpha}{607.48}$} & \multirow[t]{8}{*}{7} & \multirow{8}{*}{$<0.001$} \\
\hline Sex (male) & 0.9934 & 0.1769 & 5.617 & $<0.001$ & & & \\
\hline F. cf. nicosiai & 0.8087 & 0.2213 & 3.654 & $<0.001$ & & & \\
\hline Feb & 3.6267 & 0.4200 & 8.634 & $<0.001$ & & & \\
\hline Mar & 2.1469 & 0.3087 & 6.955 & $<0.001$ & & & \\
\hline Apr & -0.3134 & 0.2158 & -1.452 & 0.14649 & & & \\
\hline May & -1.3439 & 0.3434 & -3.914 & $<0.001$ & & & \\
\hline Jun & -2.7206 & 0.7833 & -3.473 & $<0.001$ & & & \\
\hline
\end{tabular}


Tab. 7: Parameter estimates from the generalized linear mixed model for shedding intensity of coccidian oocysts of $F$. labordi and F. cf. nicosiai

\begin{tabular}{|c|c|c|c|c|c|c|c|c|}
\hline \multicolumn{9}{|c|}{ Intensity: Isospora sp. of $F$. labordi and $F$. cf. nicosiai } \\
\hline \multicolumn{6}{|c|}{ Parameter estimates } & \multicolumn{3}{|c|}{ Likelihood ratio test } \\
\hline Fixed effects & Est. & SE & $\mathrm{df}$ & t-value & $\mathrm{p}$ & $\chi^{2}$ & $\mathrm{df}$ & $\mathrm{P}$ \\
\hline Intercept & 17358.7 & 20290.8 & 192.0 & 0.855 & 0.393 & \multirow[t]{9}{*}{29.39} & \multirow[t]{9}{*}{8} & \multirow[t]{9}{*}{$<0.001$} \\
\hline Mar & -13592.0 & 24402.5 & 189.9 & -0.557 & 0.578 & & & \\
\hline Apr & -2188.9 & 25262.6 & 197.2 & -0.087 & 0.931 & & & \\
\hline May & 21675.3 & 25424.7 & 195.0 & 0.853 & 0.395 & & & \\
\hline Sex (male) & -14996.7 & 29319.3 & 192.0 & -0.511 & 0.610 & & & \\
\hline F. cf. nicosiai & -10617.4 & 19035.0 & 192.1 & -0.558 & 0.578 & & & \\
\hline Mar (male) & 14460.4 & 37649.4 & 191.1 & 0.384 & 0.701 & & & \\
\hline Apr (male) & 5659.0 & 43324.8 & 193.6 & 0.131 & 0.896 & & & \\
\hline May (male) & 388477.9 & 84369.7 & 192.2 & 4.604 & $<0.001$ & & & \\
\hline
\end{tabular}

Tab. 8: Parameter estimates from the generalized linear mixed model for intensity of ectoparasites of $F$. labordi and F. cf. nicosiai

\begin{tabular}{|c|c|c|c|c|c|c|c|}
\hline \multicolumn{8}{|c|}{ Intensity: ectoparasite infestation of $F$. labordi and $F$. cf. nicosiai } \\
\hline \multicolumn{5}{|c|}{ Parameter estimates } & \multicolumn{3}{|c|}{ Likelihood ratio test } \\
\hline Fixed effects & Est. & SE & t-value & $\mathbf{P}$ & $\chi^{2}$ & df & $\mathbf{P}$ \\
\hline Intercept & 1.775 & 0.139 & 12.808 & $<0.001$ & \multirow[t]{13}{*}{290.43} & \multirow[t]{13}{*}{15} & \multirow[t]{13}{*}{$<0.001$} \\
\hline F. cf. nicosiai & 0.402 & 0.205 & 1.959 & 0.0501 & & & \\
\hline Feb & 0.179 & 0.144 & 1.248 & 0.212 & & & \\
\hline Mar & -0.119 & 0.161 & -0.739 & 0.46 & & & \\
\hline Apr & -1.107 & 0.228 & -4.861 & $<0.001$ & & & \\
\hline May & -1.508 & 0.398 & -3.789 & $<0.001$ & & & \\
\hline Jun & -1.547 & 0.834 & -1.854 & 0.064 & & & \\
\hline Sex (male) & 0.076 & 0.175 & 0.436 & 0.663 & & & \\
\hline F. cf. nicosiai $\mathrm{Feb}$ & -0.232 & 0.247 & -0.939 & 0.348 & & & \\
\hline F. cf. nicosiai Mar & 0.333 & 0.241 & 1.380 & 0.167 & & & \\
\hline F. cf. nicosiai Apr & 0.899 & 0.294 & 3.061 & $<0.01$ & & & \\
\hline F. cf. nicosiai Мау & -0.286 & 0.627 & -0.456 & 0.648 & & & \\
\hline Male Feb & 0.675 & 0.193 & 3.506 & $<0.001$ & & & \\
\hline
\end{tabular}




\section{Chapter 5: Stress-related changes in leukocyte profiles and telomere shortening in the shortest-lived tetrapod, Furcifer labordi}

Falk Eckhardt ${ }^{1}$, Angela Pauliny ${ }^{2}$, Nicky Rollings ${ }^{3}$, Frank Mutschmann ${ }^{4 *}$, Mats Olsson ${ }^{2}$, Cornelia Kraus $^{1,5}$, Peter M. Kappeler ${ }^{1,5}$

${ }^{1}$ Dept. Sociobiology/Anthropology, Institute of Zoology and Anthropology, University of Göttingen, Kellnerweg 6, 37077 Göttingen, Germany

${ }^{2}$ Department of Biological and Environmental Science, University of Gothenburg, Medicinaregatan 18A, 41390 Göteborg, Sweden

${ }^{3}$ School of Life and Environmental Sciences, Sydney, New South Wales, Australia

${ }^{4}$ Exomed-Labor, Schönhauser Straße 62, 13127 Berlin, Germany

${ }^{5}$ Behavioral Ecology and Sociobiology Unit, German Primate Center, Kellnerweg 4, 37077

Göttingen, Germany

* deceased

Eckhardt, F., Pauliny, A., Rollings, N., Mutschmann, F., Olsson, M., Kraus, C., Kappeler, P. M. (2020). Stress-related changes in leukocyte profiles and telomere shortening in the shortestlived tetrapod, Furcifer labordi. BMC Evolutionary Biology, accepted. 


\begin{abstract}
Life-history theory predicts that, during the lifespan of an organism, resources are allocated to either growth, somatic maintenance or reproduction. Resource allocation trade-offs determine the evolution and ecology of different life-history strategies and define an organisms' position along a fast-slow continuum in interspecific comparisons. Labord's chameleon (Furcifer labordi) from the seasonal dry forests of Madagascar is the tetrapod species with the shortest reported lifespan (4-9 months). Previous investigations revealed that their lifespan is to some degree dependent on environmental factors, such as the amount of rainfall and the length of the vegetation period. However, the intrinsic mechanisms shaping such a fast life-history remain unknown. Environmental stressors are known to increase the secretion of glucocorticoids in other vertebrates, which, in turn, can shorten telomeres via oxidative stress. To investigate to what extent age-related changes in these molecular and cellular mechanisms contribute to the relatively short lifetime of $F$. labordi, we assessed the effects of stressors indirectly via leukocyte profiles (H/L ratio) and quantified relative telomere length from blood samples in a wild population in Kirindy Forest. We compared our findings with the sympatric but longerlived sister species $F$. cf. nicosiai, which exhibit the same timing annual of reproductive events, and with wild-caught $F$. labordi that were singly housed under ambient conditions. We found that $\mathrm{H} / \mathrm{L}$ ratios were consistently higher in wild $F$. labordi compared to $F$. cf. nicosiai. Moreover, F. labordi already exhibited relatively short telomeres during the mating season when they were $3-4$ months old, and telomeres further shortened during their postreproductive lives. At the beginning of their active season, telomere length was relatively longer in $F$. cf. nicosiai, but undergoing rapid shortening towards the southern winter, when both species gradually die off. Captive $F$. labordi showed comparatively longer lifespans and lower $\mathrm{H} / \mathrm{L}$ ratios than their wild counterparts. We suggest that environmental stress and the corresponding accelerated telomere attrition have profound effects on the lifespan of $F$. labordi in the wild, suggesting physiological mechanisms proximately contributing to their relatively early senescence and mortality.
\end{abstract}

Key words: Furcifer labordi, life-history, telomeres, H/L ratio, body condition 


\section{Introduction}

Life-history theory is based on the premise that during the lifetime of an individual, energy and resources are allocated to either growth, somatic maintenance, or reproduction (Stearns 1976, Stearns 1992, Stearns 2000). For example, resources, which are invested into fast growth and early reproduction, cannot be used for somatic maintenance, which may lead to shorter lifespans. The trade-offs between traits shape life-history strategies and the distribution of species along a fast-slow continuum of life-history speeds (Sæther and Bakke 2000, Sæther et al. 2004, Salguero-Gómez et al. 2016). In spite of the supposed significance of extrinsic factors in shaping life-histories, aging research is still largely biased towards captive animals living under standardized, optimal conditions (e.g. Languille et al. 2012). In the wild, studies of senescence have largely focused on long-lived animals that face relatively low levels of extrinsic mortality (e.g. sea turtles [Plot et al. 2012], birds [Barrett et al. 2013], Soay sheep [Fairlie et al. 2016]). However, studies focusing on age-related changes in short-lived species in the wild are rare. Hence, studies of wild populations with high extrinsic mortality are essential for testing hypotheses on the evolution of lifespan and senescence.

Oxidative stress and its damage to macromolecules is one of the most cited causes of aging (Sohal and Weindruch 1996). The oxidative damage is a byproduct of aerobic respiration (Sena and Chandel 2012) and intensified by chronic stress conditions characterized by a persistent release of glucocorticoids (GCs) in vertebrates (Salman et al. 2010). Physiological stress is an important mediator in the trade-off between survival and reproduction (Boonstra et al. 2001, Ricklefs and Wikelski 2002). GCs are released in response to a wide range of stressful stimuli (e.g. Romero et al. 2000), and several of their effects parallel those observed during aging, suggesting that chronic stress has a potential to accelerate the aging process (Sapolsky et al. 1987, Velthuis et al. 2013).

The immunosuppressive effects of chronic GC elevation and their consequences for morbidity and mortality have been studied intensively (Sapolsky et al. 2000, Dahabar 2002). Alterations in key immunological parameters during chronic stress parallel those during normal immunosenescence to a large degree (Bauer 2008). These hormones are important regulators of carbohydrate, lipid, and protein metabolism (Dallman 1993), and several earlier studies linked poor body condition to elevated GC concentrations (e.g. Wingfield and Romero 2001). The direct measurement of baseline GC levels in wildlife via blood plasma can be challenging as stress hormones can rise immediately following capture (Romero and Reed 2005). However, leukocyte profiles are a suitable tool to indirectly assess stress levels as these hormones increase 
the number of heterophils and decrease the number of lymphocytes. Leukocyte responses to stress take about $12 \mathrm{~h}$ to several days in ectotherms (reviewed in Davis et al. 2008). Heterophils are the primary phagocytic leukocyte, which proliferate in circulation in response to infections, inflammation and stress (Jain 1993, Campbell 1995, Rupley 1997, Harmon 1998, Thrall 2004). Lymphocytes are involved in a variety of immunological functions such as the production of immunoglobulin and modulation of immune defense (Campbell 1996).

At the cellular level, telomere length (TL) and shortening are thought to be significant proximate contributors to the aging process. Telomeres are short, tandem-repeated sequences of DNA found at the ends of linear eukaryotic chromosomes, whose sequence (TTAGGG) is highly conserved among vertebrates (Meyne and Radliff 1989). Telomeres function in stabilizing chromosomal end integrity (Prowse and Greider 1995), inhibiting aberrant fusions and rearrangements that occur on broken chromosomes (McClintcock 1941), and aiding in the completion of duplication (Watson 1972). During each cell cycle, telomeric repeats are lost because DNA polymerase is unable to completely replicate the 3 'end of linear DNA (Watson 1972).

There is great variation among species in age-specific TL (Gomes et al. 2010). Sexual differences in TL and attrition have been suggested to contribute to sex-specific disease and mortality patterns in humans (Stindl 2004, Eskes and Haanen 2007), where women typically have longer telomeres and are longer-lived (e.g., Benetos et al. 2001). Telomerase, the enzyme that countervails telomere shortening was found to be active in stem cells, gametes and most cancer cells, but normally absent from or at very low levels in most somatic cells (Tanaka et al. 2005). However, some studies in reptiles suggested that telomerase may not be turned off in adult somatic cells (Dantzer and Fletchter 2015). Besides cell division dependent telomere shortening, elevated levels of corticosterone can further affect TL via increased oxidative damage by reactive oxygen species (ROS) (Agostinho et al. 2010, Constantini et al. 2011). Elevated GCs, particularly during long-term physiological or psychological stress, have been linked to increased oxidative stress and concomitant telomere shortening and reduced telomerase activity (Constantini et al. 2011). As the nucleobase guanine is a major oxidation target for ROS, the (TTAGGG) repeats are particularly exposed to oxidative damage (Wang et al. 2010).

Telomeres may also act as sentinels of the general level of DNA damage in a given cell. High levels of telomere damage would be indicative of high levels of damage to the coding sequences. Thus, telomeres could offer a mechanism to ensure that cells with high levels of 
DNA damage soon terminate division (von Zglinicki 2003). Overall, demanding life-history stages and harsh environmental conditions seem to be linked to a rapid rate of telomere degradation, and there is also a clear connection between physiological stress and telomere attrition in humans, laboratory rodents and wild vertebrates (Eple et al. 2004, Kartschal et al. 2007, Haussmann and Marchetto 2010, Shaley et al. 2013, Bateson 2016). This evidence suggests that telomere dynamics could be closely related to stress in wild vertebrates (reviewed in Angelier et al. 2018), and Houben et al. (2008) emphasized that telomeres are a promising biomarker for chronic oxidative stress.

Labord's chameleon (Furcifer labordi) from the seasonal deciduous dry forests in western and southwestern Madagascar has a lifespan of only 4 - 9 months (Karsten et al. 2008, Eckhardt et al. 2017). This extreme life-history makes this species an interesting model for studying potential mechanisms of accelerated senescence, especially because longer-lived sympatric congeners are available for comparative studies. During their short lives, these chameleons undergo hatching at the beginning of the wet season in November, subsequent fast juvenile growth, maturation and courtship followed by death of both sexes towards the beginning of the dry season in May (Karsten et al. 2008, Eckhardt et al. 2017). Wild females tend to live slightly longer, whereas no sex difference in lifespan was found in caged individuals kept under ambient conditions (Eckhardt et al. 2017). Fast growth rates, high reproductive rates and intense mating competition might proximately contribute to increased stress levels and telomere shortening, which in turn may facilitate the decrease of physiological functioning, ultimately leading to death (e.g., Braithwaite and Lee 1979, Oakwood et al. 2001).

To investigate whether the ratio of heterophils and lymphocytes (H/L ratio) and telomere shortening are associated with the early die-off in F. labordi in the wild, we determined their telomere dynamics and leukocyte profiles as an indict measure of physiological stress. Our study included two comparisons; one between wild $F$. labordi and their sympatric and longerlived congener $F$. cf. nicosiai, and one with $F$. labordi kept in single cages under ambient conditions, shielding them substantially from environmental stressors, like hunger or predation risk. We predicted an increase in $\mathrm{H} / \mathrm{L}$ ratios as well as rapidly shortening telomeres in postreproductive wild $F$. labordi as well as lower $\mathrm{H} / \mathrm{L}$ ratios and decelerated telomere attrition in $F$. cf. nicosiai. Furthermore, as age-related changes should be delayed in the longer-lived females of both species, we predicted females to exhibit comparatively slower rate of senescence than males. Finally, caged $F$. labordi, which were shielded from extrinsic mortality and from a 
substantial part of the costs of reproduction and starvation, were expected to exhibit slower correlates of aging compared to their wild conspecifics.

\section{Material and Methods}

\section{Study site and study species}

This study was conducted in Kirindy Forest, which is located in the region of Menabe Central,

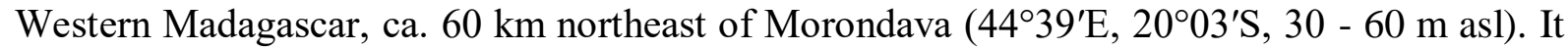
is one of the largest remaining Malagasy dry deciduous forest fragments. The local climate is characterized by a hot rainy season between November and April, followed by a cool dry season from May to October (Kappeler and Fichtel 2012). Kirindy Forest is located near the northern end of the range of Furcifer labordi, a medium-sized and sexually highly dimorphic chameleon from the western and southwestern regions of Madagascar (Glaw and Vences, 2007). Furcifer cf. nicosiai is a relatively larger species, also sexually dimorphic (Eckhardt et al. 2019a), and appears to be limited to intact dry forests (Jesu et al. 1999, Glaw and Vences 2007).

\section{Capture-mark-recapture study}

Chameleons were located at night using LED flashlights. The capture location was marked and GPS data were taken. We sampled alternating along two transects of $3 \mathrm{~km}$ length each. Animals were transported to the nearby research station in cloth bags and handled the following morning. They were sexed, age categorized (hatchling, juvenile, adult), and their snout vent length (SVL) was measured. Animals were individually marked by visual implant elastomers (VIE; Northwest Marine Technology Inc., Shaw Island, WA) (MacNeil et al. 2011). Hatchlings and small juveniles were individually marked with nail polish on the toes. All chameleons were released at their point of capture within $12 \mathrm{~h}$. Sampling took place over three field seasons: November 19, 2013 - July 8, 2014, and January 11, 2015 - July 15, 2015, and October 12, 2015 - December 17, 2015.

\section{Experimental housing}

We collected a total of 20 male and 20 female juveniles of $F$. labordi in early January, at approximately two months of age, and kept them individually without visual contact in cylindrical nylon cages (90 cm height, $60 \mathrm{~cm}$ diameter) inside a large outdoor forest enclosure. Chameleons received a standardized amount of insects, adjusted to their age and size to match 
growth and final size of the wild population. Water was offered daily with a spray flask. Between February and June, the caged animals were handled biweekly to obtain blood samples. Only captive animals were sampled repeatedly.

\section{Leukocyte profiles}

To measure leukocyte profiles, a drop of blood was taken by lateral puncture of the caudal vein. No blood was taken from females that were obviously gravid. The drop of blood was placed on a microscope slide and distributed as a blood smear. After air-drying, blood smears were processed with a rapid differential haematology staining utilizing the Diff-Quik staining solution system (Medion Diagnostics AG, Düdingen, Switzerland). We determined the ratio of heterophils to lymphocytes (H/L ratio) in at least 200 cells per slide, using the $100 \mathrm{x}$ oil objective. For identification, the general description of reptilian blood cells and terminology was used (Origgi 2007, Tamukai et al. 2011). Counting of the leukocytes started at the most distal edge of the feather end of the smear and proceeded one field of view at a time, across the entire smear in an ' $\mathrm{S}$ ' fashion. Only fields of view with $>15$ erythrocytes in a monolayer were considered (Davis and Maerz 2008). All cell counting was conducted by FE. Blood samples were taken from February onwards until mid-July in 2014 and 2015. In total, 319 samples from wild $F$. labordi, 103 samples of $F$. cf. nicosiai and 278 samples from 40 captive animals were analysed.

\section{Telomere length (TL)}

Blood samples for telomere analysis were taken between March and mid-July in 2015. In total, 66 blood samples of $F$. labordi and 39 of $F$. cf. nicosiai were obtained. Captive animals were excluded from this analysis because not enough blood samples were available.

For the determination of TL, we took approx. 5-10 $\mu \mathrm{l}$ blood from the caudal vein after lateral puncture with a capillary and transferred it into a $1.5 \mathrm{ml}$ tube containing $0.5 \mathrm{ml}$ SET buffer. Samples were directly frozen at $-20^{\circ} \mathrm{C}$. To avoid melting during transportation, samples were stored in a compressor cooling box. Telomere length was measured using real-time quantitative PCR (qPCR) using SensiMix SYBR No- ROX Kit (Bioline, Sydney, NSW, Australia) and a Rotor-gene 6000 thermocycler (Qiagen, Chadstone, VIC, Australia) according to published protocols (Rollings et al. 2017a, Rollings et al. 2017b) using techniques developed by (Plot et al. 2012) with the $18 \mathrm{~S}$ ribosomal RNA (18S) gene as the non-variable copy number reference gene. The telomere primers used were Telb1 (5'-

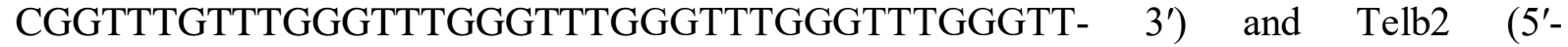


GGCTTGCCTTACCCTTACCCTTACCCTTACCCTTACCCT- 3', (Plot et al. 2012). The 18S gene (92 bp amplicon in Anolis) was selected as the reference gene as it had previously been validated in reptiles (Plot et al. 2012, Rollings et al. 2017b, Rollings et al. 2019). The primer sequences used were 18S- F (5'- GAGGTGAAATTCTTGGACCGG- 3') and 18S- R (5'CGAACCTCCGACTTTCGTTCT- 3'). Reactions were run in triplicate for each sample, with each run containing either Telb or $18 \mathrm{~S}$ primers. Amplifications were carried out in a RotorGene 6000 thermocycler (Qiagen, Australia) using an initial Taq activation step at $95^{\circ} \mathrm{C}$ for 10 min and a total of 40 cycles of $95^{\circ} \mathrm{C}$ for $15 \mathrm{~s}, 60^{\circ} \mathrm{C}$ for $15 \mathrm{~s}$, and $72^{\circ} \mathrm{C}$ for $15 \mathrm{~s}$. Each reaction had a final volume of $20 \mu \mathrm{l}$ with $10 \mathrm{ng}$ of DNA. A melt curve 412 was generated after each run over the temperature range of 60 to $95^{\circ} \mathrm{C}$ to ensure that there was no nonspecific product amplification. All of the DNA samples for a given individual were included in the same run. No- template control reactions were run in triplicate for each primer set during every qPCR run to ensure that there was no contamination.

\section{Statistical analyses}

Linear models (LM) were used to examine the influence of leukocyte profiles on TL in wild $F$. labordi and F. cf. nicosiai. As fixed factors, we added month (age), sex and species. For captive F. labordi, we used linear mixed models (LMM). As fixed factors, we added month (age), and sex, while ID was included as a random factor for recaptured samples. For all models, we compared the respective full model with the null model by using a likelihood ratio test. In addition, we visually inspected normality and homoscedasticity with residual plots. For model analysis, we used the package lme4 (Bates et al. 2016). All data analysis was conducted in R (R-Code Team 2017). To check for correlation between H/L profile and TL, we calculated the Pearson correlation coefficient.

\section{Declarations}

\section{Ethics approval and consent to participate}

All work conducted in Madagascar was done with the authorization by the Commission Ad hoc Faune et Flore / Commité d'Orientation sur la Recherche Environnementale (CAFF/CORE) of the Direction Général des Eaux et Forêts, and the Centre National de Formation, d'Etudes et de Recherche en Environnement et Forestier (CNFEREF) Morondava, Madagascar. 


\section{Results}

Concerning white blood cell counts, we found heterophils, lymphocytes, azurophils and basophils. In both species, heterophils were the most abundant leukocyte type, followed by lymphocytes and azurophils. Heterophiles exhibited a spherical shape with an eccentric mostly lobed nucleus containing clumpy basophilic purplish chromatin. Most lymphocytes contained a large nucleus with coarse chromatin, leaving only a small visible band of cytoplasma around it. Basophils were only found sporadically. On average, the $\mathrm{H} / \mathrm{L}$ ratio of F. labordi $(2.45 \pm 0.97$ $\mathrm{SD}, \mathrm{n}=319)$ was significantly higher compared to that of $\mathrm{F}$. cf. nicosiai $(1.51 \pm 0.47 \mathrm{SD}, \mathrm{n}=$ $103, \mathrm{t}=-9.921, \mathrm{p}<0.001)$. Moreover, we detected an increase of the $\mathrm{H} / \mathrm{L}$ ratio in both species between February and May (Fig. 5.1, Tab. 9), reflecting the cessation of mating activities. In captive specimen, we found an average H/L profile of $(1.42 \pm 0.14 \mathrm{SD}, \mathrm{n}=40)$ and no significant sex differences (Tab. 5.2). As in their wild conspecifics, the $\mathrm{H} / \mathrm{L}$ ratio of captive chameleons increased significantly from February until June (Tab. 10).

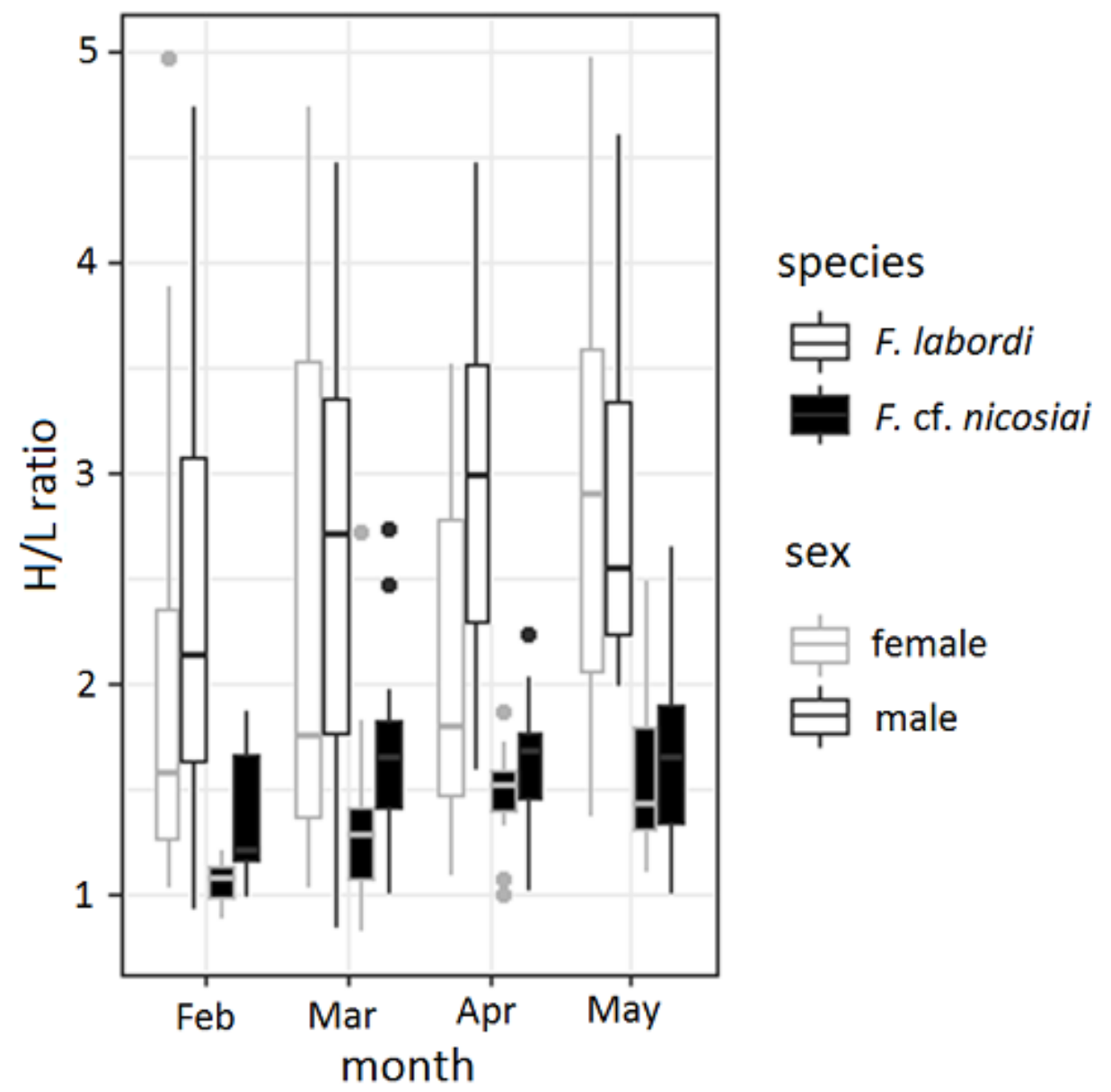

Fig. 5.1: H/L ratio of adult wild specimen of $F$. labordi and $F$. cf. nicosiai. Boxplots depict H/L ratio per species and sex from February until May. 
During our sampling period, we did not detect any significant sex and age related changes in TL in F. labordi. Average TL was significantly longer in F. cf. nicosiai $(\mathrm{t}=6.438, \mathrm{p}<0.001)$. Furthermore, TL of $F$. cf. nicosiai was comparatively long in March $(1.87 \pm 0.77 \mathrm{SD}, \mathrm{n}=14)$ and decreased dramatically until May $(1.14 \pm 0.33 \mathrm{SD}, \mathrm{n}=10, \mathrm{t}=-2.686, \mathrm{p}<0.01)$. Moreover, TL of $F$. cf. nicosiai males was significantly shorter compared to females $(\mathrm{t}=-2.67, \mathrm{p}<0.01$, $\mathrm{df}=38$ ). For statistical analyses (Tab. 11), the months June and July were excluded due to small sample sizes (but June is included in Fig. 5.2), and we found a negative correlation between the $\mathrm{H} / \mathrm{L}$ ratio and TL in $F$. labordi $(r=-0.556, \mathrm{df}=65, \mathrm{p}<0.01)$ and in $F$. cf. nicosiai $(r=-0.687$, $\mathrm{df}=38, \mathrm{p}<0.01 ;$ see Fig. 5.3)

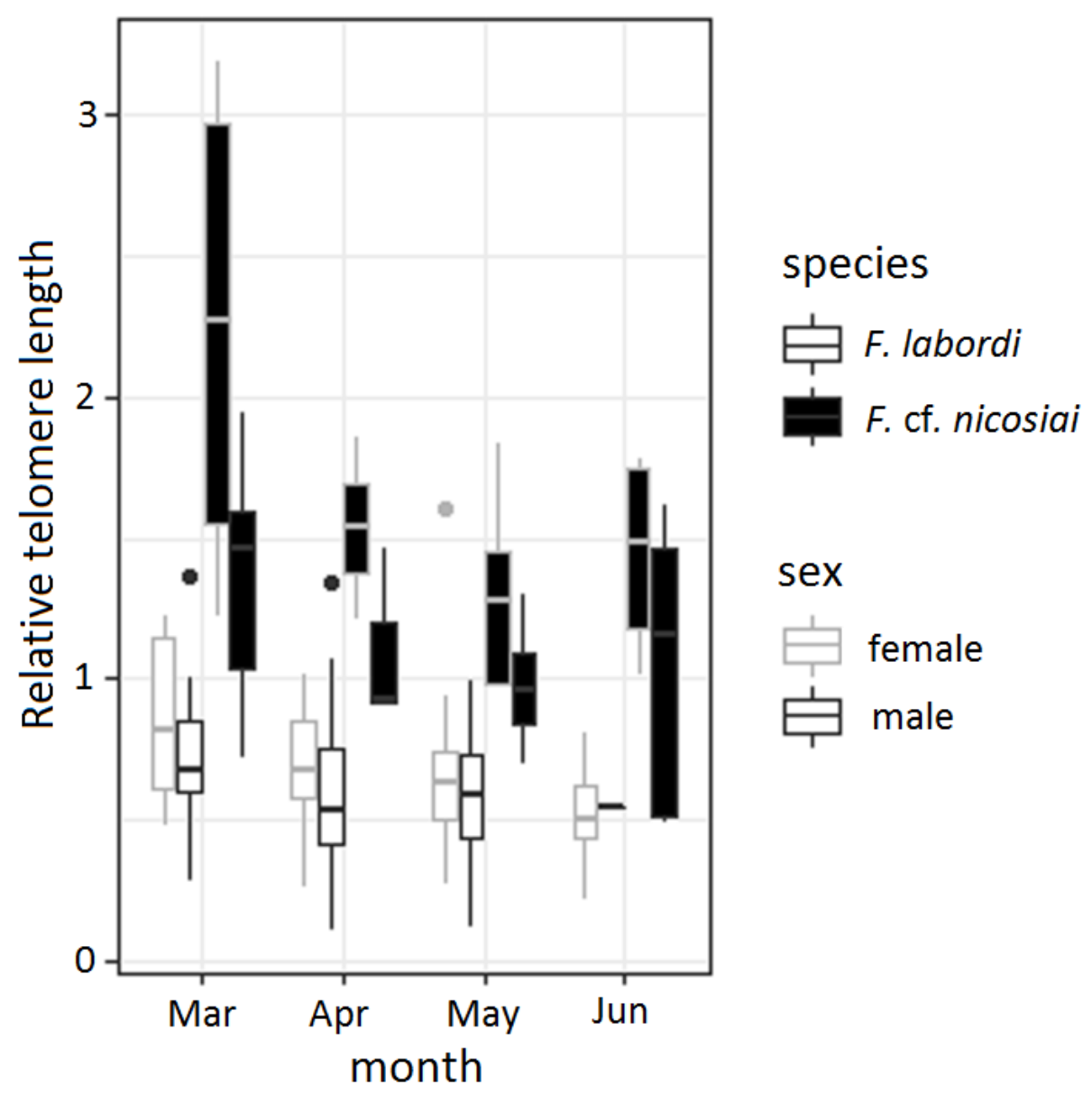

Fig. 5.2: Relative telomere length of adult wild specimen of $F$. labordi and $F$. cf. nicosiai. Boxplots depict relative TL per species and sex from March until June. 


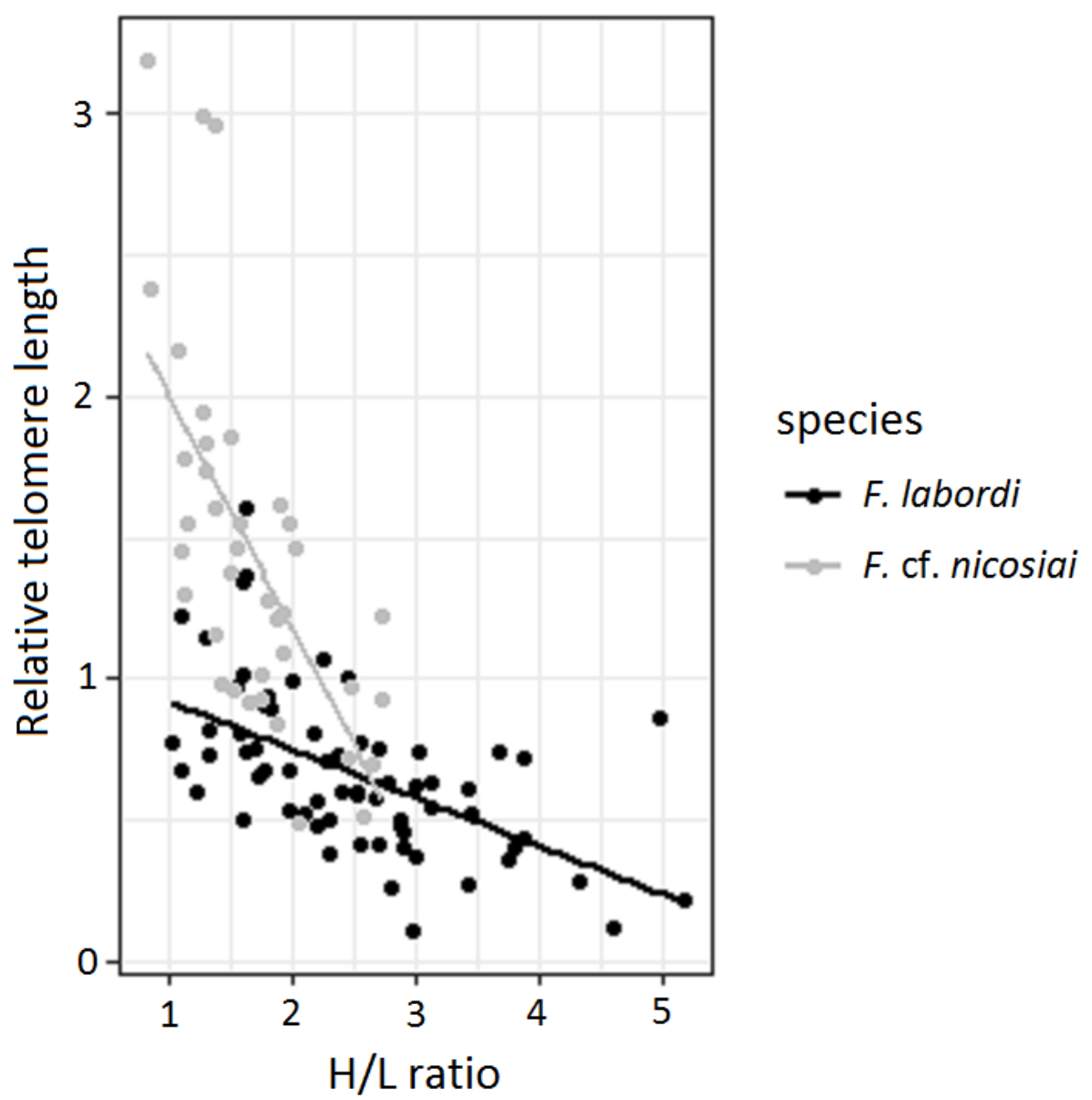

Fig. 5.3: Association of $\mathrm{H} / \mathrm{L}$ ratio and $\mathrm{TL}$ in F. labordi $(\mathrm{n}=66)$ and $F$. cf. nicosiai. $(\mathrm{n}=39)$.

\section{Discussion}

Our study revealed that $\mathrm{H} / \mathrm{L}$ ratios were consistently higher in wild $F$. labordi compared to $F$. cf. nicosiai, indicating higher stress levels in the shorter-lived species. Furcifer labordi already exhibited relatively short telomeres when they were $3-4$ months old. TL was initially comparatively longer in $F$. cf. nicosiai, but undergoing rapid shortening after the mating season. In this species, we also detected intersexual differences in $\mathrm{H} / \mathrm{L}$ ratio and $\mathrm{TL}$, with shorter living males exhibiting higher H/L ratios and shorter telomeres. Interestingly, heterophils were the most common leucocyte type in both wild and captive chameleons. Captive F. labordi exhibited comparatively longer lifespans and lower $\mathrm{H} / \mathrm{L}$ profiles than their wild conspecifics. In planning this study, we assumed that the captive chameleons would be buffered from some environmental stressors, like starvation, desiccation and predation risk. Our data therefore indicate that relatively long-lived wild $F$. labordi individuals were, on average, more stressed and lived shorter lives than their captive conspecifics, indicating a link between stress and longevity. 


\section{Baseline stress levels and leukocyte profiles}

Investigations in other reptile species indicated large differences between hematology values of different species as well as intraspecific variation as a function of season and sex (Campbell and Ellis 2007, Strik et al. 2007). In their study of blood chemistry and hematology in captive panther chameleons (Furcifer pardalis), Laube et al. (2016) found that lymphocytes were the predominant leucocyte type in both summer and winter. In contrast, Cuadrado et al. (2002) reported that heterophils were the most frequently found leucocyte type in dystoic and healthy post-reproductive females of the common chameleon (Chamaeleo chamaeleon). The H/L ratio from that study (2.24) resembled the values reported here for F. labordi (2.45). More recently, Eshar et al. (2018) found that heterophils were the most abundant leukocytes type in wild common chameleons. As part of their study of leukocyte profiles of an iguanid species, Davis et al. (2011) reviewed several studies of white blood cell profiles of iguanids and other lizard species. They extracted data on the relative numbers of all cell types (mean percentages) and categorized the studies based on whether lizards were from captivity or the wild. They showed that all wild animals had higher $\mathrm{H} / \mathrm{L}$ ratios than the captive conspecifics. In fact, the relative abundance of lymphocytes and heterophils was completely opposite in both groups, with lymphocytes being the most abundant leukocyte type in captive lizards and heterophils being most common one in wild specimens. Thus, either wild lizards naturally have higher baseline stress levels (and thus higher $\mathrm{H} / \mathrm{L}$ ratios) than captive ones, or trapping of wild animals induced stress-related alterations in the animals' leukocyte profiles, a notion also supported by the elevated H/L ratios of the captive F. labordi in our study.

During a stress response, GC secretion increases partly to mobilize more metabolic energy to deal with the stressor. While this stress response provides obvious short-term benefits, chronic elevation of GCs is harmful (Sapolsky et al. 2000, Romero and Wikelski 2001, Romero and Wikelski 2002, Mc Ewen 2004,). In the present study, we observed stress-related changes in leukocyte profiles in both chameleon species, which may contribute to their rapid senescence after the reproductive season. Captive $F$. labordi showed comparatively lower, but in relation to other captive lizards, elevated H/L ratios (Davis et al. 2011), indicating that they perceived these captive conditions as mildly stressful, but that they were also buffered from major environmental stressors. It is possible that the brief biweekly handling to obtain blood samples might have contributed to the perceived stress level of caged individuals, but this manipulation did most likely not impact the measurements of $\mathrm{H} / \mathrm{L}$ ratios because such effects were found only after $12 \mathrm{~h}$ in other species (Davis et al. 2008). 
Any interpretation of the potential physiological effects of variable $\mathrm{H} / \mathrm{L}$ ratios should take into account that a review published after our field work found inconsistent relationships between GC profiles and leukocyte profiles across studies (Davis and Maney 2018). In gopher tortoises, Gopherus polyphemus, both GC levels and leucocyte profiles changed across seasons, but the changes were not correlated (Goessling et al. 2016). Moreover, in two studies of garter snakes, Thamnophis sirtalis, conducted by the same research group, but on different populations and in different years, one study revealed a positive correlation between GC levels and H/L ratio (Sparkman and Bronikowski 2014), whereas the other did not (Gangloff et al. 2017). Furthermore, the interpretation of leukocyte dynamics relies on baseline data for the taxon of interest (Davis and Maney 2018). Reports about leukocyte profiles in chameleons in the wild (Cuarando et al. 2002, Eshar et al. 2018) and captivity (Laube et al. 2016) are rare and based on relatively small sample sizes. Our study therefore contributes valuable comparative data based on large samples of two wild chameleon species, but future studies may want to assess stress levels more directly, e.g. by measuring GC levels from fecal samples.

\section{Telomere dynamics}

Telomere dynamics differed between the two chameleon species. Telomeres were relatively longer in $F$. cf. nicosiai, but shortened rapidly with the disappearance of the adult cohort. In contrast, the telomeres of $F$. labordi were relatively short, but a deterioration over time was not detectable. The first three months in the life of $F$. labordi are characterized by fast growth rates, whereas juvenile $F$. cf. nicosiai show much slower growth and reach maturity at an age of $11-$ 12 months (Eckhardt et al. 2019a). The lifespan of F. cf. nicosiai is longer, but both species mate at the same time and die off afterwards. A study of wild jackdaws (Corvus monedula) revealed that long telomeres shorten more rapidly than short ones, regardless of the individual's age (Salomons et al. 2009). Additionally, telomere degradation was highest in humans with long telomeres (Nordfjäll et al. 2009). These studies suggest that mechanisms for telomere maintenance exist in vivo, which potentially protect the shortest telomeres from further attrition and might explain why we could not detect any significant TL reduction in F. labordi. It would therefore seem interesting to also examine telomerase activity in these species. In ectothermic vertebrates, the expression of telomerase is frequently found in somatic tissues and is thought to be due to the indeterminate growth (Gomes et al. 2010). Thus, regulation by this enzyme might enable $F$. labordi to maintain its TL up to a certain level.

Whether TL is a universal predictor of longevity is still up for debate. Whittemore et al. (2019) found that the telomere shortening rate, but not the initial telomere length alone, is a 
powerful predictor of life span in several bird and mammal species. These results support the notion that critical telomere shortening and the consequent onset of telomeric DNA damage and cellular senescence are a general determinant of species life span. In humans, telomere attrition is also more rapid in the first decade of life, stabilizes in adulthood and is followed by a gradual loss at old age (Frenck et al. 1998). We could not study telomere dynamics because of low recapture rates and a lack of data on juveniles, but a relatively large male juvenile $F$. cf. nicosiai was sampled at approx. 4 months of age and showed a rTL of 3.44, which was the highest measured in this species. In contrast, TL of hatchling pythons (Lisais fuscus) was significantly shorter than that of older snakes, increasing during their first year of life and subsequently decreasing with age (Ujvari et al. 2009). Similar curvilinear telomere dynamics were found in frilled-necked lizards (Chlamydosaurus kingii) (Ujvari et al. 2017).

In $F$. cf. nicosiai, we also observed sexual dimorphism in telomere length across the sampling period, with females having longer average telomeres. The associated longer female survival may be adaptive as the maturation of eggs after insemination takes several weeks, and female chameleons are capable of producing additional clutches from stored sperm (Tolley et al. 2014, FE pers. observation). In several other species, including sand lizards (Lacerta agilis) (Olsson et al. 2011), Medaka fish (Gopolakrishnan et al. 2013) and humans (Gomes et al. 2010), females also live longer and have longer telomeres. The actual mechanisms contributing to sexspecific telomere patterns are unknown, however. Previous work on humans suggested that the difference in TL stems from larger body mass in men compared to women (Seluanov et al. 2007), leading to the assumption that larger bodies require more tissue growth and cell division. However, female sand lizards are larger than males (Gullberg et al. 1997) and have longer telomeres. Gopalakrishnan et al. (2013) postulated that estrogen is a key factor contributing to the decelerated telomere shortening in female Medaka fish, but corresponding data from other species are lacking. Thus, telomere attrition probably depends on multiple factors that remain to be identified.

Nowadays, telomere attrition is widely recognized as one of the hallmarks of aging (e.g. Lopez-Otin et al. 2013), and telomeric assessments are widely used in evolutionary biology as biomarkers of somatic integrity. However, limited attention has been paid to addressing the fundamental question raised by these relationships: Which role do telomeres play in shaping the evolution of life-history trade-offs and senescence (Young 2018)? While it is broadly accepted that telomere degradation can have causal effects on cell fates, the extent to which it contributes to age-related declines on organismal level is less clear. A proximate causal role for 
telomeres would more possibly reflect an adaptive strategy, born out of telomere maintenance costs and/or a function for telomere attrition (e.g. in counteracting cancer), the relative importance of which is currently unclear. Nevertheless, it is frequently mentioned that telomere length as a predictor of overall health could instead reflect it acting as a non-causal biomarker of accumulated damage to other biological structures that themselves have causal deleterious effects on the organismal performance (e.g. Simons 2015). While it is mechanistically conceivable that telomere dynamics are one proximate cause of current-future trade-offs and senescence, whether telomeres play a significant proximate causal role relative to alternative mechanisms, such as oxidative damage to other biological structures, is currently uncertain (Young 2018). Finally, advances in understanding of the selection pressures that might have shaped a proximate causal role for telomeres according to life-history trade-offs have the potential to shed light on the nature of the evolutionary restrictions at play in life-history evolution and help explain the form of the current-future trade-offs and ageing trajectories (Young 2018).

\section{Stress-related leukocyte profiles and telomere shortening}

In both species, we found a negative correlation between average $\mathrm{H} / \mathrm{L}$ ratio and TL. Chronical stress has potentially negative consequence through an increase in oxidative damage (Agostinho et al. 2010, Constantini et al. 2011) and ultimately telomere shortening (Wang et al. 2010). Oxidative stress also dramatically decreases telomerase activity (Borrás et al. 2004, Kurz et al. 2004). Therefore, oxidative stress not only accelerates telomere shortening by direct damage to telomeres, but also by inhibiting telomere restoration as well. Even though we are well aware of the correlational nature of our study, we suggest that physiological stress negatively affected TL in our two study species. Although our findings and additional studies suggest a strong association between stress and telomere shortening (Haussmann et al. 2011, Quirici et al. 2016), we cannot discard other mechanisms that could affect TL, like alterations of early growth rates (e.g. Schultner et al. 2014). More direct future studies should acknowledge that the link between stress response and telomere degradation is probably not straightforward and depends on the benefits and costs of activating an emergency life-history state that is species- and context-dependent.

At an ultimate level, rates of extrinsic mortality are thought to determine where a species falls on the slow-fast continuum, with high rates of extrinsic mortality selecting for fast lifehistories (Williams 1957). The results of our previous capture-mark-recapture study (Eckhardt et al. 2019a) also suggest that extrinsic mortality rates in both chameleon species are 
presumably high in adults. Williams also postulated that juvenile mortality has no influence on the evolution of senescence; predicting that senescence should be associated with extrinsic mortality rates (Williams 1957). However, formal, mathematical theory (Abrams 1993, Caswell 2007, Wensink et al. 2017) showed that this particular prediction is wrong. Accordingly, selection leading to senescence does not directly depend on survival to old age, but rather on the shape of the stable age distribution. The aim of evolutionary theories of aging is to clarify why organismal fitness mechanisms decline with age. Moorad et al. (Moorad et al. 2019) therefore proposed to investigate the actual phenomenon of aging, not its proxies. More theory and careful physiological measurements from many species under many different environmental conditions are therefore required to further illuminate factors that shape lifehistories. Remarkably, Reznick and colleagues (2004) even found that guppies (Poecilia reticulata) derived from natural populations with high levels of predation live the longest in the laboratory. This study demonstrates that our understanding of the evolution of senescence will profit from modeling numerous aging parameters, traits other than age at death as well as the causes of mortality.

Although there are many examples of negative correlations between lifespan and the apparent extrinsic risk of death faced by organisms, this risk is more often deduced than measured. In our study species, besides extrinsic mortality at old age, several factors might impact the short lifespan of this species. High juvenile mortality in F. labordi might lead to the extremely high investment in reproduction that in turn facilitates the pronounced stress response and relatively short telomeres. As physiological stress also has a strong influence on immune responses (Padgett and Glaser 2003), the increasing gastrointestinal - and blood parasite burden observed in both species in the wild towards the dry season (Eckhardt et al. 2019b) might reflect an unavoidable consequence of this adaptation. This notion about the physiological processes contributing to such a short life span in F. labordi is also supported by a maximum lifespan in caged individuals of 16 months, indicating that their lifetime is indeed bounded by molecular and cellular mechanisms of aging.

\section{Conclusions}

The results of our study provide rare information about leukocyte profiles and telomere dynamics in relation to senescence and mortality patterns of two chameleon species in the wild. The results of this study suggest that the presumably energetically demanding reproductive season in the short-lived species contributes to environmental stress ensued by increased oxidative damage and subsequent accelerated telomere shortening. To fully understand 
telomere dynamics and their relation to stress-related measures $(\mathrm{H} / \mathrm{L}$ profiles) in these species, repeated samples from wild specimens and samples from younger life stages are necessary, however.

Tab. 9: Parameters of the LM on the influence on $\mathrm{H} / \mathrm{L}$ ratio

\begin{tabular}{|c|c|c|c|c|c|c|c|}
\hline Fixed Effects & Estimate & SE & t-value & $\mathbf{P}$ & $\mathbf{F}$ & df & $\mathbf{P}$ \\
\hline (Intercept) & 1.974 & 0.095 & 20.766 & $<0.001$ & \multirow[t]{6}{*}{25.64} & \multirow[t]{6}{*}{400} & \multirow[t]{6}{*}{$<0.001$} \\
\hline March & 0.325 & 0.105 & 3.093 & $<0.01$ & & & \\
\hline April & 0.374 & 0.119 & 3.140 & $<0.01$ & & & \\
\hline May & 0.735 & 0.139 & 5.366 & $<0.001$ & & & \\
\hline Sex: male & 0.356 & 0.087 & 4.102 & $<0.001$ & & & \\
\hline $\begin{array}{l}\text { Species: } \\
F \text {. cf. nicosiai }\end{array}$ & -1.022 & 0.103 & -9.921 & $<0.001$ & & & \\
\hline
\end{tabular}

Tab. 10: Parameters of the LMM on $\mathrm{H} / \mathrm{L}$ ratio in captive $F$. labordi

\begin{tabular}{|c|c|c|c|c|c|c|c|c|}
\hline Fixed effects & Estimate & SE & df & t-value & $\mathbf{P}$ & $\chi^{2}$ & df & $\mathbf{P}$ \\
\hline (Intercept) & 1.185647 & 0.056175 & 163.3084 & 21.10641 & $<0.001$ & \multirow[t]{6}{*}{33.75} & \multirow[t]{6}{*}{5} & \multirow[t]{6}{*}{$<0.001$} \\
\hline sex: male & -0.00934 & 0.041367 & 33.16293 & -0.22582 & 0.822726 & & & \\
\hline March & 0.222828 & 0.075443 & 239.0659 & 2.95359 & $<0.01$ & & & \\
\hline April & 0.192228 & 0.079707 & 238.8112 & 2.411677 & $<0.05$ & & & \\
\hline May & 0.39695 & 0,072926 & 243.9702 & 5.443204 & $<0.001$ & & & \\
\hline June & 0.295445 & 0.059703 & 175.842 & 4.948552 & $<0.001$ & & & \\
\hline
\end{tabular}

Tab. 11: Parameters of the LM on the telomere length of $F$. labordi and $F$. cf. nicosiai

\begin{tabular}{|c|c|c|c|c|c|c|c|}
\hline Fixed effects & Estimate & SE & t-value & $\mathbf{P}$ & $\mathbf{F}$ & df & $\mathbf{P}$ \\
\hline Intercept & 0.8249 & 0.1162 & 7.100 & $<0.001$ & \multirow[t]{8}{*}{25.67} & \multirow[t]{8}{*}{80} & \multirow[t]{8}{*}{$<0.001$} \\
\hline $\begin{array}{l}\text { Species } F \text {. cf. } \\
\text { nicosiai }\end{array}$ & 1.3070 & 0.1660 & 7.871 & $<0.001$ & & & \\
\hline April & -0.1001 & 0.1291 & -0.775 & 0.441 & & & \\
\hline May & -0.1343 & 0.1229 & -1.092 & 0.278 & & & \\
\hline sex male & -0.1015 & 0.1055 & -0.962 & 0.339 & & & \\
\hline $\begin{array}{l}\text { species F. cf. } \\
\text { nicosiai April }\end{array}$ & -0.3844 & 0.2378 & -1.616 & 0.11 & & & \\
\hline $\begin{array}{l}\text { species } F \text {. cf. } \\
\text { nicosiai May }\end{array}$ & -0.5464 & 0.2001 & -2.731 & $<0.01$ & & & \\
\hline $\begin{array}{l}\text { Species } F \text {. cf. } \\
\text { nicosiai sex } \\
\text { male }\end{array}$ & -0.5176 & 0.1773 & -2.919 & $<0.01$ & & & \\
\hline
\end{tabular}




\section{Chapter 6: General Discussion}

The aim of this thesis was to disentangle the extrinsic and intrinsic mechanisms shaping the short life-history of the annual chameleon F. labordi. I aimed to shed light on the ultimate and proximate factors by examining a wild population of $F$. labordi and compared my findings to captive specimens. Moreover, I related my findings with the sympatric and longer living $F$. cf. nicosiai. Besides the assessment of differences in life-histories, the interspecific comparison was applied to investigate if changes might be age-dependent or seasonally influenced. In the previous chapters, I have presented original research on the internal and environmental mechanisms influencing the lifespan of $F$. labordi and the congeneric species $F$. cf. nicosiai. In this chapter, I will discuss the external drivers of the disappearance of F. labordi in the wild by comparing two populations from different habitats and vegetation periods as well as the results from the experimental housing of this species. Additionally, I will consider intersexual variations in life-history and lifespan. Moreover, I will contrast the wild living F. labordi with the caged ones regarding lifespan and discuss the differences. Subsequently, I will summarize the interspecific differences in life-history concerning the comparison with the congeneric species. In this context, I will discuss the factors favouring the evolution of relatively fast lifehistories found in chameleons in general. Furthermore, I will outline the examined intrinsic factors driving senescence in F. labordi and consider their interplay. Finally, I will propose future research suggestions to better understand the causes and consequences of aging in the study species and reptiles as a group.

\section{Intraspecific, interannual and intersexual differences in lifespan in $F$. labordi in the wild}

I found considerable variability in the life-history of $F$. labordi between the population in the southern and drier habitat (Ranobe) and northern and wetter part of their distribution range (Kirindy) that was attributed to more extensive precipitation (Chapter 2). In addition, both populations differ considerably in different aspects. In Kirindy, males were considerably larger compared to the population in Ranobe. Moreover, females in Kirindy seemed to be capable of producing at least two clutches and are therefore not strictly semelparous, whereas females in Ranobe seemed to be restricted to a single clutch (Karsten et al. 2008). In addition, probably due to the longer active season, animals in Kirindy required more time to reach sexual maturity. 
In total, the observed differences between both populations can be ascribed to ecological differences in their habitat, suggesting that the life-history is to some degree variable and not fully programmed. Furthermore, the slower growth rates that I observed in Kirindy probably lead to a comparatively decelerated shortening of the telomeres and might in turn facilitate the longer lifespan is this population. Interestingly, Karsten et al. (2008) reported that they found several obviously weak individuals and unmutilated dead bodies in the wild. I rarely observed dead weak animals or dead bodies in the wild. Only one male was so weak that he fell down from a branch. Considering the high differences in sample size of adult individuals of both populations, animals from Ranobe seem to suffer from high senescent declines, whereas geriatric animals were rarely found in Kirindy. These observations indicate that F. labordi in Kirindy may suffer from substantially higher predation rates concealing apparent senescent declines. This could be attributed to the different types of habitats both populations live in. Ranobe is a spiny forest with a sand substrate, and vegetation that usually does not exceed $3 \mathrm{~m}$ in height except for occasional trees that may reach up to $10 \mathrm{~m}$ in height (Vose et al. 1992). In contrast, whereas the Kirindy forest is characterized by rather dense vegetation and in average higher trees (Zinner et al. 2014). Therefore, the number of predators such as snakes and birds might be considerably higher as this forest might inhabit more species or specimens that feed on chameleons. Here, predators might directly eliminate individuals with slight senescent declines. Moreover, Karsten et al. (2008) also observed negative growth in some adult individuals towards the dry season, whereas specimens in Kirindy showed indeterminate growth until their disappearance. Interestingly, also chameleon species composition differs between both habitats. While $F$. labordi lives sympatrically with $F$. verrucosus in Rabobe (Karsten et al. 2008). The latter species has never been observed within the Kirindy forest, but frequently in degraded forest fragments and scrubland nearby villages in the region. Here, $F$. verrucosus is living sympatrically with the smaller sized $F$. viridis, which seems to have an annual cycle as well (pers. observation).

Furthermore, I found that the lifespan of $F$. labordi could vary significantly between years depending on the rainy season. After an unusually long previous rainy season in 2015, both sexes survived considerably longer and one female was capable of surviving until a second breeding season. Thus, in rare cases, a very small proportion of adult females may survive the dry season under favourable environmental conditions, and they may even enter the next reproductive season. These results indicate that the lifespan of this species highly depends on precipitation pattern and vegetation period. The climate of Madagascar is highly variable (Dewar and Richard 2007). In response to high climate fluctuations, many mammals of 
Madagascar differ from relatives in more stable environments in that the Malagasy species exhibit more extreme versions of both "short-lived" and "long-lived" life-histories (Dewar and Richard 2007).

The short life-history of $F$. labordi seemingly has a strong influence on intra- and intersexual selection. Karsten et al. (2009b) showed that potentially receptive females were selective according to the male's body size and size corrected rostral width. Males used their rostral appendages during courtship encounters in which they tried to persuade resistant females to permit copulation. Here, broader rostral appendages may be beneficial if females use the amount of pressure applied by the male as a possible indication for male physical performance in assessing suitable mates. Concerning intrasexual selection, game theory predicts that more size-matched rivals should have more intense physical encounters (Earley and Dugatkin 2002). Indeed, Karsten and colleagues (2009a) found that during male-male contests, the more naturally size-matched $F$. labordi had much more physically intense encounters than $F$. verrucosus where males were less equally sized. Interestingly, during male-male combats, the shape of the rostral appendage does not seem to influence the outcome of the fight. Within males, intrasexual selection seems to be restricted to body size and casque height. Therefore, males should invest highly in growth. Growth rates in males are extreme as males can potentially increase body size from hatchling to adult by $300-400 \%$ in two to three months (Karsten et al. 2009a, Eckhardt et al. 2019a). The strong allocation to growth by males in many species might result in decreased somatic maintenance and earlier respectively faster aging (Kirkwood and Rose 1991), which increases the magnitude of the sex gap in aging in favouring females. The hormonal regulation associated with growing and maintenance of secondary sexual traits as found in male $F$. labordi is likely to have far-reaching deleterious effects on their adult survival. Furthermore, the extensive male allocation to specific sexual traits (e.g., large body mass or conspicuous ornaments [e.g. Weckerly 1998, Emlen 2008]) is assumed as energetically costly (Kotiaho 2001). As predicted by recent evolutionary theories of aging (e.g., disposable soma theory, [Kirkwood and Rose 1991]), the stronger reproductive expenses by males during the onset of reproduction might be costly in terms of aging (Lemaitre et al. 2015). For example, in most sexually dimorphic and polygynous mammal species, males grow faster and larger than females because attaining a large body rapidly can be advantageous to increase access to mating opportunities (Dmitriew 2011). On the other hand, rapid growth is associated with many physiological costs (e.g. increased oxidative damage and faster speed of telomere attrition (Geiger et al. 2012), steeper rate of body mass decline with increasing age, (Douhard et al. 2017), possibly resulting in higher mortality rates in adult males (Metcalfe and 
Monanghan 2003). In addition, testosterone that controls the development of many sexual traits in males is likely to have a negative effect on some aspects of biological performance, such as immunocompetence (Foo et al. 2017).

The costs of sexual selection and sexual dimorphism has long been considered the best explanation for the observed sex gap in senescence. Recent data suggests that sex chromosomes may play an important role in shaping the sex gape. This is mostly true in species, such as monogamous birds, with no or very little sexual dimorphism, which display some sex gap in aging and longevity. Consequently, it is currently unclear what the underlying mechanisms are. Within their review on studies of wild tetrapod species, Pipoly et al. (2015) found that taxa with female heterogamety had a significantly more male biased adult sex ratio compared to taxa with male heterogamety. Mammals are fixed for the XX/XY type with male heterogamety, whereas birds are fixed for the ZZ/ZW type with female heterogamety. Among reptiles and amphibians both patterns occur. The type of genetic sex determination explains up to $36 \%$ of variance in adult sex ratio in reptiles, and $76.5 \%$ of species exhibiting the ZZ/ZW type showed male biased adult sex ratio whereas it was $24.2 \%$ in the species with the XX/XY type (Pipoly et al. 2015). Recently, the chameleon genus Furcifer was found to have female heterogamety (Ravatsos et al. 2015). Controversially to the assumption of male bias in adult survival, I detected a female bias in wild F. labordi as well as $F$. cf. nicosiai, indicating that several additional factors in these species might lead to the observed pattern.

\section{Lifespan of $F$. labordi in captivity}

By keeping specimens in captivity, I found that both sexes lived comparatively longer compared to their wild conspecifics (Chapter 2). Again, these findings indicate that the short lifespan in the species is not fully programmed and depends on several extrinsic factors of mortality such as predation, food, water availability, encounter rate with parasites, and exhaustion from reproduction. Interestingly, in captivity, I found no significant difference in longevity between both sexes. This leads to the assumption that faster growth and higher testosterone levels alone might not be solely responsible for the faster die-off in males in the wild. Similar results were found in mouse lemurs Microcebus murinus, where survival in the wild was strongly femalebiased (Kraus et al. 2008, Languille et al. 2012), whereas males in captivity exhibited longer lifespans (Perret 1997). Probably, male behaviour that is influenced by testosterone leads to the shorter lifespan we observed in nature. However, I did not measure testosterone levels and captive males might have considerably lower levels as they were shielded from intraspecific 
encounters. A comparative study in captivity using normal and castrated males may disentangle the direct effect of testosterone on the lifespan. Nevertheless, captive males might have comparatively lower testosterone levels as they were visually shielded from male as well as female conspecifics. Anecdotal reports from some lizard species in zoos indicate that the visual absence of other males lowers their display behaviour towards females (e.g. Petr Kodym, pers. comm.). Therefore, the influence of lower testosterone levels on the extended lifespan of males in captivity cannot be excluded. Roaming and fighting for females probably involves an increased risk of predation and pathogen encounters in the wild. In general, F. labordi males tended to be much more aggressive and exhibited fatal injuries resulting from intrasexual competition compared to the larger and longer living Furcifer species in Kirindy (pers. observation). Similarly, Karsten and colleagues (2009b) found that F. labordi showed higher aggression and had higher graded antagonism scores per trial during male-male encounters than did the larger sized $F$. verrucosus. These observations imply that male $F$. labordi are high in testosterone levels most likely resulting in increased risky behaviours. Ultimately, their low probability of survival and relatively high densities during mating season might have led to an increased enhancement of testosterone.

By indirectly examining stress hormone levels via $\mathrm{H} / \mathrm{L}$ ratio, captive specimens showed lower H/L ratios (Chapter 5) probably resulting from lower physiological stress compared to the wild living ones (Eckhardt et al. 2020). Moreover, the extenuated encounter rate with parasites might have additionally contributed to their longer lifespan in captivity (Chapter 4). Overall, as several factors of extrinsic mortality were excluded in captivity, I can only speculate which factors are essentially responsible for the shorter life expectancy in nature. Finally, the conduction of cage experiments with a controlled manipulation of single factors such as visibility of conspecifics or parasite burden could clarify the direct influence of these effects on the lifespan of this species.

\section{Interspecific comparison and life-histories of chameleons}

While comparing the life-histories of $F$. labordi with these of the $F$. cf. nicosiai and $F$. oustaleti (Chapter 3), I found that all three species differed in hatching time, growth rates, body size at maturity, recapture rates and roosting heights suggesting some interspecific niche segregation among the species. Long-term ecological studies on chameleon communities are scarce. Although Karsten et al. (2008) indicates synchronous hatching of F. labordi and F. verrucosus in Ranobe, a detailed look at the data shows that the cohort hatchlings in $F$. verrucosus emerges 
after the one of F. labordi. Therefore, interspecific time shifts in the period of hatching and other ecological determinants might occur more often within sympatric chameleon species. Giving the lack of ecological studies within this lizard family, additional research is necessary to unravel the factors regulating the coexistence of sympatric chameleon species. Notably, the study of Luiselli (2007) revealed that chameleon communities are not randomly organized, but instead show precise deterministic patterns. In lowland rainforest, chameleon communities are arranged deterministically along the food niche resource axis, but not along the habitat niche resource axis. The opposite holds for chameleon communities inhabiting montane rainforests. As chameleons inhabit various habitats (e.g. dry forests, heathers etc.), additional research is required to understand the composition of chameleon communities in detail. However, my findings indicate, that species in the Kirindy forest might be assembled both, along the food niche and habitat niche resource axis.

Interestingly, I found that $F$. cf. nicosiai and $F$. oustaleti exhibited unexpectedly short lifespans as well. Only $F$. oustaleti, the largest of all three species, and one of the world's largest chameleons, seemed to be at least temporary perennial. Publications on life-histories of chameleons in nature are rare, but available studies suggest that chameleons show rather short lifespans in nature (Andreone et al. 2005, Karsten et al. 2008, Tolley et al. 2010). In general, compared to other lizards of comparable size, chameleons seem to have remarkably shorter lifespans. Also in captivity, chameleons show relatively short lifespans and high mortality rates that is probably due to their naturally fast life-histories (Robinson et al. 2016). An important variable of the life-history is age at maturity, which in lizards is generally positively correlated with body size (Meiri et al. 2012). However, such as F. labordi, several medium-sized Malagasy chameleons from the genus Furcifer (e.g. F. lateralis) are known to reach maturity within one season (Raselimanana and Rakotomalala 2003), suggesting a short lifespan in these species as well. Within captivity, the maximum documented lifespan of $F$. lateralis was approx. five years, while their lifespan in captivity typically ranges from two to three years (Gehring 2008). Moreover, indicative of fast life-histories, compared to many other similar-sized lizard taxa, chameleons have the largest clutch sizes and are among the most productive ones (Meiri et al. 2012). Interestingly, large clutch volumes and high relative clutch mass have mainly been documented in reptiles with cryptic behaviour, where the probability of escaping predators does not depend on rapid movements (Vitt and Price 1982).

The short documented life-histories in chameleons might be partially due to their inability to store enough fat reserves to endure energy-demanding periods such as the mating 
season or aestivation. As most chameleons have a laterally compressed body and depend on their ability to hide behind branches, the storage of fat reserves might be disadvantageous in terms of predation avoidance. In contrast to many other lizards, chameleons are not able to store fat in their tails (Pond 1978). Since chameleons highly rely on camouflage, but are the slowest of all lizards (Abu-Ghalyun 1988), their probability of escaping after the detection of a predator is relatively low. Their specialization for grasping is, thought to exhibit a trade-off with running ability. Ultimately, the inability to store fat to endure strenuous periods combined with the reduced possibility of survival after being detected by a predator might have selected for fast live cycles. The restricted time and probability of reproduction may also have driven the often mentioned high aggression in males (e.g. Nečas 1999, Karsten et al. 2009a), probably resulting in intense intrasexual selection in this group. Especially males offer large casques that are a good indicator of bite force as individual bearing higher heads probably have more jaw musculature, and in some species, casque height is positively correlated with fighting outcome (Stuart-Fox et al. 2006). Furthermore, chameleons possess an acrodont dentation. In squamates, this kind of dentation is found in chameleons and agamid lizards. Acrodont teeth are superficially attached to the tooth-bearing bone and teeth are worn down with age. With the exception of chameleons, most acrodontic species also have a number of conical pleurodont (teeth that are replaced throughout life) in the rostral-most portion of the upper and lower jaws (e.g. Cooper et al. 1970). Tooth erosion is a frequent hallmark of aging among different organisms, particularly in mammals (Finch 1990). The fact that chameleons have no replaceable but easily wear off teeth shows again that they are physically not adapted for long lifespans. Actually, especially males of all three Furcifer species from Kirindy showed worn teeth towards the end of the mating season (personal observation).

According to their study of ecological drivers of longevity in squamates and tuataras, Scharf et al. (2015) documented that besides age at maturity, hatchling size is positively correlated with longevity. The three Furcifer species in Kirindy exhibited similar body size (2.5 - $3.0 \mathrm{~cm}$ ) (Chapter 3), which is comparatively small compared to similar-sized lizards, predicting short life-histories in this species. They also found that carnivorous species were shorter living than omnivorous or herbivorous species of similar size. These findings are explained by the assumption that carnivorous animals may be faster growing, become injured while pursuing prey, and are more likely to acquire parasites through their diet. According to the aging theory, this leads to reduced longevity in carnivorous species (Huges and Raynolds 2005). Chameleons are predominantly feeding on invertebrates and rarely digest plant matter (Tolley and Herrel 2013), which in turn may contribute to their short life-histories. In total, their 
high morphological specialization to the cryptic and prominently vegetation but not shelter associated live style as well as the obvious specialization to feed on mobile food via the projectile tongue have ultimately selected for fast live histories. Thus, their short lifespans leading to high investment in growth, reproduction, and low investment in self-maintenance, as for instance, seen in their incapability to replace lost or wear off teeth.

Chameleons are a young clade of lizards, dating back to the onset of the Cenozoic, whereas most other lizards are much older (Tolley and Herrel 2013). Despite their young age, there are more than 210 described chameleon species and when considering the age of this clade, the number of species is relatively high compared to other lizard families. It seems that the diversification of this family is linked to their invasion of the arboreal habitats some 45 million years ago (Herrel and Tolley 2013). Lastly, their specialization might have driven a high species diversity that is in turn accompanied with fast life-histories. Actually, their short lifespans presumably facilitated species divergence due to shorter generation times. In addition, probably because of their life-history, several chameleon species demonstrated to be successful invasive species when escaping into suitable environments (e.g. Chiaverano et al. 2014, Smith et al. 2016).

Conversely, a recent study in one of the largest chameleon species, Calumma parsonii based on skeletochronology of preserved specimens revealed that the highest minimum age was nine years for a male and eight years for a female, affirming a considerably longer lifespan (Tessa et al. 2017). This species takes 3 to 5 years to reach maturity (Brady and Griffiths 1999) and occurs in rainforests where environmental conditions are comparatively stable, which might explain the slower life-history compared to the ones reported here. Besides $C$. parsonii, some other relatively large rainforest dwelling congeners (e.g. C. globifer, C. ambreense, and C. oushaugnessyi) exist that might have comparable longer lifespans in nature. Life-history studies, including small-sized genera such as Brookesia are absent. Regarding my personal observation in the Kirindy forest, Bookesia brygooi exhibited high fluctuations in population densities concerning differences in rainy seasons. From the onset of the dry season, no specimens were observed. The small amount of eggs per clutch (2 - 5) and their relatively short incubation period (Glaw and Vences 2007) indicates that there are overlapping generations, at least within their active period. However, concerning the lack of long-term studies in chameleons, further examinations are necessary to evaluate differences in life-histories originating from seasonal or more stable habitats. In general, high temperatures should lead to high metabolic rates, and therefore to a fast rate of living that could shorten lifespan (Sohal 
1986) predicting that montane species might be longer living. Interestingly, on the African mainland but not Madagascar, viviparity has evolved in several chameleon clades (e.g. Huges and Blackburn 2019), and most viviparous species are associated with high elevation grasslands and heathers. It would be interesting to investigate if reproduction biology has an influence on the life-history and lifespan in chameleons. In summary, most chameleon species seem to be rather short living and the notorious rapid death of captivity probably represent the natural adult lifespan. Consequently, a new assessment may be necessary concerning the viability of chameleon conservation and breeding programs. Especially chameleons with annual lifehistory traits linked to particular climate events such as the onset of the rainy season may suffer from unexpected extreme weather conditions caused by climate change.

\section{Intrinsic mechanisms of senescence in $F$. labordi}

High extrinsic mortality rates are known to select for early reproduction, placing animals under additional physiological stress that can, in turn, increase intrinsic mortality (Quinlan 2010). Glucocorticoids are known to suppress maturation, differentiation, and proliferation of all kinds of immune cells (Sternberg 2006), and even activate apoptosis in immature T and B cells and mature T cells (Sapolsky et al. 2000). This is measurable both in the decreasing number of some classes of immune cells, especially the T - and B - cells of the adaptive immune system. On the other hand, proinflammmatory cytokines are increasingly produced. This has led to the word "inflammaging", pronouncing the close connection between aging and inflammatory processes. Reasons for the low number and performance of B - and T lymphocytes are likely to be caused by the proliferative senescence of stem cell production in the bone marrow due to telomere shortening. These changes in the immune system increase the susceptibility to infections (Rensing and Rippe 2013). Among the T-lymphocytes, the T-helper cells from the type Th2 are involved in parasite resistance (Malaguanera et al. 2001). Tissue destruction is often caused by parasites and Th2 cell-mediated immunity evolved as an adaptive mechanisms of tissue repair that quickly heals wounds they cause (Allen and Wynn 2011). In F. labordi and F. cf. nicosiai I found that the prevalence of gastrointestinal- and blood parasites highly increased towards the end of the reproductive season, indicating a down-regulation of the adaptive immune system in both species. The examination of fecal samples indicates that $F$. cf. nicosiai invests into an adaptive immune system and therefore self-maintenance in the younger stages. In wild $F$. labordi and F. cf. nicosiai, I observed continuously elevated H/L ratios that most likely contribute to the increasing gastrointestinal - and blood parasite burden. Overall, the results of 
Chapter 4 and Chapter 5 indicate that elevated GC levels of wild F. labordi and F. cf. nicosiai may lead to accelerated telomere shortening and thereby a downregulation of the immune system (Eckhardt et al. 2020). However, the parasite burden observed in fecal and blood samples revealed the combined outcome of several factors: the parasites encountered by the host, when the parasite matured and reproduced within the host, and how effective the host's immune system was in preventing or eradicating the infection. While it is problematic to disentangle these factors, I found males having higher parasite infection rates than females. Moreover, older animals suffered from higher parasite burden, suggesting a downregulation of the acquired immunity in both species. Finally, the conduction of cage experiments, including both species and sexes with a controlled manipulation of parasite burden, could clarify the direct influence of the effect of parasites on the lifespan of both species.

Cellular proliferation is a key factor of an effective adaptive immune system. Thus, the role of telomeres in leukocytes, especially in lymphocytes, is of great interest (Weng 2008). Short telomeres of leukocytes have also been associated with several immune-related diseases (Andrews et al. 2010). The relatively short TL in F. labordi and the rapidly decreasing TL in F. cf. nicosiai might be connected with the increased burden of gastrointestinal - and blood parasites that I found towards the dry season in both species. In turn, the presence of pathogens was linked to accelerated telomere loss in mice (Ilmonen et al. 2008) and birds (Ashgar et al. 2015), which might also lead to a shortened lifespan in the two wild living chameleon species. Especially the presence of blood parasites might negatively affect the TL of both chameleon species as it was detected in birds (Ashgar et al. 2015). In particular, the prevalence of filarial infection was high in F. cf. nicosiai, which may have contributed to the accelerated telomere loss in this species.

Both in the wild and captivity, the accumulation of molecular and cellular damage would be expected to lead to physiological and physical deterioration at old age. However, the level of deterioration may be influenced by factors such as resource availability and lifelong tradeoffs among growth, reproduction and somatic maintenance. In the comparative study, F. labordi in captivity was significantly longer living than the wild conspecifics. However, the fact that the maximum age of a captive individual was 16 months indicates that intrinsic mechanisms play an essential role in the lifespan of $F$. labordi. Captive specimens showed comparably lower $\mathrm{H} / \mathrm{L}$ ratios and were, for the most part, shielded from the risk of parasitic infections. The documented average and maximum lifespan of the captive individuals (Chapter 2) suggests 
that besides elevated GC-levels and parasite infections, additional factors are jointly responsible for the short life expectancy in this species.

The vertebrate organism is highly complex, and no physiological parameter acts in isolation. Hence, measuring several different aspects of senescence can lead to a better understanding of organismal senescence (Burger and Promislow 2006, Nussey et al. 2008). One of the main problems in developing a coherent aging theory is unraveling causes from effects. Just because two processes parallel each other, we cannot postulate a causal relation in any direction. Therefore, it is challenging to predict which, if any, mechanistic theory of aging is correct. One approach to infer the impact on aging of the pathways described here is using a system-level methodology. By disturbing each component of a pathway under study and integrating the observed effects, it is likely to distinguish causes from effects and formulate new hypotheses (de Magalhaes and Toussaint 2004).

For F. labordi and chameleons in general, further insights of senescence could be gained via the study of e.g. body composition, sex hormone levels and further health indicators. Longitudinal studies of multiple indicators of physiological and physical functioning are required to resolve the significance and interplay of the different parameters. To determine which traits best influence the aging phenotype, further comparison and connections between the different components of health also warrant further studies. For example, parasite burden is a widely employed indicator of general health. While parasites may cause disease, it is also likely that bacterial or viral infections that could not be measured within this thesis are more direct mediators of morbidity and mortality than parasites alone. Especially in wild living males of $F$. labordi, the number of facial wounds was increasing towards the end of the reproductive season and often resulted in eye infections. Moreover, future studies would benefit from direct investigation of immune function, including markers representing the functioning of the different parameters of the immune system. Additionally, GCs were measured indirectly by the $\mathrm{H} / \mathrm{L}$ profiles of blood samples. The increase in heterophils is known to be connected with permanent physiological stress and might also be influenced by other factors such as infections and inflammations (Jain 1993, Campbell 1995, Rupley 1997, Thrall 2004). Therefore, a direct measurement of GCs could be advantageous to obtain, but difficulties according to direct measurements of baseline stress levels were already discussed in Chapter 5. Moreover, oxidative stress that is one of the most cited causes of aging (Sohal et al. 1996) would be an essential factor to quantify. In addition, testosterone levels, which may have sex-specific immunosuppressive effects, were interesting to examine regarding senescence in this species. 
In summary, there is a lot of potential work to shed light on the mechanisms behind the short lifespan of F. labordi. However, the analysis of most parameters requires blood samples and sometimes relatively large quantities. Specifically, in F. labordi the removal of blood was often difficult due to their small body size. Therefore, larger and additionally fast living chameleon species might be more suitable for these studies. Including larger chameleon species also gives the advantage that samples could be taken from younger stages, giving additional information about factors such as telomere dynamics during lifetime. Concerning standardized housing under laboratory conditions for aging studies, researchers should consider that most chameleon species have to be housed in single cages, have special requirements according to light, temperature, food and water supply and equipment of the enclosure. Thus, longitudinal studies in the laboratory will be time-consuming and costly.

Primarily, the congeneric and larger species $F$. cf. nicosiai was selected to compare aging mechanisms and examine if physiological alterations and parasite burden might be age intdependent or seasonally influenced. During my study period, this species appeared to be longer living, but their reproduction period is restricted to the rainy season, followed by senescent declines as well. In this species, slowly growing juveniles are the longest-lasting phase (approx. 10 months).

\section{Potential of aging research in reptiles}

Regarding vertebrates, most studies focusing on the relationship between lifespan and the related factors have been conducted on mammals and birds (e.g. Holmes et al. 2001, Wilkinson and South 2002, Brunet-Rossinni and Austad 2004, Speakman 2005, Turbill et al. 2011, Healy et al. 2014). This is probably due to the fact that the ecology and life-history of many reptiles makes them difficult to monitor in the wild (McDiarmid et al. 2012). Moreover, their husbandry is partially laborious and expensive. Therefore, reptiles are underutilized models in studying the evolution and mechanisms of senescence (Bronikowski 2008). Their special physiology, indeterminate growth, and often increasing female fecundity with proceeding age should motivate the investigation of how life-history at the organismal level, physiology at the mechanistic level, and natural selection at the evolutionary timescale define lifespan in this diverse taxonomic group.

Finch (1990) suggested that reptiles tend to show lower incidence and intensity of senescence than most mammals. However, some species show signs of aging comparable to 
what is documented in mammals (Majhi et al. 2000, Jena et al. 2002; Olsson and Shine 2002). Recently, reptiles were found to have three times more variation in life-history traits in comparison to mammals (Babich Morrow et al. 2019), indicating broad taxonomic divergence in aging phenotypes. Furthermore, a recent study of longevity in reptiles indicates that body mass explained little of the variance in reptile longevity, which is controversial to the findings in mammals (Stark et al. 2019). They explain this result by the assumption that reptiles as ectotherms are less affected by metabolic byproducts due to their lower metabolic rates. (e.g. Bronikowski and Vleck 2010). Intriguingly, several squamate species have tissue regenerative capacities that surpass those of mammals by far (e.g. Sun et al. 2018). Until now, there has been little consideration of how these regenerative capabilities impair the rate of aging in these species (Hoekstra et al. 2019). Therefore, it is highly possible that reptiles may feature various mechanisms to delay aging and age-related debilitation, making them an interesting model to study aging. Overall, comparisons among different animal taxa can yield insights into those mechanisms of aging that are fixed versus those that have evolved independently in different taxonomic lineages.

Interesting examples about divergence of aging mechanisms in this group are pythons Lisais fuscus (Ujvari and Madson 2009) and frilled-necked lizards Clamydosaurus kingii (Ujvari 2017), which were found to have curvilinear telomere dynamics. Furthermore, research of the European freshwater turtles Emys orbicularis did not exhibit reduction in TL during aging, which implies a control in TL by the expression of the telomerase in somatic stem cells of this species (Girondot and Garcia 1999). Moreover, in Alligator mississippiensis, an inverse relationship has been detected between TL and body length (Scott et al. 2006).

Chameleons are an interesting group to study mechanisms that are related with fast aging in reptiles. As mentioned in previous chapters, this lizard family is a rather fast-living taxon. A great advantage of these animals for studies in the wild is that population density is at least seasonally often very high, and they are easy to capture during night. However, regular repeated measurements in the wild might be difficult to achieve, as the recapture rate is often rather low. Furthermore, especially in smaller species and age stages obtaining adequate blood samples might be challenging.

Semelparity in reptiles has almost exclusively been detected in chameleons (e.g. Karsten et al. 2008, Eckhardt et al. 2017), agamids (Henle 1991, Dickman et al. 1999), and iguanid lizards (Rodríguez-Romero et al. 2011), which all assemble the squamate infraorder Iguania (Forst et al. 2001). Apart from this taxonomic group only tendencys for semelparity were 
observed in populations of the the viviparous asp viper Vipera aspis (Bonnet 2011). Therefore, semelparity in reptiles, respectively annual life-histories might be confined towards the infraorder Iguania. Typically, species belonging to this infraorder show high sexual dimorphism that is often accompanied with male ornamentations (e.g. Ord and Stuard-Fox 2006). Within this group, sexual dimorphism is highest compared to the remaining reptile taxa (Vitt and Caldwell 2013). Up to my knowledge, sexual dimorphism that is driven by sexual selection has never been considered in analysis about longevity in reptiles (e.g. Scharf et al. 2015, Stark et al. 2019), but should be included in future analysis. However, besides several short living species, several large-bodied species are known to reach lifespans of more than 20 years (e.g. rock iguanas Cyclura spp., Magelhaes and Costa 2009).

Besides the examination of aging mechanisms, the measurement of stress hormones, oxidative stress and telomere dynamics can additionally offer valuable clues for species conservation. For example, GC levels were found to predict survival probabilities of animals in the wild (e.g. Romero and Wikelski 2001). Furthermore, once the relationship between TL and the age has been well determined for a given species, it is possible to use blood samples to estimate the age of animals in nature (Haussmann and Vleck 2002). This might enable researchers to monitor populations regarding age structure relatively time-efficient.

\section{Conclusion}

In this thesis, I have provided rare information about extrinsic and intrinsic mechanisms shaping the life-history of the shortest living tetrapod species. I have demonstrated that the lifespan of this species is highly connected to environmental factors and, therefore, not exclusively inevitable. Via a comparative approach, I could provide rare data of the comparability of lifespan of both sexes of $F$. labordi in the wild and captivity. The results indicate that males as the shorter living sex in the wild, are capable of reaching comparable lifespans as captive females, when exogenous factors of mortality are excluded. Therefore, faster growth rates and higher testosterone levels in males that are often suspected to lead to intersexual differences in lifespan might play a subordinate role in this species. In this connection, the data of Chapter 4 and Chapter 5 suggest that physiological stress also has a strong influence on immune responses. The increasing gastrointestinal - and blood parasite burden observed in F. labordi in the wild towards the dry season might reflect an unavoidable consequence of their adaptation. The influence of physiological processes contributing to such a short lifespan in F. labordi is 
also supported by a maximum lifespan in caged individuals of 16 months, indicating that their lifetime is indeed bounded by molecular and cellular mechanisms of aging.

I discovered interspecific differences in several aspects of the three sympatric Furcifer species with seasonal adjustment that might be related to the partitioning of overall food availability and contributes valuable life-history data on enigmatic chameleon species. Additionally, I showed that the lifespan of $F$. labordi and $F$. cf. nicosiai usually ends after the reproductive season. Moreover, F. oustaleti as one of the largest chameleon species in the world, showed unregular survival until a second reproductive season. As discussed in the section "Interspecific comparison and life-histories in chameleons", the lizard family Chamaeleonidae seems to be the taxon exhibiting the fastest life-histories in reptiles. I have outlined the characteristics of chameleons such as the inability of fat storage and low escape probability after the detection of a predator that might favour fast life-histories. In this connection, I have discussed the advantages and disadvanages of this life-history. On the one hand, chameleons are a young but relatively species-rich clade. Their short generation times and numerous offspring might have facilitated species divergence. Additionally, probably because of their life-histories, several chameleon species are successful invasive species when escaping into suitable environment. On the other hand, short life-histories accompanied with investment in only one mating season might be disadvantageous in relation to harsh environmental inconsistancies. In case of repeated missing regional rainfalls that might arise more frequently in the nearer future due to climate change, annual chameleon species are in danger of extinction. Consequently, chameleon conservation and breeding programs should consider potentially short lifespans.

Overall, in my thesis I contributed valuable data about life-histories of chameleons in the wild. I have discussed the most likely explanations for my findings. The results of this thesis broaden the current knowledge of life-histories and aging in reptiles. Moreover, chameleons that rarely find consideration for studies regarding life-history and ecology became in this connection a better-studied group. 


\section{References}

Abrams, P.A. (1993). Does increased mortality favor the evolution of more rapid senescence?. Evolution, 47(3), 877-887.

Abu-Ghalyun, Y., Greenwald, L., Hetherington, T.E., Gaunt, A.S. (1988). The physiological basis of slow locomotion in chamaeleons. Journal for Experimental Zoology Part A, 245(3), 225-231.

Agostinho, P., Cunha R.A., Oliveira, C. (2010). Neuroinflammation, oxidative stress and the pathogenesis of Alzheimer's disease. Current Pharmaceutical Design, 16(25), 27662778 .

Akani, G.C., Ogbalu, O.K., Luiselli, L. (2001). Life-history and ecological distribution of chameleons (Reptilia, Chamaeleonidae) from the rain forests of Nigeria: conservation implications. Animal Biodiversity and Conservation, 24(2), 1-15.

Albright, J.W., Albright, J.F. (1994). Ageing alters the competence of the immune system to control parasitic infection. Immunology Letters, 40, 279-285.

Alexander, J., Stimson, W.H. (1988). Sex hormones and the course of parasitic infection. Parasitology Today, 4(7), 189-193.

Allen, J.E., Wynn, T.A. (2011). Evolution of Th2 immunity: a rapid repair response to tissue destructive pathogens. PloS Pathogens, 7(5), e1002003.9.

Altmann, J., Gesquiere, L., Galbany, J., Onyango, P.O., Alberts, S.C. (2010). Life history context of reproductive aging in a wild primate model. Annals of the New York Academy of Sciences, 1204, 127.

Andrews, R.M., Donoghue, S. (2004). Effects of temperature and moisture on embryonic diapause of the veiled chameleon (Chamaeleo calyptratus). Journal. of Experimental Zoology Part A, 301(8), 629-635.

Andrews, R.M., Diaz-Paniagua, C., Marco, A., Portheault, A. (2008). Developmental arrest during embryonic development of the common chameleon (Chamaeleo chamaeleon) in Spain. Physiological and Biochemical Zoology, 81(3), 336-344.

Andrews, N.P., Fujii, H., Goronzy, J.J., Weyand, C.M. (2010). Telomeres and immunological diseases of aging. Gerontology, 56(4), 390-403. 
Andreone, F., Guarino, F.M., Randrianirina, J.E. (2005). Life history traits, age profile, and conservation of the panther chameleon, Furcifer pardalis (Cuvier 1829), at Nosy Be, NW Madagascar. Tropical Zoology, 18(2), 209-225.

Angelier, F., Costantini, D., Blevin, P., Chastel, O. (2018). Do glucocorticoids mediate the link between environmental conditions and telomere dynamics in wild vertebrates? A review. General and Comparative Endocrinology, 256, 99-111.

Arnold, E.N. (1986). Mite pockets of lizards, a possible means of reducing damage by ectoparasites. Biological Journal of Linnean Society, 29(1), 1-21.

Asghar, M., Hasselquist, D., Hansson, B., Zehtindjiev, P., Westerdahl, H., Bensch, S. (2015). Hidden costs of infection: chronic malaria accelerates telomere degradation and senescence in wild birds. Science, 347(6220), 436-438.

Austad, S.N. (1993). Retarded senescence in an insular population of Virginia opossums (Didelphis virginiana). Journal of Zoology, 229, 695-708.

Austad, S.N. (1997). Comparative aging and life histories in mammals. Experimental Gerontology, 32, 23-38.

Austad, S.N., Fischer, K.E. (1991). Mammalian aging, metabolism, and ecology: evidence from the bats and marsupials. Journal of Gerontology, 46(2), B47-B53.

Barrett, E.L., Richardson, D.S. (2011). Sex differences in telomeres and lifespan. Aging Cell, 10(6), 913-92.

Barrett, E.L., Burke, T.A., Hammers, M., Komdeur, J., Richardson, D.S. (2013). Telomere length and dynamics predict mortality in a wild longitudinal study. Molecular Ecology, 22(1), 249-259.

Bartlett, C.M. (1986). The reptilian filarioid genus Foleyella Seurat, 1917 (Onchocercidae: Dirofilariinae) and its relationship to other dirofilariine genera. Systematic Parasitology, 9, 43-56.

Bateman, A.J. (1948). Intra-sexual selection in Drosophila. Heredity, 2, 349-368

Bates, D., Mächler, M., Bolker, B., Walker, S. (2014). Fitting linear mixed-effects models using lme4. ArXiv Prepr ArXiv14065823.

Bauer, M.E. (2008). Chronic Stress and Immunosenescence: A Review. Neuroimmunomodulation, 15, 241-250 
Beery, A.K., Lin, J., Biddle, J.S., Francis, D.D., Blackburn, E.H., Epel, E.S. (2012). Chronic stress elevates telomerase activity in rats. Biology Letters, 8(6), 1063-1066.

Benetos, A., Okuda, K., Lajemi, M., Kimura, M., Thomas, F., et al. (2001). Telomere length as an indicator of biological aging: the gender effect and relation with pulse pressure and pulse wave velocity. Hypertension, 37(2), 381-385.

Benton, T.G., Grant, A. (1999). Optimal reproductive effort in stochastic, density-dependent environments. Evolution, 53, 677-688.

Beveridge, I., Barker, I.K. (1976). The parasites of Antechinus stuartii Macleay from Powelltown, Victoria, with observations on seasonal and sex-related variations in numbers of helminths. Australian Journal of Zoology, 24(2), 265-272.

Biallas, S. (2013). Zur Bedeutung von Endoparasiten bei Chamäleons (Sauria: Chamaeleonidae) aus Wildfängen und Nachzuchten.

Bland, J.M., Altman, D.G. (1998). Survival probabilities (the Kaplan-Meier method). Bmj, 317(7172), 1572-1580.

Boonstra, R., McColl, C.J., Karels, T.J. (2001). Reproduction at all costs: the adaptive stress response of male acrtic ground squirrels. Ecology, 82, 1930-1946.

Bohr, C.T, Zhou, F., Vallabhaneni, H., Wang, Z, Rhee, D.B., et al. (2010). Characterization of oxidative guanine damage and repair in mammalian telomeres. PLoS Genetics, 6(5), e1000951.

Bonduriansky, R., Maklakov, A., Zajitschek, F., Brooks, R. (2008). Sexual selection, sexual conflict and the evolution of ageing and life span. Functional Ecology, 22, 443-453.

Bonnet, X. (2011). The evolution of semelparity. Reproductive biology and phylogeny of snakes. Reproductive Biology and Phylogeny Series. Science Publishers Inc, 17, 645672.

Bordes, F., Morand, S. (2009). Parasite diversity: an overlooked metric of parasite pressures?. Oikos, 118(6), 801-806.

Borrás, C., Esteve, J.M., Viña, J.R., Sastre, J., Viña, J., Pallardó, F.V. (2004). Glutathione regulates telomerase activity in 3T3 fibroblasts. Journal of Biological Chemistry, 279(33), 34332-34335. 
Bouwhuis, S., Choquet, R., Sheldon, B.C., Verhulst, S. (2012). The forms and fitness cost of senescence: age- specific recapture, survival, reproduction, and reproductive value in a wild bird population. The American Naturalist, 179, E15-E27.

Bouwhuis, S., Sheldon, B., Verhulst, S., Charmantier, A. (2009). Great tits growing old: selective disappearance and the partitioning of senescence to stages within the breeding cycle. Proceedings of the Royal Society B: Biological Sciences, 276, 2769-2777.

Bradley, A.J., McDonald, I.R. Lee, A.K. (1980). Stress and mortality in a small marsupial (Antechinus stuartii, Macleay). General and Comparative Endocrinology, 40, 188-200.

Bradley, A.J. (1997). Reproduction and life history in the red-tailed phascogale, Phascogale calura (Marsupialia: Dasyuridae): the adaptive-stress senescence hypothesis. Journal of Zoology, 241(4), 739-755.

Brady, L.D., Griffiths, R.A. (1999). Status assessment of chameleons in Madagascar, Gland, Switzerland, and Cambridge, United Kingdom: IUCN Species Survival Commission.

Braithwaite, R.W., Lee, A.K. (1979). A mammalian example of semelparity. The American Naturalist, 113(1), 151-155.

Bronikowski, A.M., Alberts, S.C., Altmann, J., Packer, C., Carey, K.D., Tatar, M. (2002). The aging baboon: comparative demography in a non-human primate. Proceedings of the National Academy of Science. USA, 99, 9591-9595.

Bronikowski, A.M. (2008). The evolution of aging phenotypes in snakes: a review and synthesis with new data. Age, 30(2-3), 169.

Bronikowski, A., Vleck, D. (2010). Metabolism, body size and life span: a case study in evolutionarily divergent populations of the garter snake (Thamnophis elegans). Integrative and Comparative Biology, 50(5), 880-887.

Brunet-Rossinni, A.K., Austad, S.N. (2004). Ageing studies on bats: a review. Biogerontology, 5(4), 211-222.

Brygoo, E.R. (1963). Contribution à la connaissance de la Parasitologie des Caméléons malgaches-(2e partie). Annales de Parasitologie Humaine et Comparée, 38(4), 525-739.

Buffenstein, R. (2005). "The naked mole-rat: a new long-living model for human aging research." The Journal of Gerontology. Series A. Biological Science and Medical Science, 60(11), 1369-1377 
Buffenstein, R. (2008). Negligible senescence in the longest living rodent, the naked mole-rat: insights from a successfully aging species. Journal of Comparative Physiology B, 178(4), 439-445.

Bull, C.M., Burzacott, D. (1993). The impact of tick load on the fitness of their lizard hosts. Oecologia, 96(3), 415-419.

Burger, J.M., Promislow, D.E. (2006). Are functional and demographic senescence genetically independent?. Experimental Gerontology, 41(11), 1108-1116.

Campbell, T.W. (1995). Avian Hematology and Cytology. Iowa State University Press, Ames, Iowa.

Campbell, T.W., Ellis, C.K. (2007). Avian and exotic animal hematology and cytology. 3rd ed. Ames (IA): Blackwell Publishing; 2007, p. 287

Carey, J.R., Judge, D.S. (2001). Life span extension in humans is self-reinforcing: a general theory of longevity. Population and Development Review, 27(3), 411-436.

Castanet, J. (1994). Age estimation and longevity in reptiles. Gerontology, 40(2-4), 174-192.

Caswell, H. (2007). Extrinsic mortality and the evolution of senescence. Trends in Ecology \& Evolution, 4(22), 173-174.

Cayuela, H., Cruickshank, S.S., Brandt, H., Ozgul, A., Schmidt, B.R. (2019). Habitat-driven life history variation in an amphibian metapopulation. Oikos, 128(9), 1265-1276.

Charlesworth, B. (1994). Evolution in age-structured populations (Vol. 2). Cambridge: Cambridge University Press.

Charnov, E.L. Schaffer, W.M. (1973). Life-history consequences of natural selection: Cole's rule revisited. The American Naturalist, 107, 791-793.

Charnov, E.L. (1993). Life history invariants: some explorations of symmetry in evolutionary ecology (Vol. 6). Oxford University Press, USA.

Chiaverano, L.M., Wright, M.J., Holland, B.S. (2014). Movement behavior is habitat dependent in invasive Jackson's chameleons in Hawaii. Journal of Herpetology, 48(4), 471-479.

Christensen, K., Doblhammer, G., Rau, R., Vaupel, J.W. (2009). Ageing populations: the challenges ahead. The Lancet, 374, 1196-1208. 
Choi, J., Fauce, S.R., Effros, R.B. (2008). Reduced telomerase activity in human T lymphocytes exposed to cortisol. Brain, Behavior, and Immunity, 22(4), 600-605.

Clarke, A.D., Lewis, A., Telmer, K.H., Shrimpton, J.M. (2007). Life history and age at maturity of an anadromous smelt, the eulachon Thaleichthys pacificus (Richardson). Journal of Fish Biology, 71(5), 1479-1493.

Clutton-Brock, T., Isvaran K. (2007). Sex differences in ageing in natural populations of vertebrates. Proceedings of the Royal Society B: Biological Sciences, 274(1629), 30973104.

Cockburn, A. (2006). Prevalence of different modes of parental care in birds. Proceedings of the Royal Society B: Biological Sciences, 273(1592), 1375-1383.

Cohen, A.A. (2004). "Female post-reproductive lifespan: a general mammalian trait." Biological Review of the Cambridge Philosophical Society, 79(4), 733-750.

Cohen, J.J. (1972). Thymus-derived lymphocytes sequestered in bone marrow of hydrocortisone-treated mice. Journal of Immunology, 108(3), 841-844.

Cole, L.C. (1954). The population consequences of life history phenomena. The Quarterly Review of Biology, 29(2), 103-137.

Congdon, J.D., Nagle, R.D., Kinney, O.M., van Loben Sels, R.C. (2001). "Hypotheses of aging in a long-lived vertebrate, Blanding's turtle (Emydoidea blandingii)." Experimental Gerontolology, 36(4-6), 813-827.

Congdon, J.D., Nagle, R.D., Kinney, O.M., van Loben Sels, R.C., Quinter, T., Tinkle, D.W. (2003). "Testing hypotheses of aging in long-lived painted turtles (Chrysemys picta)." Experimental Gerontolology, 38(7), 765-772.

Constantini, D., Marasco, V., Moller, A.P. (2011). A meta-analysis of glucocorticoids as modulators of oxidative stress in vertebrates. Journal of Comparative Physiology B, $181,447-456$.

Cooper, J.S., Poole, D.F.G., Lawson, R. (1970). The dentition of agamid lizards with special reference to tooth replacement. Journal of Zoology, 162(1), 85-98.

Cooper, N., Kamilar, J.M., Nunn, C.L. (2012). Host longevity and parasite species richness in mammals. PLoS One, 7(8), e42190. 
Cox, F.E. (2001). Concomitant infections, parasites and immune responses. Parasitology, 122(S1), S23-S38.

Cox, R.M., John-Alder, H.B. (2007). Increased mite parasitism as a cost of testosterone in male striped plateau lizards Sceloporus virgatus. Functional Ecology, 21(2), 327-334.

Cuadrado, M. (2001). Mate guarding and social mating system in male common chameleons (Chamaeleo chamaeleon). Journal of Zoology, 255(4), 425-435.

Dantzer, B., Fletcher, Q.E. (2015). Telomeres shorten more slowly in slow-aging wild animals than in fast-aging ones. Experimental Gerontology, 71, 38-47.

Davis, A.K., Maerz, J.C. (2008). Comparison of hematological stress indicators in recently captured and captive paedomorphic mole salamanders, Ambystoma talpoideum. Copeia, 2008(3), 613-617.

Davis, A.K., Maney, D.L., Maerz, J.C. (2008). The use of leukocyte profiles to measure stress in vertebrates: a review for ecologists. Functional Ecology, 22(5), 760-772.

Davis, A.K., Ruyle, L.E., Maerz, J.C. (2011). Effect of trapping method on leukocyte profiles of black-chested spiny-tailed iguanas (Ctenosaura melanosterna): Implications for Zoologists in the field. ISRN Zoology, 2011.

Davis, A.K., Maney, D.L. (2018). The use of glucocorticoid hormones or leucocyte profiles to measure stress in vertebrates: What's the difference? Methods in Ecolology and Evolution, 9(6), 1556-1568.

Dawbin, W.H. (1982). The tuatara Sphenodon punctatus: aspects of life history, growth and longevity. NZ Wildlife Service, Department of Internal Affairs.

De Magalhaes, J.P., Toussaint, O. (2004). GenAge: a genomic and proteomic network map of human ageing. FEBS letters, 571(1-3), 243-247.

De Magalhaes, J.P., Costa, J., Church, G.M (2007). An Analysis of the Relationship Between Metabolism, Developmental Schedules, and Longevity Using Phylogenetic Independent Contrasts. The Journals of Gerontology Series A: Biological Sciences and Medical Sciences, 62, 149-160.

De Magalhaes, J.P., Costa, J. (2009). A database of vertebrate longevity records and their relation to other life-history traits. Journal of Evolutionary Biology, 22(8), 1770-1774. 
Dewar, R.E., Richard, A.F. (2007). Evolution in the hypervariable environment of Madagascar. Proceedings of the National Academy of Sciences, 104(34), 13723-13727.

Dhabhar, F.S. (2002). A hassle a day may keep the doctor away: stress and the augmentation of immune function. Integrative and Comparative Biology, 42, 556-564.

Dhabhar, F.S. (2009). Enhancing versus Suppressive Effects of Stress on Immune Function: Implications for Immunoprotection and Immunopathology. Neuroimmunomodulation, $16,300-317$.

Diaz-Paniagua, C., Cuadrado, M., Blazquez, M.C., Mateo, J.A. (2002). Reproduction of Chamaeleo chamaeleon under contrasting environmental conditions. Herpetological Journal, 12(3), 99-104.

Dickhoff, W.W., Yan, L., Plisetskaya, E.M., Sullivan, C.V., Swanson, P., Hara, A., Bernard, M. G. (1989). Relationship between metabolic and reproductive hormones in salmonid fish. Fish Physiology and Biochemistry, 7(1-6), 147-155.

Dickman, C.R., Braithwaite, R.W. (1992) Postmating mortality of males in the dasyurid marsupials, Dasyurus and Parantechinus. Journal of Mammalogy, 73, 143-147.

Dickman, C.R., Letnic, M., Mahon, P.S. (1999). Population dynamics of two species of dragon lizards in arid Australia: the effect of rainfall. Oecologia, 119, 357-366.

Dierenfeld, E.S., Norkus, E.B., Carroll, K., Ferguson, G.W. (2002). Carotenoids, vitamin A, and vitamin E concentrations during egg development in panther chameleons (Furcifer pardalis). Zoo Biology, 21(3), 295-303.

Dmitriew, C.M. (2011). The evolution of growth trajectories: What limits growth rate? Biological Reviews, 86, 97-116.

Douhard, M., Pigeon, G., Festa-Bianchet, M., Coltman, D.W., Guillemette, S., Pelletier, F. (2017). Environmental and evolutionary effects on horn growth of male bighorn sheep. Oikos, 126(7), 1031-1041.

Dunham, A.E., Miles, D.B. (1985). Patterns of covariation in life history traits of squamate reptiles: the effects of size and phylogeny considered. American Naturalist, 126, 231257. 
Earley, R.L., Dugatkin, L.A. (2002). Eavesdropping on visual cues in green swordtail (Xiphophorus helleri) fights: a case for networking. Proceedings of the Royal Society of London. Series B: Biological Sciences, 269(1494), 943-952.

Eckhardt, F., Kappeler, P.M., Kraus, C. (2017). Highly variable lifespan in an annual reptile, Labord's chameleon (Furcifer labordi). Scientific Reports, 7(1), 11397. https://doi.org/10.1038/s41598-017-11701-3

Eckhardt, F., Kraus, C., Kappeler, P.M. (2019a). Life histories, demographies and population dynamics of three sympatric chameleon species (Furcifer spp.) from western Madagascar. Amphibia-Reptilia, 40(1), 41-54.

Eckhardt, F., Strube, C., Mathes, K.A., Mutschmann, F., Thiesler, H., Kraus, C., Kappeler, P.M. (2019b). Parasite burden in a short-lived chameleon, Furcifer labordi. International Journal for Parasitology: Parasites and Wildlife, 10, 231-240.

Eckhardt, F., Pauliny, A., Rollings, N., Mutschmann, F., Olsson, M., Kraus, C., Kappeler, P. M. (2020). Stress-related changes in leukocyte profiles and telomere shortening in the shortest-lived tetrapod, Furcifer labordi. BMC Evolutionary Biology, accepted.

Emlen, D.J. (2008). The evolution of animal weapons. Annual Review of Ecology, Evolution, and Systematics, 39, 387-413.

Epel, E.S., Blackburn, E.H., Lin, J., Dhabhar, F.S., Adler, N.E., Morrow, J.D., Cawthon, R.M. (2004). Accelerated telomere shortening in response to life stress. Proceedings of the National Academy of Science. USA, 101, 17312-17315.

Eshar, D., Ammersbach, M., Shacham, B., Katzir, G., Beaufrère, H. (2018). Venous blood gases, plasma biochemistry, and hematology of wild-caught common chameleons (Chamaeleo chamaeleon). Canadian Journal of Veterinary Research, 82(2), 106-114.

Ezeamama, A.E., McGarvey, S.T., Acosta, L.P., Zierler, S., Manalo D.L., et al. (2008). The synergistic effect of concomitant schistosomiasis, hookworm, and trichuris infections on children's anemia burden. PLOS Neglected Tropical Disseases, 2, e245248.

Fairlie, J., Holland, R., Pilkington, J.G., Pemberton, J.M., Harrington, L., Nussey, D. H. (2016). Lifelong leukocyte telomere dynamics and survival in a free-living mammal. Aging Cell, 15(1), 140-148. 
Fenner, A.L., Godfrey, S.S., Bull, C.M. (2011). Using social networks to deduce whether residents or dispersers spread parasites in a lizard population. Journal of Animal Ecology, 80(4), 835-843.

Finch, C.E. (1990). Longevity, Senescence, and the Genome. The University of Chicago Press, Chicago and London.

Finch, C.E., Austad, S.N. (2001). History and prospects: symposium on organisms with slow aging. Experimental Gerontology, 36(4-6), 593-597.

Fisher, D.O., Dickman, C.R., Jones, M.E., Blomberg, S.P. (2013). Sperm competition drives the evolution of suicidal reproduction in mammals. Proceedings of the National Academy of Sciences, 110(44), 17910-17914.

Foo, Y.Z., Nakagawa, S., Rhodes, G., Simmons, L.W. (2017). The effects of sex hormones on immune function: a meta-analysis. Biological Reviews, 92(1), 551-571.

Frost, D.R., Etheridge, R., Janies, D., Titus, T.A. (2001). Total evidence, sequence alignment, evolution of polychrotid lizards, and a reclassification of the Iguania (Squamata: Iguania). American Museum Novitates, 2001(3343), 1-39.

Frenck, R.W., Blackburn, E.H., Shannon, K.M. (1998). The rate of telomere sequence loss in human leukocytes varies with age. Proceedings of the National Academy of Sciences, 95(10), 5607-5610.

Gadgil, M., Bossert, W.H. (1970). Life historical consequences of natural selection. The American Naturalist, 104(935), 1-24.

Gaillard, J.M. (1994). Senescence in natural populations of mammals: a reanalysis. Evolution, $48,509-516$.

Gangloff, E.J., Sparkman A.M., Holden K.G., Corwin C.J., Topf M., Bronikowski A.M. (2017).

Geographic variation and within- individual correlations of physiological stress markers in a widespread reptile, the common garter snake (Thamnophis sirtalis). Comparative Biochemistry and Physiology A, 205, 68-76.

Gehring, P.S. (2008). Anmerkungen zum Lebensalter von Teppichchamäleons (Furcifer lateralis) im Terrarium. Chamaeleo Mitteilungsblatt der AG Chamäleons, 18(2), 5-7.

Gehring, P.S., Althaus, T. (2017). Pantherchamäleons - Münster, Natur und Tier Verlag

Gehring, P.S., Lutzmann, N., Furrer, S., Sossinka, R. (2008). Habitat preferences and activity patterns of Furcifer pardalis (Cuvier, 1829) in the Masoala Rain Forest Hall of the Zurich Zoo. Salamandra, 44(3), 129-140. 
Geiger S., Le Vaillant, M., Lebard, T., Reichert, S., Stier, A., Le Maho, Y., et al. (2012). Catching-up but telomere loss: half-opening the black box of growth and ageing tradeoff in wild king penguin chicks. Molecular Ecology, 21, 1500-1510.

Girondot, M., Garcia, J. (1998). Senescence and longevity in turtles: what telomeres tell us. Current Studies in Herpetology, 133-137.

Gist, D.H., Kaplan, M. L. (1976). Effects of stress and ACTH on plasma corticosterone levels in the caiman Caiman crocodilus. General and Comparative Endocrinology, 28(4), 413 419.

Glaw, F., Vences, M. (2007). A Fieldguide to the Amphibians and Reptiles of Madagascar. Cologne: Vences \& Glaw Verlag.

Glaw, F. (2015). Taxonomic checklist of chameleons (Squamata: Chamaeleonidae). Vertebrate Zoology, 65(2), 167-246.

Goessling, J.M., Guyer C., Mendona, M.T. (2016). Seasonal acclimation of constitutive immunity in gopher tortoises Gopherus polyphemus. Physiological and Biochemical Zoology, 89, 487-497.

Gomes, N.M., Shay, J. W., Wright, W.E. (2010). Telomere biology in Metazoa. FEBS letters, 584(17), 3741-3751.

Gonzalez, O., Zedrosser, A., Pelletier, F., Swenson, J.E., Festa-Bianchet, M. (2012). Litter reductions reveal a trade-off between offspring size and number in brown bears. Behavioral Ecology and Sociobiology, 66(7), 1025-1032.

Gopalakrishnan, S., Cheung, N.K., Yip, B.W., Au, D.W. (2013). Medaka fish exhibits longevity gender gap, a natural drop in estrogen and telomere shortening during aging: a unique model for studying sex-dependent longevity. Frontiers in Zoology, 10(1), 78.

Gosden, R.G. (1996). Cheating time: science, sex and ageing (Vol. 20). Macmillan.

Graham, A.L. (2008). Ecological rules governing helminth-microparasite coinfection. Proceedings of the National Academy of Sciences, 105(2), 566-570.

Grandidier, A. (1872). Descriptions de quelques Reptiles nouveaux découverts á Madagascar en 1870. Annales des Sciences Naturelles, Zoologie et Paléontologie, 15(5), 6-11 
Hariharan, I.K., Wake, D.B., Wake, M.H. (2016). Indeterminate growth: could it represent the ancestral condition?. Cold Spring Harbor Perspectives in Biology, 8(2), a019174.

Hallas, G., Bull, C.M. (2006). Influence of drying time on nematode eggs in scats of scincid lizard Egernia stokesii. Journal of Parasitology, 92, 192-194.

Halliday, T. R., Verrell, P. A. (1988): Body size and age in amphibians and reptiles. Journal of Herpetology, 253-265.

Hämäläinen, A., Raharivololona, B., Ravoniarimbinina, P., Kraus, C. (2015). Host sex and age influence endoparasite burdens in the gray mouse lemur. Frontiers in Zoology, 12(1), 25.

Hamilton, W.D. (1966). "The moulding of senescence by natural selection." Journal of Theoretical Biology, 12(1), 12-45.

Haussmann, M.F., Marchetto, N.M. (2010). Telomeres: Linking stress and survival, ecology and evolution. Current Zoology, 56, 714-727

Haussmann, M.F., Longenecker, A.S., Marchetto, N.M., Juliano, S.A., Bowden, R.M. (2011). Embryonic exposure to corticosterone modifies the juvenile stress response, oxidative stress and telomere length. Proceedings of the Royal Society B: Biological Sciences, 279(1732), 1447-1456.

Hayflick, L. (2000). "The future of ageing." Nature, 408(6809), 267-269.

Hayward, A.D. (2013). Causes and consequences of intra- and inter-host heterogeneity in defence against nematodes. Parasite Immunology, 35, 362-373.

Hayward, L.S., Wingfield, J.C. (2004). Maternal corticosterone is transferred to avian yolk and may alter offspring growth and adult phenotype. General and Comparative Endocrinology, 135(3), 365-371.

Hayward, A.D., Wilson, A.J., Pilkington, J.G., Clutton-Brock, T.H., Pemberton, J.M., Kruuk, L.E. (2013). Reproductive senescence in female Soay sheep: variation across traits and contributions of individual ageing and selective disappearance. Functional Ecology, 27(1), 184-195.

Healy, K., Guillerme, T., Finlay, S., Kane, A., Kelly, S.B.A., McClean, D., Kelly, D.J., Donohue, I., Jackson, A.L., Cooper, N., (2014). Ecology and mode-of-life explain 
lifespan variation in birds and mammals. Proceedings of the Royal Society B: Biological Sciences, 281(1784), 20140298.

Hendry, A.P., Morbey, Y.E., Berg, O.K., Wenburg, J.K. (2004). Adaptive variation in senescence: reproductive lifespan in a wild salmon population. Proceedings of the Royal Society of London. Series B: Biological Sciences, 271(1536), 259-266.

Henle, K. (1991). Life history patterns in lizards of the arid and semiarid zone of Australia. Oecologia, 88(3), 347-358.

Helle, S., Lummaa, V., Jokela J., (2004). Accelerated immunosenescence in preindustrial twin mothers. Proceedings of the National Academy of Science. USA, 101, 12391-12396.

Hindle, A.G., Horning, M., Mellish, J.A.E., Lawler, J.M. (2009). Diving into old age: muscular senescence in a large-bodied, long-lived mammal, the Weddell seal (Leptonychotes weddellii). Journal of Experimental Biology, 212(6), 790-796.

Hoekstra, L.A., Schwartz, T.S., Sparkman, A.M., Miller, D.A., Bronikowski, A.M. (2019). The untapped potential of reptile biodiversity for understanding how and why animals age. Functional Ecology, 34(1), 38-54.

Holmes, D.J., Austad, S.N. (1995). "Birds as animal models for the comparative biology of aging: a prospectus." The Journal of Gerontology. Series A. Biological Science and Medical Science, 50(2), B59-66.

Holmes, D.J., Fluckiger, R., Austad, S.N. (2001). "Comparative biology of aging in birds: an update." Experimental Gerontology, 36(4-6), 869-883.

Holmes, D.J., Ottinger, M.A. (2003). Birds as long-lived animal models for the study of aging. Experimental Gerontology, 38(11-12), 1365-1375.

Houben, J.M., Moonen, H.J., van Schooten, F.J., Hageman, G.J. (2008). Telomere length assessment: biomarker of chronic oxidative stress?. Free Radical Biology and Medicine, 44(3), 235-246.

Hudson, P.J., Dobson, A.P., Newborn, D. (1992). Do Parasites make prey vulnerable to predation? red grouse and parasites. Journal of Animal Ecology, 61, 681-692.

Hughes, K.A., Alipaz, J.A., Drnevich, J.M., Reynolds, R.M. (2002). A test of evolutionary theories of aging. Proceedings of the National Academy of Sciences, 99(22), 1428614291. 
Hughes, K.A., Reynolds, R.M. (2005). Evolutionary and mechanistic theories of aging. Annual Review of Entomology, 50, 421-445.

Hughes, D.F., Blackburn, D.G. (2019). Evolutionary origins of viviparity in Chamaeleonidae. Journal of Zoological Systematics and Evolutionary Research, 58(1), 284-302.

Humphreys, N.E., Grencis, R.K. (2002). Effects of ageing on the immunoregulation of parasitic infection. Infection and Immunity, 70(9), 5148-5157.

Hunt, J., Jennions, M.D., Spyrou, N., Brooks, R. (2006). "Artificial selection on male longevity influences age-dependent reproductive effort in the black field cricket Teleogryllus commodus." Amrican Naturalist, 168(3), E72-86.

Huse, G. (1998). Sex-specific life history strategies in capelin (Mallotus villosus)?. Canadian Journal of Fisheries and Aquatic Sciences, 55(3), 631-638.

Hutton, J.M. (1986). Age determination of living Nile crocodiles from the cortical stratification of bone. Copeia, 332-341.

Ilmonen, P., Kotrschal, A., Penn, D.J. (2008). Telomere attrition due to infection. PloS One, $3(5), \mathrm{e} 2143$.

Irizarry-Rovira, A.R., Wolf, A., Bolek, M., Christian, J.A., DeNicola, D.B. (2002). Blood smear from a wild-caught panther chameleon (Furcifer pardalis). Veterinary Clinical Pathology, 31, 129-132.

Jain, N.C. (1993). Essentials of Veterinary Hematology. Blackwell Publishing, Philadelphia, PA.

Jena, B.S., Nayak, S.B., Patnaik, B.K. (2002). "Age-related effect of aluminium on the catalase activities of the brains of two species of poikilothermic vertebrates." Gerontology, 48(1), 34-38.

Jesu, R., Mattioli, F., Schimmenti, G. (1999). On the discovery of a new large chameleon inhabiting the limestone outcrops of western Madagascar: Furcifer nicosiai sp. nov. (Reptilia, Chamaeleonidae). Doriana, 8, 1-14.

Jones, O.R., Gaillard, J.M., Tuljapurkar, S., Alho, J.S., Armitage, K.B., Becker, P.H., et al. (2008). Senescence rates are determined by ranking on the fast-slow life-history continuum. Ecology Letters, 11(7), 664-673. 
Jones, O.R, Scheuerlein, A., Salguero-Gomez, R., Camarda, C.G., Schaible, R., et al. (2014). Diversity of ageing across the tree of life. Nature, 505, 169-173.

Johnson, P.T.J., Buller, I.D. (2010). Parasite competition hidden by correlated coinfection: using surveys and experiments to understand parasite interactions. Ecology, 92, 535541.

Kappeler, P.M., Fichtel, C. (2012). A 15-year perspective on the social organization and life history of sifaka in Kirindy Forest. In Long-term field studies of primates (pp. 101-121). Springer, Berlin, Heidelberg.

Karsten, K.B., Andriamandimbiarisoa, L.N., Fox, S. F., Raxworthy, C.J. (2008). A unique life history among tetrapods: An annual chameleon living mostly as an egg. Proceedings of the National Academy of Science. USA, 105, 8980-8984.

Karsten, K.B., Andriamandimbiarisoa, L.N., Fox, S.F., Raxworthy, C.J. (2009a). Social behavior of two species of chameleons in Madagascar: insights into sexual selection. Herpetologica, 65, 54-69.

Karsten, K.B., Andriamandimbiarisoa, L.N., Fox, S.F., Raxworthy, C.J. (2009b). Sexual selection on body size and secondary sexual characters in 2 closely related, sympatric chameleons in Madagascar. Behavioural Ecology, 20, 1079-1088.

Keller, L., Jemielity, S. (2006). Social insects as a model to study the molecular basis of ageing. Experimental Gerontology, 41(6), 553-556.

Kirkwood, T.B.L. (1977). Evolution of aging. Nature, 270, 301-304.

Kirkwood, T.B.L, Austad, S.N. (2000). "Why do we age?" Nature, 408(6809), 233-238.

Kirkwood, T.B.L. (2002). Evolution of ageing. Mechanisms of ageing and development, 123(7), 737-745.

Kirkwood, T.B.L. (2005). Understanding the odd science of aging. Cell, 120, 437-447.

Kirkwood, T.B.L., Holliday, R. (1979). The evolution of ageing and longevity. Proceedings of the Royal Society of London. Series B. Biological Sciences, 205(1161), 531-546.

Kirkwood, T.B.L., Rose, M.R. (1991). Evolution of senescence: late survival sacrificed for reproduction. Philosophical Transactions of the Royal Society of London. Series B: Biological Sciences, 332(1262), 15-24. 
Klein, S.L. (2000). The effects of hormones on sex differences in infection: from genes to behavior. Neuroscience and Biobehavioral Reviews, 24, 627-638.

Kotiaho, J.S. (2001). Costs of sexual traits: a mismatch between theoretical considerations and empirical evidence. Biological Reviews, 76(3), 365-376.

Kotrschal, A., Ilmonen, P., Penn, D.J. (2007). Stress impacts telomere dynamics. Biology Letters, 3(2), 128-130.

Kurz, D.J., Decary, S., Hong, Y., Trivier, E., Akhmedov, A., Erusalimsky, J.D. (2004). Chronic oxidative stress compromises telomere integrity and accelerates the onset of senescence in human endothelial cells. Journal of Cell Science, 117(11), 2417-2426.

Kraus, C., Eberle, M., Kappeler, P.M. (2008). The costs of risky male behaviour: sex differences in seasonal survival in a small sexually monomorphic primate. Proceedings of the Royal Society B: Biological Science, 275, 1635-1644.

Languille, S., Blanc, S., Blin, O., Canale, C.I., Dal-Pan, A., Devau, G., et al. (2012). The grey mouse lemur: a non-human primate model for ageing studies. Ageing Research Reviews, 11(1), 150-162.

Le, P.P., Friedman, J.R., Schug, J., Brestelli, J.E., Parker, J.B., Bochkis, I.M., Kaestner, K.H. (2005). Glucocorticoid receptor-dependent gene regulatory networks. PLOS Genetics, $1,159-170$.

Lee, A.K., Woolley, P. Braithwaite, R.W. (1982). Life history strategies of dasyurid marsupials. In Carnivorous marsupials, M. Archer, ed. (Sydney: Royal Zoological Society of New South Wales), pp. 1-11.

Lee, K.A. (2006). Linking immune defenses and life history at the levels of the individual and the species. Integrative Comparative Biology, 46(6), 1000-1015.

Lemaitre, J.F, Gaillard, J.M, Pemberton, J.M, Clutton-Brock, T.H., Nussey, D.H. (2014). Early life expenditure in sexual competition is associated with increased reproductive senescence in male red deer. Proceedings of the Royal Society B: Biological Sciences, $281,20140792$.

Lehtinen, R.M., MacDonald, M.C. (2011). Live fast, die young? A six-year field study of longevity and survivorship in Blanchard's cricket frog (Acris crepitans blanchardi). Herpetological Review, 42(4), 504-507. 
Liker, A., Székely, T. (2005). Mortality costs of sexual selection and parental care in natural populations of birds. Evolution, 59(4), 890-897.

Lopes, G.P., Leiner, N.O. (2015). Semelparity in a population of Gracilinanus agilis (Didelphimorphia: Didelphidae) inhabiting the Brazilian cerrado. Mammalian Biology, 80(1), 1-6.

López-Otín, C., Blasco, M.A., Partridge, L., Serrano, M., Kroemer, G. (2013). The hallmarks of aging. Cell, 153(6), 1194-1217.

Love, O.P., Chin, E.H., Wynne-Edwards, K.E., Williams, T.D. (2005). Stress hormones: a link between maternal condition and sex-biased reproductive investment. The American Naturalist, 166(6), 751-766.

Luiselli, L. (2007). Nonrandom co-occurrence patterns of rainforest chameleons. African Journal of Ecology, 45(3), 336-346.

Lutzmann, N. (2007). Untersuchungen zur Ökologie der Chamäleonfauna der MasoalaHalbinsel, Nord-Ost Madagaskar. Doktorarbeit. Universitäts- und Landesbibliothek Bonn.

McNamara, J.M., Houston, A.I. (1996). State-dependent life histories. Nature, 380(6571), 215221.

MacNeil, J.E., Dharmarajan, G., Williams, R.N. (2011). Sala marker: A code generator and standardized marking system for use with visible implant elastomers. Herpetological Conservation Biology, 6, 260-265.

Maia, J.P., Crottini, A., Harris, D.J. (2014). Microscopic and molecular characterization of Hepatozoon domerguei (Apicomplexa) and Foleyella furcata (Nematoda) in wild endemic reptiles from Madagascar. Parasite, 21.

Majhi, S., Jena, B.S., Patnaik, B.K. (2000). "Effect of age on lipid peroxides, lipofuscin and ascorbic acid contents of the lungs of male garden lizard." Comp Biochem Physiol C Toxicol Pharmacol, 126(3), 293-298.

Malaguarnera, L., Ferlito, L., Imbesi, R., Gulizia, G., Di Mauro, S., Maugeri, D., et al. (2001). Immunosenescence: a review. Archives of Gerontology and Geriatrics, 32, 1-14.

Mancianti, F., Magi, M., Bicchi, F., Salvadori, M., Verni, F. (2000). Filariosis in chameleons (Chamaeleo sp.). Parasitologia, 42, 103-103. 
Mangel, M., Abrahams, M.V. (2001). Age and longevity in fish, with consideration of the ferox trout. Experimental Gerontology, 36(4-6), 765-790.

Marcogliese, D.J., Pietrock M. (2011). Combined effects of parasites and contaminants on animal health: parasites do matter. Trends in Parasitology, 27, 123-230.

Marnett, L.J. (2002). Oxyradicals, lipid peroxidation and DNA damage. Toxicology, 181, 219222.

Masoro, E.J. (2005). Overview of caloric restriction and ageing. Mechanisms of Ageing and Development, 126(9), 913-922.

McDiarmid, R.W., Foster, M.S., Guyer, C., Chernoff, N., Gibbons, J.W. (2012). Reptile biodiversity: Standard methods for inventory and monitoring. Oakland, CA: University of California Press.

Medawar, P.B. (1952). An Unsolved Problem of Biology. H. K. Lewis, London.

Metcalfe, N.B., and Monaghan, P. (2003). Growth versus lifespan: perspectives from evolutionary ecology. Experimental Gerontology, 38(9), 935-940.

Meiri, S., Brown, J.H., Sibly, R.M. (2012): The ecology of lizard reproductive output. Global Ecology and Biogeography, 21(5), 592-602.

Miller, R.A. (1999). "Kleemeier award lecture: are there genes for aging?". The Journal of Gerontology A. Biological Science and Medical Science, 54(7), B297-307.

Miller, R.A., Harper, J.M., Dysko, R.C., Durkee, S.J., Austad, S.N. (2002). Longer life spans and delayed maturation in wild-derived mice. Experimental Biology and Medicine, 227, 500-508.

Mills, S.C., Grapputo, A., Jokinen, I., Koskela, E., Mappes, T., Poikonen, T. (2010). Fitness trade-offs mediated by immunosuppression costs in a small mammal. Evolution, 64, 166-179.

Modrý, D., Šlapeta, J.R., Koudela, B. (2000). Six new species of coccidia (Apicomplexa: Eimeriidae) from east African chameleons (Sauria: Chamaeleonidae). Journal of Parasitology, 86(2), 373-379.

Monaghan, P. (2014). Organismal stress, telomeres and life histories. Journal of Experimental Biology, 217(1), 57-66. 
Monaghan, P., Charmantier, A., Nussey, D., Ricklefs, R. (2008). The evolutionary ecology of senescence. Functional Ecology, 22, 371-378.

Monaghan, P., Eisenberg, D.T., Harrington, L., Nussey, D. (2018). Understanding diversity in telomere dynamics, 20160435.

Moorad, J.A., Promislow, D.E. (2009). What can genetic variation tell us about the evolution of senescence?. Proceedings of the Royal Society B: Biological Sciences, 276(1665), 2271-2278.

Moorad, J.A, Promislow, D.E., Silvertown, J. (2019). Evolutionary Ecology of Senescence and a Reassessment of Williams' Extrinsic Mortality'Hypothesis. Trends in Ecology \& Evolution, 34(6), 519-530.

Moore S.L., Wilson, K. (2002). Parasites as a viability cost of sexual selection in natural populations of mammals. Science, 297, 2015-2018.

Morbey, Y.E., Brassil, C.E., Hendry, A.P. (2005). Rapid senescence in Pacific salmon. The American Naturalist, 166(5), 556-568.

Morrow, C.B., Kerkhoff, A. J., Ernest, S.M. (2019). Macroevolution of dimensionless life history metrics in tetrapods. bioRxiv, 520361.

Morsy, K., Ramadan, N., Al Hashimi, S., Ali, M., Bashtar, A. R. (2012). First description of the adult stages of Postorchigenes sp. (Trematoda: Lecithodendriidae) and Malagashitrema sp. (Trematoda: Homalometridae) infecting the common chameleon Chamaeleo chamaeleon (Reptilia: Chamaeleonidae) in Egypt. Life Science Journal, 4, 9.

Müller, R., Lutzmann, N., Walbröl, U. (2016). Furcifer pardalis: das Pantherchamäleon. Natur und Tier-Verlag.

Myneni, R.B., Hall, F.G., Sellers, P.J., Marshak, A.L. (1995). The interpretation of spectral vegetation indexes. IEEE T. Geosci. Remote 33(2), 481-486.

Nečas, P. (1999): Chameleons: nature's hidden jewels. Krieger Pub. Co.

Nordfjäll, K., Svenson, U., Norrback, K.F., Adolfsson, R., Lenner, P., Roos, G. (2009). The individual blood cell telomere attrition rate is telomere length dependent. PloS Genetics, 5(2), e1000375. 
Nussey, D.H., Coulson, T., Festa-Bianchet, M., Gaillard, J. M. (2008). Measuring senescence in wild animal populations: towards a longitudinal approach. Functional Ecology, 22(3), 393-406.

Nussey, D.H., Kruuk, L.E., Morris, A., Clements, M.N., Pemberton, J.M., Clutton-Brock, T.H. (2009). Inter-and intrasexual variation in aging patterns across reproductive traits in a wild red deer population. The American Naturalist, 174, 342-357.

Nussey, D.H., Coulson, T., Delorme, D., Clutton-Brock, T.H., Pemberton, J.M., FestaBianchet, M., Gaillard, J.M. (2011). Patterns of body mass senescence and selective disappearance differ among three species of free-living ungulates. Ecology, 92, 19361947.

Nussey, D.H., Froy, H., Lemaitre, J. F., Gaillard, J.M., Austad, S.N. (2013). "Senescence in natural populations of animals: widespread evidence and its implications for biogerontology." Ageing Research Reviews, 12(1), 214-225.

Nussey, D.H., Baird, D., Barrett, E., Boner, W., Fairlie, J., Gemmell, N., et al. (2014). Measuring telomere length and telomere dynamics in evolutionary biology and ecology. Methods in Ecology and Evolution, 5, 299-310.

Nylin, S., Gotthard, K. (1998). Plasticity in life-history traits. Annual Review of Entomology, 43(1), 63-83.

Oakwood, M., Bradley, A.J., Cockburn, A. (2001). Semelparity in a large marsupial. Proceedings of the Royal Society of London. Series B: Biological Sciences, 268(1465), 407-411.

Olsen, N.J., Kovacs, W.J. (1996). Gonadal steroids and immunity. Endocrine Reviews, 17(4), 369-384.

Olsson, M., Shine, R. (2002). "Growth to death in lizards." Evolution - International Journal of Organic Evolution, 56(9), 1867-1870.

Olsson, M., Pauliny, A., Wapstra, E., Uller, T., Schwartz, T., Miller, E., Blomqvist, D. (2011). Sexual differences in telomere selection in the wild. Molecular Ecology, 20, 2085-2099.

Ord, T.J., Stuart-Fox, D. (2006). Ornament evolution in dragon lizards: multiple gains and widespread losses reveal a complex history of evolutionary change. Journal of Evolutionary Biology, 19, 797-808. 
Origgi, F.C. (2007). Reptile immunology. In: Jacobson E (ed.). Infectious diseases and pathology of reptiles, color atlas and text. Boca Raton (FL): CRC Press; 2007. p. 131166.

Owen-Smith, N. (1993). Comparative mortality rates of male and female kudus: the costs of sexual size dimorphism. Journal of Animal Ecology, 62, 428-440.

Padgett, D.A., Glaser, R. (2003). How stress influences the immune response. Trends in Immunology, 24(8), 444-448.

Pardo, D., Barbraud, C., Weimerskirch, H. (2013). Females better face senescence in the wandering albatross. Oecologia, 173(4), 1283-1294.

Partridge, L., Gems, D. (2002). Ageing: a lethal side-effect. Nature, 418, 921-921.

Paterson, S., Lello, J. (2003). Mixed models: getting the best use of parasitological data. Parasitology Today, 19, 370-375.

Patnaik, B.K. (1994). Ageing in reptiles. Gerontology, 40(2-4), 200-220.

Perez, V.I., Buffenstein, R., Masamsetti, V., Leonard, S., Salmon, A.B., et al. (2009). "Protein stability and resistance to oxidative stress are determinants of longevity in the longest-living rodent, the naked mole-rat." Proceedings of National Academy of Science, USA, 106(9), 3059-3064.

Perret, M. (1997). Change in photoperiodic cycle affects life span in a Prosimian primate (Microcebus murinus). Journal of Biological Rhythms, 12(2), 136-145.

Petney, T.N., Andrews. R.H. (1998). Multiparasite communities in animals and humans: frequency, structure and pathogenic significance. International Journal of Parasitology, $28,377-393$

Pianka, E.R. (1970). On r-and K-selection. The American Naturalist, 104, 592-597.

Pipoly, I., Bókony, V., Kirkpatrick, M., Donald, P.F., Székely, T., Liker, A. (2015). The genetic sex-determination system predicts adult sex ratios in tetrapods. Nature, 527(7576), 91.

Plot, V., Criscuolo, F., Zahn, S., \& Georges, J. Y. (2012). Telomeres, age and reproduction in a long-lived reptile. PloS One, 7(7), e40855. 
Pond, C.M. (1978). Morphological aspects and the ecological and mechanical consequences of fat deposition in wild vertebrates. Annual Review of Ecology, Evolution, and Systematics, 9(1), 519-570.

Prötzel, D., Vences, M., Scherz, M.D., Vieites, D.R., Glaw, F. (2017). Splitting and lumping: an integrative taxonomic assessment of Malagasy chameleons in the Calumma guibei complex results in the new species $C$. gehringi sp. nov. Vertebrate Zoology, 67(2), 231249.

Prötzel, D., Vences, M., Hawlitschek, O., Scherz, M.D., Ratsoavina, F.M., Glaw, F. (2018). Endangered beauties: micro-CT cranial osteology, molecular genetics and external morphology reveal three new species of chameleons in the Calumma boettgeri complex (Squamata: Chamaeleonidae). Zoological Journal of the Linnean Society, 184(2), 471498.

Promislow, D. (2003). Mate choice, sexual conflict, and evolution of senescence. Behavior Genetics, 33, 191-201.

Promislow, D.E., Montgomerie, R., Martin, T.E. (1992). Mortality costs of sexual dimorphism in birds. Proceedings of the Royal Society of London. Series B: Biological Sciences, 250(1328), 143-150.

Quinlan, R.J. (2010). Extrinsic mortality effects on reproductive strategies in a Caribbean community. Human Nature, 21(2), 124-139.

Quirici, V., Guerrero, C.J., Krause, J.S., Wingfield, J.C., Vásquez, R.A. (2016). The relationship of telomere length to baseline corticosterone levels in nestlings of an altricial passerine bird in natural populations. Frontiers in Zoology, 13(1), 1.

R Core Team (2017). R: A language and environment for statistical computing. Vienna, Austria: R Foundation for Statistical Computing. URL https://www.R-project.org/.

Randrianantoandro, C., Razafimahatratra, B., Soazandry, M., Ratsimbazafy, J., Jenkins, R.K. (2010). Habitat use by chameleons in a deciduous forest in western Madagascar. Amphibia-Reptilia, 31(1), 27-35.

Raselimanana, A.P., Rakotomalala, D. (2003). Chamaeleonidae, chameleons. The Natural History of Madagascar. University of Chicago Press, Chicago, 960-969. 
Rovatsos, M., Pokorná, M.J., Altmanová, M., Kratochvíl, L. (2015). Female heterogamety in Madagascar chameleons (Squamata: Chamaeleonidae: Furcifer): differentiation of sex and neo-sex chromosomes. Scientific Reports, 5, 13196.

Razafimahatratra, B., Mori, A., Hasegawa, M. (2008). Sleeping site pattern and sleeping behavior of Brookesia decaryi (Chamaeleonidae) in Ampijoroa dry forest, northwestern Madagascar. Current Herpetology, 27(2), 93-99.

Rensing, L., Rippe, V. (2014). Altern. Springer Berlin Heidelberg.

Reznick, D.A., Bryga, H., Endler, J.A. (1990). Experimentally induced life-history evolution in a natural population. Nature, 346, 357-359.

Reznick, D.N., Bryant, M.J., Roff, D., Ghalambor, C.K., Ghalambor, D.E. (2004). Effect of extrinsic mortality ont he evolution of senescence in guppies. Nature, 431, 1095-1099.

Ricklefs, R.E. (1998). Evolutionary theories of aging: confirmation of a fundamental prediction, with implications for the genetic basis and evolution of life span. The American Naturalist, 152(1), 24-44.

Ricklefs, R.E., Miller, G.L. (1999). Ecology. WH Freeman and Company. New York City, NY.

Ricklefs, R.E., Wikelski, M. (2002). The physiology/life-history nexus. Trends in Ecology \& Evolution, 17(10), 462-468.

Ricklefs, R.E. (2010). "Life-history connections to rates of aging in terrestrial vertebrates." Proceedings of the National Academy of Science. USA, 107(22), 10314-10319.

Roberts C.W., Walker W., Alexander, J. (2001). Sex-associated hormones and immunity to protozoan parasites. Clinical Microbiology Reviews, 14 (3), 476-488.

Roberts, M.L., Buchanan, K.L., Evans, M.R. (2004). Testing the immunocompetence handicap hypothesis: a review of the evidence. Animal Behaviour, 68(2), 227-239.

Robinson, J.E., John, F.A.S., Griffiths, R.A., Roberts, D.L. (2015). Captive reptile mortality rates in the home and implications for the wildlife trade. PloS One, 10(11), e0141460.

Rocha, F., Guerra, A., González, Á.F. (2001). A review of reproductive strategies in cephalopods. Biological Reviews, 76(3), 291-304.

Rodríguez-Romero, F., Smith, G.R., Méndez-Sánchez, F., Hernández-Gallegos, O., Nava, P.S., de la Cruz, F.R.M. (2011). Demography of a semelparous, high-elevation population of 
Sceloporus bicanthalis (Lacertilia: Phrynosomatidae) from the Nevado de Toluca volcano, Mexico. The Southwestern Naturalist, 56(1), 71-78.

Rollings, N., Friesen, C. R., Sudyka, J., Whittington, C., Giraudeau, M., Wilson, M., Olsson, M. (2017a). Telomere dynamics in a lizard with morph- specific reproductive investment and self- maintenance. Ecology and Evolution, 7, 5163-5169.

Rollings, N., Uhrig, E.J., Krohmer, R.W., Waye, H.L., Mason, R.T., Olsson, M., et al. (2017b). Age-related sex differences in body condition and telomere dynamics of red-sided garter snakes. Proceedings of the Royal Society B: Biological Sciences, 284(1852), 20162146.

Rollings N., Friesen, C.R., Whittington, C.M., Johansson R., Shine, R., Olsson, M. (2019). Sexand tissue specific differences in telomere length in a reptile. Ecology and Evolution, $9(11), 6211-6219$.

Rollo, C.D. (2002). "Growth negatively impacts the life span of mammals." Evolution \& Development, 4(1), 55-61.

Romero, L.M., Reed, J.M. (2005). Collecting baseline corticosterone samples in the field: is under 3 min good enough?. Comparative Biochemistry and Physiology Part A: Molecular \& Integrative Physiology, 140(1), 73-79.

Romero, L.M., Reed, J. M., Wingfield, J. C. (2000). Effects of weather on corticosterone responses in wild free-living passerine birds. General and Comparative Endocrinology, 118(1), 113-122.

Romero, L.M., Wikelski, M. (2001). Corticosterone levels predict survival probabilities of Galapagos marine iguanas during El Nino events. Proceedings of the National Academy of Sciences, 98(13), 7366-7370.

Romero, L.M., Wikelski, M. (2002). Severe effects of low-level oil contamination on wildlife predicted by the corticosterone-stress response: preliminary data and a research agenda. Spill Science \& Technology Bulletin, 7(5-6), 309-313.

Ruby, J.G., Smith, M., Buffenstein, R. (2018). Naked mole-rat mortality rates defy Gompertzian laws by not increasing with age. Elife, 7, e31157.

Rueppell, O., Christine, S., Mulcrone, C., Groves, L. (2007). Aging without functional senescence in honeybee workers. Current Biology, 17, R274-R275.

Rupley, A.E. (1997). Manual of Avian Practice. W.B. Saunders Company, Philadelphia PA. 
Saether, B.E. (1988). Pattern of covariation between life-history traits of European birds. Nature, 331, 616-617.

Sæther, B.E., Bakke, Ø. (2000). Avian life history variation and contribution of demographic traits to the population growth rate. Ecology, 81(3), 642-653.

Sæther, B.E., Engen, S., Pape Møller, A., Weimerskirch, H., Visser M.E., Fiedler, W. (2004). Life-history variation predicts the effects of demographic stochasticity on avian population dynamics. The American Naturalist, 164(6), 793-802.

Salmon, A.B., Richardson, A., Pérez, V.I. (2010). Update on the oxidative stress theory of aging: does oxidative stress play a role in aging or healthy aging?. Free Radical Biology and Medicine, 48(5), 642-655.

Salomons, H.M., Mulder, G.V., van de Zande, L., Haussmann, M.F., Linskens, M.H., Verhulst, S. (2009). Telomere shortening and survival in free-living corvids. Proceedings of the Royal Society B: Biological Sciences, 276(1670), 3157-3165.

Sapolsky, R., Armanini, M., Packan, D., and Tombaugh, G. (1987). Stress and glucocorticoids in aging. Endocrinology and Metabolism Clinics of North America, 16, 965-980.

Sapolsky, R.M., Romero, L.M., and Munck, A.U. (2000). How do glucocorticoids influence stress responses? Integrating permissive, suppressive, stimulatory, and preparative actions. Endocrine Reviews, 21, 55-89.

Scharf, I., Feldman, A., Novosolov, M., Pincheira-Donoso, D., Das, I., Böhm, M., et al. (2015). Late bloomers and baby boomers: ecological drivers of longevity in squamates and the tuatara. Global Ecology and Biogeography, 24(4), 396-405.

Schmidt, C.M., Jarvis, J. U., Bennett, N.C. (2013). The long-lived queen: reproduction and longevity in female eusocial Damaraland mole-rats (Fukomys damarensis). African Zoology, 48(1), 193-196.

Schmidt, A.L., Taggart, D.A., Holz, P., Temple-Smith, P.D. Bradley, A.J. (2006). Plasma steroids and steroid-binding capacity in male semelparous dasyurid marsupials (Phascogale tapoatafa) that survive beyond the breeding season in captivity. General and Comparative Endocrinology, 149, 236-243.

Schneider, J.M., Lubin, Y. (1997). Does high adult mortality explain semelparity in the spider Stegodyphus lineatus (Eresidae)?. Oikos, 92-100. 
Schneller, P., Pantchev, N., Norden, N. (2008). Parasitology in snakes, lizards and chelonians: a husbandry guide. Edition Chimaira.

Schultner, J., Moe, B., Chastel, O., Bech, C., Kitaysky, A.S. (2014). Migration and stress during reproduction govern telomere dynamics in a seabird. Biology Letters, 10, 20130889.

Schuurs, A.H.W.M., Verheul, H.A.M. (1990). Effects of gender and sex steroids on the immune response. Journal of Steroid Biochemistry, 35(2), 157-172.

Schwartz, T.S., Bronikowski, A.M. (2011). Molecular stress pathways and the evolution of life histories in reptiles. Molecular Mechanisms of Life History Evolution, 193-209.

Scott, N.M., Haussmann, M.F., Elsey, R.M., Trosclair, P.L., Vleck, C.M. (2006). Telomere length shortens with body length in Alligator mississippiensis. Southeastern Naturalist, 5(4), 685-693.

Sena, L.A., Chandel, N.S. (2012). Physiological roles of mitochondrial reactive oxygen species. Molecular Cell, 48(2), 158-167.

Sentis, M., Chang, Y., Scherz, M.D., Proetzel, D., Glaw, F. (2018). Rising from the ashes: resurrection of the Malagasy chameleons Furcifer monoceras and F. voeltzkowi (Squamata: Chamaeleonidae), based on micro-CT scans and external morphology. Zootaxa, 4483(3), 549-566.

Shine, R., Charnov, E.L. (1992). Patterns of survival, growth, and maturation in snakes and lizards. Amrican Naturalist, 139(6), 1257-1269.

Sibley, R.M., Calow, P. (1986). Physiological Ecology of Animals. An Evolutionary ApproachBlackwell Scientific Publications.

Sloss, M.W., Kemp, R.L., Zajac, A.M. (1994). Veterinary Clinical Parasitology, 6th Edition, (Ames, IA: Iowa State University Press).

Smith, F., Charnov, E. (2001). Fitness trade-offs select for semelparous reproduction in an extreme environment.

Smith, D., Vinci, J., Anderson, C.V., Eckles, J.K., Ridgley, F., Mazzotti, F.J. (2016). Observations on mesting and clutch size in Furcifer oustaleti (Oustalet's Chameleon) in South Florida. Southeastern Naturalist, 15, 75-88. 
Soazandry, M., Razafimahatratra, B., Randrianantoandro, C., Jenkins, R., Ratsimbazafy, J. (2010). Habitat use by chameleons in a deciduous forest in western Madagascar. Amphibia-Reptilia, 31(1), 27-35.

Sohal, R. S., Weindruch, R. (1996). Oxidative stress, caloric restriction, and aging. Science, 273(5271), 59-63.

Sparkman, A.M., Arnold, S.J., Bronikowski, A.M. (2007). An empirical test of evolutionary theories for reproductive senescence and reproductive effort in the garter snake Thamnophis elegans. Proceedings of the Royal Society B: Biological Sciences, 274(1612), 943-950.

Sparkman, A.M., Bronikowski, A.M., Williams, S., Parsai, S., Manhart, W., Palacios, M.G. (2014). Physiological indices of stress in wild and captive garter snakes: Correlations, repeatability, and ecological variation. Comparative Biochemistry and Physiology A, $174,11-17$.

Speakman, J.R. (2005). Body size, energy metabolism and lifespan. Journal of Experimental Biology, 208 (9), 1717-1730.

Spencer, C.C., Promislow, D.E. (2002). "Biologists finally horn in on senescence in the wild." Science of Aging Knowledge Environment, 2002(47), pe19.

Stark, G., Tamar, K., Itescu, Y., Feldman, A., Meiri, S. (2018). Cold and isolated ectotherms: drivers of reptilian longevity. Biological Journal of the Linnean Society, 125(4), 730740.

Stearns, S.C. (1992). The evolution of life histories (Vol. 249). Oxford: Oxford University Press.

Sternberg, E.M. (2006). Neural regulation of innate immunity: a coordinated nonspecific host response to pathogens. Nature Reviews Immunology, 6(4), 318.

Strik, N.I., Alleman, R., Harr, K.E. (2007). Circulating inflammatory cells. In: Jacobson E. (ed.) Infectious diseases and pathology of reptiles, color atlas and text. Boca Raton (FL): CRC Press, p. 167-218.

Stuart-Fox, D.M., Firth, D., Moussalli, A., Whiting, M.J. (2006). Multiple signals in chameleon contests: designing and analysing animal contests as a tournament. Animal Behaviour, 71(6), 1263-1271. 
Sun, A.X., Londono, R., Hudnall, M.L., Tuan, R.S., Lozito, T.P. (2018). Differences in neural stem cell identity and differentiation capacity drive divergent regenerative outcomes in lizards and salamanders. Proceedings of the National Academy of Sciences, 115(35), E8256-E8265.

Széll, Z., Sréter, T., Varga, I. (2001). Ivermectin toxicosis in a chameleon (Chamaeleo senegalensis) infected with Foleyella furcata. Journal of Zoo and Wildlife Medicine, 32, 115-117.

Tamukai K, Takami Y, Akabane Y, Kanazawa Y, Une Y. (2011). Plasma biochemical reference values in clinically healthy captive bearded dragons (Pogona vitticeps) and the effects of sex and season. Veterinary Clinical Pathology, 40, 368-373.

Tanaka, H., Horikawa, I., Barrett, J.C., Oshimura, M. (2005). Evidence for inactivation of distinct telomerase repressor genes in different types of human cancers. International Journal of Cancer, 115(4), 653-657.

Takeda, T., Hosokawa, M., Takeshita, S., Irino, M., Higuchi, K., Matsushita, T., et al. (1981). A new murine model of accelerated senescence. Mechanisms of ageing and development, 17(2), 183-194.

Tessa, G., Glaw, F., Andreone, F. (2017). Longevity in Calumma parsonii, the World's largest chameleon. Experimental Gerontology, 89, 41-44.

Temple, S.A. (1987). Do predators always capture substandard individuals disproportionately from prey populations?. Ecology, 68, 669-674.

Terres, G., Morrison, S.L., Habicht, G.S. (1968). A quantitative difference in the immune response between male and female mice. Proceedings of the Society for Experimental Biology and Medicine, 127(3), 664-667.

Thrall, M.A. (2004). Hematology of amphibians, Veterinary Hematology and Clinical Chemistry: Text and Clinical Case Presentations. Lippincott Williams \& Wilkins, Philadelphia, PA.

Tolley, K.A., Raw, R.N., Altwegg, R., Measey, J.G. (2010). Chameleons on the move: survival and movement of the Cape dwarf chameleon, Bradypodion pumilum, within a fragmented urban habitat. African Zoology, 45 (1), 99-106.

Tolley, K.A., Herrel, A. (2013). The biology of chameleons. University of California Press. 
Tolley, K.A., Townsend, T.M., Vences, M. (2013). Large-scale phylogeny of chameleons suggests African origins and Eocene diversification. Proceedings of the Royal Society B: Biological Sciences, 280(1759), 20130184.

Tolley, K.A., Chauke, L.F., Jackson, J.C. Feldheim, K.A. (2014). Multiple paternity and sperm storage in the Cape dwarf chameleon (Bradypodion pumilum). African Journal of Herpetology, 63(1), 47-56.

Travin, D.Y., Feniouk, B.A. (2016). Aging in birds. Biochemistry (Moscow), 81(12), 15581563.

Tullberg, B.S., Ah-King, M., Temrin, H. (2002). Phylogenetic reconstruction of parental-care systems in the ancestors of birds. Philosophical Transactions of the Royal Society of London. Series B: Biological Sciences, 357(1419), 251-257.

Turbill, C., Bieber, C., Ruf, T. (2011). Hibernation is associated with increased survival and the evolution of slow life histories among mammals. Proceedings of the Royal Society B: Biological Sciences, 278(1723), 3355-3363.

Ujvari, B., Madsen, T. (2009). Short telomeres in hatchling snakes: erythrocyte telomere dynamics and longevity in tropical pythons. PloS One, 4(10), e7493.

Ujvari, B., Biro, P.A., Charters, J.E., Brown, G., Heasman, K., Beckmann, C., Madsen, T. (2017). Curvilinear telomere length dynamics in a squamate reptile. Functional Ecology, 31(3), 753-759.

Uller, T., Olsson, M. (2003). Prenatal exposure to testosterone increases ectoparasite susceptibility in the common lizard (Lacerta vivipara). Proceedings of the Royal Society of London B: Biological Sciences, 270(1526), 1867-1870.

Ungvari, Z., Parrado-Fernandez, C., Csiszar, A., de Cabo, R. (2008). Mechanisms underlying caloric restriction and lifespan regulation: implications for vascular aging. Circulation research, 102(5), 519-528.

Valdesalici, S., Cellerino, A. (2003). Extremely short lifespan in the annual fish Nothobranchius furzeri. Proceedings of the Royal Society of London. Series B: Biological Sciences, 270(suppl_2), S189-S191. 
Veldhuis, J.D., Sharma, A., Roelfsema, F. (2013). Age-Dependent and Gender-Dependent Regulation of Hypothalamic-Adrenocorticotropic-Adrenal Axis. Endocrinology and Metabolism Clinlics, 42, 201.

Verbeke, G., Molenberghs, G. (2005). Models for Discrete Longitudinal Data. New York: Springer Science+Business Media.

Vitt, L.J., Price, H.J. (1982). Ecological and evolutionary determinants of relative clutch mass in lizards. Herpetologica, 38, 237-255.

Vitt, L.J., Caldwell, J.P. (2013). Herpetology: an introductory biology of amphibians and reptiles. Academic press.

Von Zglinicki, T. (2003). Replicative senescence and the art of counting. Experimental Gerontology, 38(11-12), 1259-1264.

Vose, R.S., Schmoyer, R.L., Steurer, P.M., Peterson, T.C., Heim, R., Karl, T.R., Eischeid, J.K. (1992). The Global Historical Climatology Network: Long-Term Monthly Temperature, Precipitation, Sea Level Pressure, and Station Pressure Data. ORNL/CDIAC-53, CDIAC NDP-041, Carbon Dioxide Information Analysis Center, OakRidge National Laboratory, Oak Ridge, TN, available atftp://ftp.ncdc.noaa.gov/pub/data/ghcn/v1/

Walker, L.C., Herndon, J.G. (2010). Mosaic aging. Medical Hypotheses, 74, 1048-1051.

Warner, D.A., Miller, D.A., Bronikowski, A.M., Janzen, F.J. (2016). Decades of field data reveal that turtles senesce in the wild. Proceedings of the National Academy of Sciences, 113(23), 6502-6507.

Wasser, D.E., Sherman, P.W. (2010). Avian longevities and their interpretation under evolutionary theories of senescence. Journal of Zoology, 280(2), 103-155.

Weckerly, F.W. (1998). Sexual-size dimorphism: influence of mass and mating systems in the most dimorphic mammals. Journal of Mammalogy, 79(1), 33-52.

Weng, N.P. (2008). Telomere and adaptive immunity. Mechanisms of ageing and development, $129(1-2), 60-66$.

Wensink, M.J., Caswell, H., \& Baudisch, A. (2017). The rarity of survival to old age does not drive the evolution of senescence. Evolutionary Biology, 44(1), 5-10. 
Whittemore, K., Vera, E., Martínez-Nevado, E., Sanpera, C., Blasco, M.A. (2019). Telomere shortening rate predicts species life span. Proceedings of the National Academy of Sciences, 201902452.

Wilkinson, G.S., South, J.M. (2002). Life history, ecology andlongevity in bats. Aging Cell, 1, 124-131.

Williams, G.C. (1957). Pleiotropy, natural selection, and the evolution of senescence. Evolution, 11, 398-411.

Williams, P.D., Day, T., Fletcher, Q., Rowe, L. (2006). The shaping of senescence in the wild. Trends in Ecology \& Evolution, 21, 458-463.

Wingfield, J.C. Romero, L.M. (2001). in Handbook of Physiology: The Endocrine System, eds. McEwen, B. S. \& Goodman, H. M. (Oxford Univ. Press).

Wolfe, K.M., Mills, H.R., Garkaklis, M.J. Bencini, R. (2004). Post-mating survival in a small marsupial is associated with nutrient inputs from seabirds. Ecology, 85, 1740-1746.

Zimmerman, L.M., Vogel, L.A., Bowden, R.M. (2010). Understanding the vertebrate immune system: insights from the reptilian perspective. Journal of Experimental Biology, 213(5), 661-671.

Zinner, D., Wygoda, C., Razafimanantsoa, L., Rasoloarison, R., Andrianandrasana, H.T., Ganzhorn, J. U., Torkler, F. (2014). Analysis of deforestation patterns in the central Menabe, Madagascar, between 1973 and 2010. Regional Environment Change, 14(1), 157-166.

Zug, G.R. (1991). Age determination in turtles.

Zuk, M. (2002). Immune defense and host life history. American Naturalist, 160, 9-22.

Zuk, M., Bryant, M.J., Kolluru, G.R., Mirmovitch, V. (1996). Trade-offs in parasitology, evolution and behavior. Parasitology Today, 12(2), 46.

Zuk, M., McKean, K.A. (1996). Sex differences in parasite infections: patterns and processes. International Journal for Parasitology, 26(10), 1009-1024. 


\section{Acknowledgement}

First, I have to thank Peter Kappeler and Cornelia Kraus for giving me the opportunity to work on this interesting topic. I am deeply grateful for all your guidance, advices and freedom I felt during the project. I am obliged to the Ministère de l'Environment et des Eaux et Fôrets, MINEEF, Direction des Eaux et Forêts of Madagascar and CNFEREF Morondava, for authorizing my work in Kirindy. I am very thankful to the Kirindy field station team, including all the field assistants and cooks. In particular, I am deeply appreciative to Bruno Tsiverimana for taking care for the caged chameleons when I was not in the field. In this regard, I am much obliged that I was a part of the field station and becoming acquainted with parts of the Malagasy culture, giving the worthy opportunity to see issues from other perspectives. Especially, I want to thank Leon Razafimanantsoa for running everything smoothly during my stay in the field station and Rodin Rasoloarison for organizing the permits for my work. I am also indebted to the interns Wanda von Bremen and Camilla Cenni for supporting me in data collection.

The sample analyses for the thesis were done in collaboration with several people: I am grateful to Prof. Dr. Christina Strube, Dr. Karina Mathes and the Department of Parasitology from the University of Veterinary Medicine Hannover. I am thankful to Dr. Frank Mutschmann, who regrettably deceased in 2018. I admire his huge contribution of knowledge in reptile medicine. I am thankful to Prof. Dr. Mats Olsson and Dr. Angela Pauliny from the University of Gothenburg for supporting the telomere analysis. Moreover, I want to thank the "Deutsche Gesellschaft für Herpetologie und Terrarienkunde" for partly financing the analysis of the telomeres via the Wilhelm-Peters Fonds.

During my $\mathrm{PhD}$, I met several terrific people who enriched and often still enrich my life. First, I want to thank Bako for the cheering of the ups and support during the downs during my last years. I have to thank Flavia, Josue, Tilman, Andrea, Franzi, Anna, Luca, Wanda, Jan, Finja, Camilla, Julia, Sylvio, Charlotte and numerous other people relieving long field seasons in Kirindy. Many thanks to my parents, sisters and friends for staying in touch during my long absences and for supporting my choices. I am thankful for every bit of encouragement from all of you. In particular, I have to thank my family for supporting my deep passion in herpetology from my childhood onwards and subsequently tolerating various terrariums in our house. I am grateful to Daniel Kahlen who gave me the opportunity to work in a reptile zoo during my adolescence and thereby learning a lot about this animal group. Furthermore, I am glad for long and helpful discussions about chameleon biology with Dr. Sebastian Gehring and Dr. Nicola Lutzmann. 


\section{List of Figures}

Figure 1: Hypothesized pathways by which age and chronic stress affect lifespan.

Figure 2.1: Growth curves of F. labordi in Kirindy Forest.

Figure 2.2: Kaplan-Meier survival curves of $F$. labordi in captivity.

Figure 3.1: Averaged life histories of the three Furcifer species in Kirindy Forest.

Figure 3.2: Abundance of Furcifer labordi and adult and juvenile $F$. cf. nicosiai as well as adult and juvenile $F$. oustaleti from January to July 2015.

Figure 3.3: Percentage of chameleons that were recaptured at least twice, or multiple times in the second field season between January and July 2015.

Figure 3.4: Growth curves of (A) F. labordi in 2013/14, (B) F. cf. nicosiai in 2014 (C) F. oustaleti in 2015.

Figure 3.5: Percentage of SVL difference of (A) F. labordi and (B) F. cf. nicosiai between 2014 and 2015.

Figure 3.6: Boxplots showing roosting heights of adult specimens of F. labordi, F. cf. nicosiai in the reproductive season in 2014 and F. labordi, F. cf. nicosiai and F. oustaleti in the reproductive season 2015 .

Figure 4.1: Prevalence in percentage of gastrointestinal parasitic infection A) in F. labordi males and females, B) F. labordi and F. cf. nicosiai (adult stages).

Figure 4.2: Composition of gastrointestinal parasite taxa in the fecal samples of A) adult F. labordi and B) adult F. cf. nicosiai from January to June and in total.

Figure 4.3: Prevalence of filarial infection in F. labordi and F. cf. nicosiai.

Figure 4.4: Prevalence of mite infestation in A) F. labordi males and females, B) F. labordi and $F$. cf. nicosiai.

Figure 4.5: Intensity of mite infestation in adult $F$. labordi and $F$. cf. nicosiai.

Figure 5.1: $\mathrm{H} / \mathrm{L}$ ratio of adult wild specimen of $F$. labordi and $F$. cf. nicosiai from February until May.

Figure 5.2: Relative TL of adult wild specimen of $F$. labordi and F. cf. nicosiai from March until June. 
Figure 5.3: Association of $\mathrm{H} / \mathrm{L}$ ratio and TL in F. labordi $(\mathrm{n}=66)$ and $F$. cf. nicosiai $(\mathrm{n}=39)$.

\section{List of tables}

Tabel 1: Averaged NDVI for the onset of the rainy season (Nov - Dec), rainy season (Jan Apr), and dry season (May - Oct).

Table 2: Total number of detected Furcifer labordi females per month and number of gravid females during reproduction time in 2014 and 2015.

Table 3: Number of fecal samples collected per species (F. labordi and F. cf. nicosiai) and sex (F. labordi) per month.

Table 4: Number of blood samples collected per species per month.

Table 5: Number of individuals per species/sex and month that were inspected for ectoparasites.

Table 6: Parameter estimates from the generalized linear mixed model for the prevalences of A) gastrointestinal parasites in F. labordi B) gastrointestinal parasites of both species, C) blood parasites in both species, D) ectoparasites in both species.

Table 7: Parameter estimates from the generalized linear mixed model for shedding intensity of coccidian oocysts of $F$. labordi and $F$. cf. nicosiai.

Table 8: Parameter estimates from the generalized linear mixed model for intensity of ectoparasites of $F$. labordi and F. cf. nicosiai.

Table 9: Parameters of the LM on the influence on H/L ratio.

Table 10: Parameters of the LMM on H/L ratio in captive $F$. labordi.

Table 11: Parameters of the LM on the telomere length of F. labordi and F. cf. nicosiai. 
$\underline{\text { Curriculum Vitae }}$ 


\section{Publications}

\section{Publications related to the PhD-thesis}

Eckhardt, F., Pauliny, A., Rollings, N., Mutschmann, F., Olsson, M., Kraus, C., Kappeler, P. M. (2020). Stress-related changes in leukocyte profiles and telomere shortening in the shortest-lived tetrapod, Furcifer labordi. BMC Evolutionary Biology, - accepted.

Eckhardt, F., Strube, C., Mathes, K.A., Mutschmann, F., Thiesler, H., Kraus, C., Kappeler, P.M. (2019). Parasite burden in a short-lived chameleon, Furcifer labordi. International Journal for Parasitology: Parasites and Wildlife, 10, 231-240. https://doi.org/10.1016/j.ijppaw.2019.09.010

Eckhardt, F., Kraus, C., Kappeler, P.M. (2019). Life histories, demographies and populationdynamics of three sympatric chameleon species (Furcifer spp.) from western Madagascar. Amphibia-Reptilia, 40(1), 41-54. https://doi.org/10.1163/1568538120181039

Eckhardt, F., Kappeler, P. M., Kraus, C. (2017). Highly variable lifespan in an annual reptile, Labord's chameleon (Furcifer labordi). Scientific Reports, 7(1), 11397. https://doi.org/10.1038/s41598-017-11701-3

\section{Publications not related to the PhD-thesis}

Eckhardt, F.S. (2018). Triplet from a single egg in the Panther Chameleon (Furcifer pardalis). Herpetology Notes, 11, 777-779.

Gehring, P. S., Tolley, K. A., Eckhardt, F. S., Townsend, T. M., Ziegler, T., Ratsoavina, F., Vences, M. (2012). Hiding deep in the trees: discovery of divergent mitochondrial lineages in Malagasy chameleons of the Calumma nasutum group. Ecology and Evolution, 2(7), 1468-1479.

Eckhardt, F.S., Gehring, P.S., Bartel, L., Bellmann, J., Beuker, J., Hahne, D., et al. (2012). Assessing sexual dimorphism in a species of Malagasy chameleon (Calumma boettgeri) with a newly defined set of morphometric and meristic measurements. Herpetology Notes, 5, 335-344. 


\section{$\underline{\text { Declaration }}$}

I hereby declare that I have written this thesis independently and with no other aids or sources than quoted.

Göttingen, 